\begin{abstract}
Rodriguez, B. Ximena. Evaluation of Slow Release Substrates for Anaerobic Bioremediation. (Under the direction of Dr. Robert C. Borden)

A variety of anaerobic bioremediation processes are being developed for the in-situ treatment of groundwater contaminants. The most common approach for enhancing in-situ anaerobic biotransformation processes is to flush a readily biodegradable, soluble substrate through the treatment zone. The substrate serves as a carbon source for cell growth and as an electron donor for energy generation. While this approach can be very effective, operating costs can be high because of problems associated with clogging of pumps, piping and mixers, as well as the labor for extensive monitoring and process control.
\end{abstract}

An alternative approach for stimulating anaerobic biotransformation processes is to generate a biological reducing zone (BRZ) by injecting one or more low solubility, slowly biodegrading substrates throughout the proposed treatment interval. We evaluated a variety of common substrates to assess their potential use in a BRZ. Initial screening studies were conducted by incubating $50 \mathrm{mg}$ of the target substrate with anaerobic digester sludge and monitoring gas production over time.

All of the vegetable oils generated significant gas production while the petroleum based materials did not result in significant gas production in any incubation. The organic acids and carbohydrates resulted in rapid gas production with no initial inhibition of methanogenesis. The surfactants resulted in the most rapid and complete gas production. 
Sucrose esters of fatty acids (SEFAs) are readily biodegradable at low concentrations but can be inhibitory to microbiological processes at higher concentrations.

Follow-up studies examined the suitability of soybean oil and a sucrose fatty acid ester (SEFA) for stimulating reductive dechlorination in flow through columns. The influent and effluent from each column were periodically monitored for chlorinated solvents (PCE, TCE, DCE isomers, VC), electron acceptors and donors (oxygen, nitrate, phosphate, sulfate, methane, ethene and ethane), $\mathrm{pH}$, and dissolved organic carbon. Some columns received 200 $\mathrm{mg} / \mathrm{L} \mathrm{Na} \mathrm{SO}_{4}$ in the influent to evaluate the effect of high background sulfate levels on substrate longevity and reductive dechlorination, with $\mathrm{pH} \sim 6$. Three columns received dilute $\mathrm{HCl}(0.01 \mathrm{~N})$ in the influent to inhibit biological activity, having a $\mathrm{pH}$ of $\sim 2$.

After 15 months of operation, the carbon content of the soybean oil amended columns was significantly higher than the SEFA (S-270) amended columns or unamended control columns indicating a one time addition of a low solubility organic substrate can support anaerobic bioremediation processes for an extended time period. PCE removal was low in all of the columns because of the very short hydraulic retention time and high PCE loading. cis-DCE production was significant in all soybean oil treated columns. Fewer degradation products and less methane were produced for the columns treated with sulfate, which is in agreement with thermodynamics and several studies regarding the inhibition of dechlorinating activity in the presence of excess sulfate.

A similar study was conducted for perchlorate and TCA reduction, using liquid and hydrogenated soybean oil in intermittent flow columns. Initial microcosm and columns results were favorable, showing perchlorate reduction in added carbon treatments. In general, 
TCA was not significantly depleted, presumably because of the short contact time of the fluid inside the column. Extensive perchlorate and nitrate reduction were observed in columns treated with liquid and hydrogenated soybean oil but not in the untreated control column.

This work successfully demonstrated the potential application of emulsified soybean oil into groundwater systems contaminated with chlorinated compounds. By incorporating liquid soybean oil and solid soybean wax emulsions, the longevity and reducing capabilities of the treatment area can be controlled. The overall benefits include the in-situ approach, low environmental impact, and effective removal of chlorinated compounds. 


\title{
EVALUATION OF SLOW RELEASE SUBSTRATES FOR ANAEROBIC BIOREMEDIATION
}

\author{
by
}

\section{XIMENA RODRIGUEZ}

A thesis submitted to the Graduate Faculty of

North Carolina State University

in partial fulfillment of the

requirements for the Degree of

Master in Science

\section{CIVIL, CONSTRUCTION AND ENVIRONMENTAL ENGINEERING}

Raleigh, NC

2004

APPROVED BY:

Dr. Morton Barlaz

Dr. Francis De Los Reyes

Dr. Robert Borden 


\section{PERSONAL BIOGRAPHY}

Ximena Rodriguez is originally from Bogotá, Colombia, where she attended La Salle University receiving her degree in Environmental and Sanitary Engineering. She also received a degree from University Politécnico Grancolombiano in Business Management.

Ximena began her graduate education at North Carolina State University in the spring semester of 2003, in the Civil, Construction and Environmental Department, where she worked under the direction of Dr. Robert C. Borden. 


\section{ACKNOWLEDGEMENTS}

To my family, without whom none of these accomplishments would have ever been possible.

I would like to thank Dr. Robert Borden for his support, his infinite kindness and all his teachings in the professional and personal fields.

Thanks to Dr. Detlef Knappe, Dr. Francis de los Reyes III, Dr. Morton Barlaz and Dr.

Joel Ducoste, because they are magnificent Professors, and although it could seem impossible, they are even better as human beings.

Special gratitude to Nick Lindow. 'Thank you' is not enough for all his help and gentleness. Thanks also to Kapo Coulibaly, Cam Long and Yong Jung.

Thanks to the Strategic Environmental Research and Development Program (SERDP), for funding of this project. 


\section{TABLE OF CONTENTS}

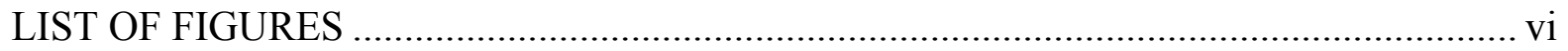

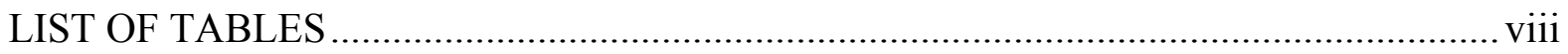

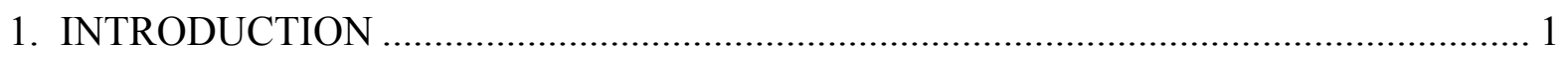

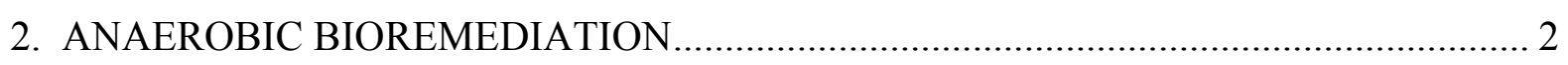

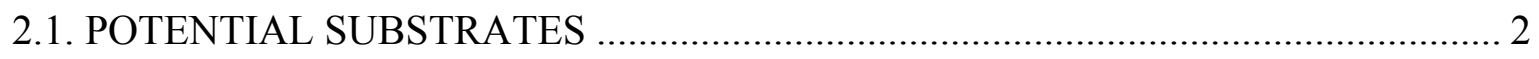

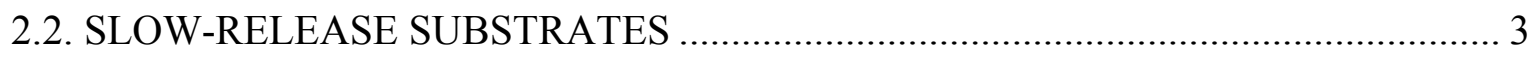

2.3. SUBSTRATE BIODEGRADATION PATHWAYS............................................... 5

2.4. MEASUREMENT OF METHANOGENIC BIODEGRADATION RATES ............... 7

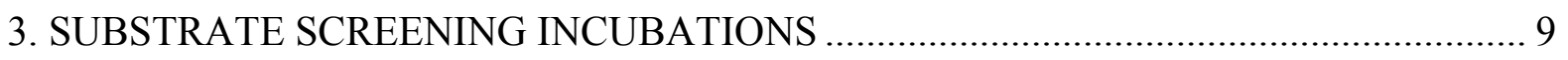

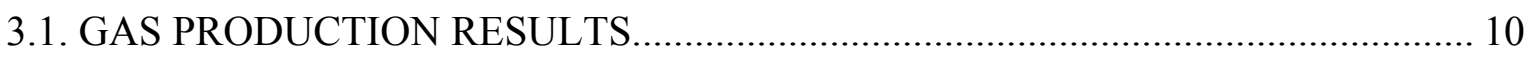

4. CHLORINATED COMPOUNDS IN INTERMITTENT FLOW COLUMNS ................... 16

4.1. INTERMITTENT FLOW COLUMN EXPERIMENTS ………………………....... 16

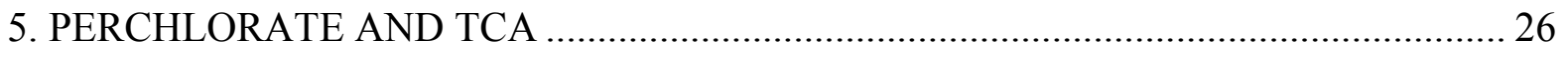

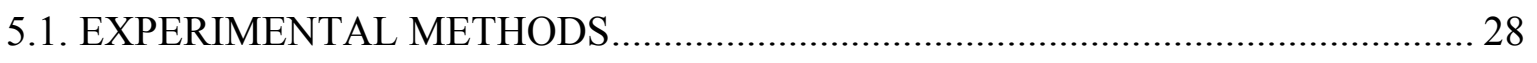

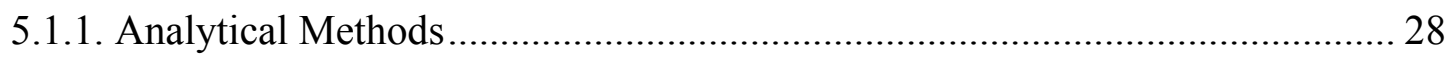

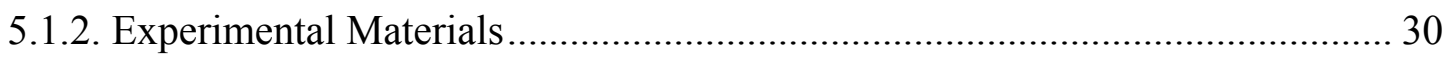

5.1.3. Microcosm Procedure ………………………………................................ 30

5.1.4. Intermittent Flow Column Procedure ……………………………………….... 32

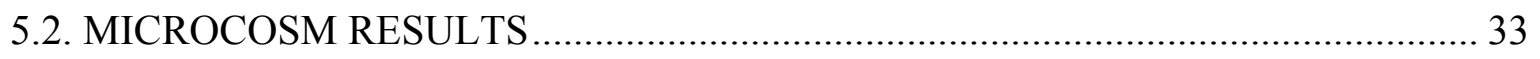

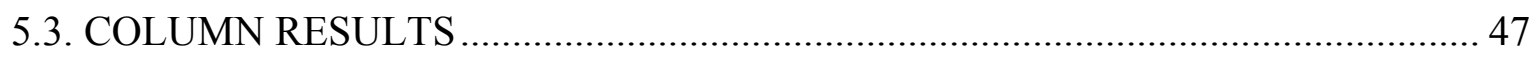


5.4. DISCUSSION AND CONCLUSIONS

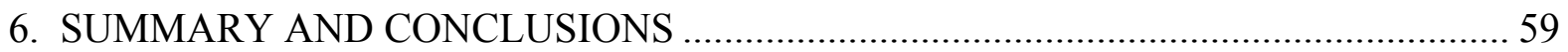

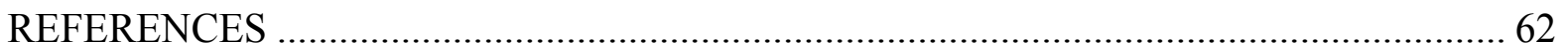

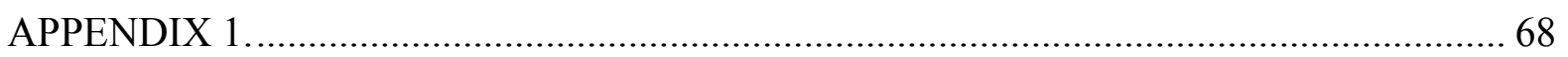

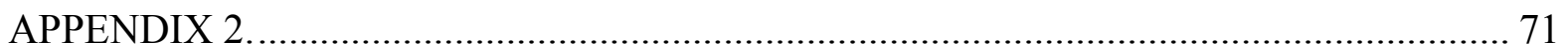

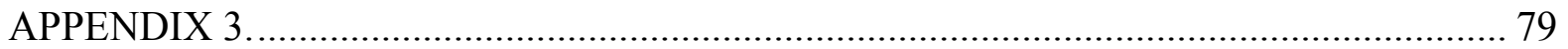




\section{LIST OF FIGURES}

Figure 1. Cumulative gas production under methanogenic conditions from different food grade substrates. Errors bars are \pm 1 standard deviation from triplicate incubations.

Figure 2. Cumulative gas production per milligram organic carbon corrected for background gas production.

Figure 3. Gas production per milligram organic carbon during different time periods. Production has been corrected for gas production in no-added carbon controls. 14

Figure 4. Gas production after 300 days in SEFA incubations.................................... 15

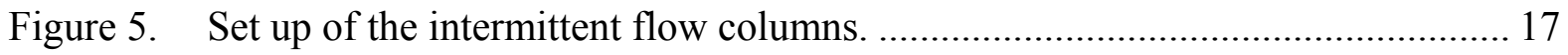

Figure 6. Effect of substrate added and influent solution composition on final carbon content, cis-DCE produced, $\mathrm{CH}_{4}$ produced and effluent $\mathrm{SO}_{4}$. Error bars are experimental range in duplicate columns.

Figure 7. Perchlorate and chloride concentrations in microcosms on days 2 and 14. Errors bars are standard deviation from triplicate incubations. 35

Figure 8. Variation in nitrate, sulfate and $\mathrm{pH}$ in microcosm treatments. 37

Figure 9. Treatment 1-Water only - analytical results for microcosm concentrations in $\mathrm{mg} / \mathrm{L}$ : chloride, nitrate and sulfate; acetate ( $\mathrm{mg} / \mathrm{L}$ of carbon), TOC and methane; TCA, DCA, 1,1 DCE, CA, VC and Eth.

Figure 10. Treatment 2-No carbon - analytical results for microcosm concentrations in $\mathrm{mg} / \mathrm{L}$ : chloride, nitrate and sulfate; acetate (mg/L of carbon), TOC and methane; TCA, DCA, 1,1 DCE, CA, VC and Eth....

Figure 11. Treatment 4-Oil only - analytical results for microcosm concentrations in $\mathrm{mg} / \mathrm{L}$ : chloride, nitrate and sulfate; acetate ( $\mathrm{mg} / \mathrm{L}$ of carbon), TOC and methane; TCA, DCA, 1,1 DCE, CA, VC and Eth.

Figure 12. Treatment 5-Wax only - analytical results for microcosm concentrations in $\mathrm{mg} / \mathrm{L}$ : chloride, nitrate and sulfate; acetate (mg/l of carbon), TOC and methane; TCA, DCA, 1,1 DCE, CA, VC and Eth.

Figure 13. Treatment 6- Oil bioaugmented - analytical results for microcosm concentrations in $\mathrm{mg} / \mathrm{L}$ : chloride, nitrate and sulfate; acetate (mg/L of carbon), TOC and methane; TCA, DCA, 1,1 DCE, CA, VC and Eth. 
Figure 14. Treatment 7-Wax bioaugmented - analytical results for microcosm concentrations in $\mathrm{mg} / \mathrm{L}$ : chloride, nitrate and sulfate; acetate (mg/L of carbon), TOC and methane; TCA, DCA, 1,1 DCE, CA, VC and Eth............................. 46

Figure 15. TCA and $\mathrm{ClO}_{4}$ concentrations in the influent. Column 1- Oil, column 2-Wax, and column 3-No carbon (control)

Figure 16. Perchlorate concentration in columns effluent. Data from external commercial lab for each one of the columns is included.

Figure 17a. Analytical results for column 1-Oil effluent concentrations in mg/L. Top: TCA, DCA, 1,1, DCE, CA, VC and Eth; bottom: TOC and acetate (mg/L TOC)........ 51

Figure 17b. Analytical results for column 2-Wax effluent concentrations in mg/L. Top: TCA, DCA, 1,1, DCE, CA, VC and Eth; bottom: TOC and acetate (mg/L TOC)....... 52

Figure 17c. Analytical results for column 3- No carbon (control) effluent concentrations in mg/L. Top: TCA, DCA, 1,1, DCE, CA, VC and Eth; bottom: TOC and acetate $(\mathrm{mg} / \mathrm{L}$ TOC $)$ 


\section{LIST OF TABLES}

Table 1. Experimental treatments in intermittent flow column experiments ...................... 19

Table 2a. Carbon balance for chlorinated columns treated with emulsified soybean oil...... 21

Table $2 \mathrm{~b}$. Carbon balance for chlorinated columns treated with S-270.............................. 22

Table 2c. Carbon balance for chlorinated columns treated with no added substrate. ........... 23

Table 3. Basic setup for the seven treatments of microcosms...................................... 32

Table 4. Carbon balance for perchlorate columns. Column 1-Oil, column 2-Wax, column 3-

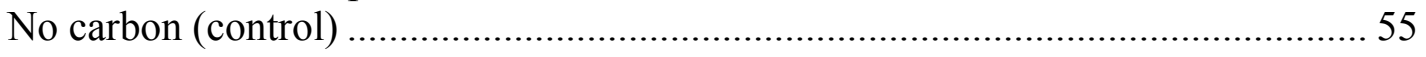

Table 5. Initial and final permeability in perchlorate columns. Column 1-Oil, column 2-Wax,

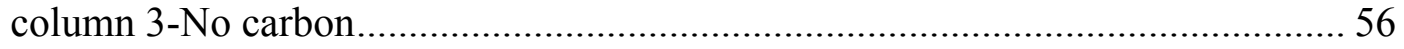




\section{INTRODUCTION}

A variety of anaerobic bioremediation processes are being developed for the in-situ treatment of groundwater contaminants such as chlorinated solvents, perchlorate $\left(\mathrm{ClO}_{3}{ }^{-}\right)$, chromate $\left(\mathrm{CrO}_{4}^{-2}\right)$, nitrate $\left(\mathrm{NO}_{3}{ }^{-}\right)$and also acid mine drainage (Morse et al., 1998; Hunter, 2001; Hunter, 2002; ARCADIS, 2002). The most common approach for enhancing in-situ anaerobic biotransformation processes is to flush a readily biodegradable, soluble substrate through the treatment zone. This substrate serves as a carbon source for cell growth and as an electron donor for energy generation. While this approach can be very effective (Ellis et al., 2000; Major et al., 1991), operating costs can be high because of problems associated with clogging of pumps, piping, and mixers, as well as labor for extensive monitoring and process control.

An alternative approach for stimulating anaerobic biotransformation processes is to generate a biological reducing zone (BRZ) by injecting one or more low solubility, slowly biodegrading substrates throughout the proposed treatment interval. These substrates would slowly biodegrade over time, consuming oxygen and supporting the anaerobic biotransformation of problem contaminants. BRZs could be used for source area treatment and in barriers to prevent downgradient plume migration. In this paper, we evaluate a variety of common substrates to assess their potential use in BRZs. Initial screening studies were conducted by incubating $50 \mathrm{mg}$ of the target substrate with anaerobic digester sludge and monitoring gas production over time. Follow-up studies examined the suitability of soybean oil and a sucrose fatty acid ester (SEFA) for stimulating reductive dechlorination in flow through columns, and liquid and hydrogenated soybean oil for perchlorate reduction. 


\section{ANAEROBIC BIOREMEDIATION}

Enhanced in-situ anaerobic bioremediation has most commonly been employed for treatment of chlorinated solvents and other oxidized contaminants. In this process, one or more organic substrates are added to the subsurface to consume competing electron acceptors, provide a hydrogen source to drive contaminant reduction, and as a carbon source for cell growth. This approach has been most commonly employed for enhanced reductive dechlorination of chlorinated solvents under highly reduced anaerobic conditions. However, anaerobic bioremediation has also been employed for in-situ treatment of nitrate (Bengtsson and Annadotter, 1989; Earth Tech, 2001) and perchlorate (Department of Defense, 2001). Toxic metals and radionuclides cannot be destroyed. However, the toxicity and mobility of some metals and radionuclides can be dramatically altered by microbial activity including zinc immobilization and hexavalent chromium reduction (Rodin, 2001; Cooper et al., 2000; Straub et al., 1996; Weber et al., 2001; Regenesis, 2003).

\subsection{POTENTIAL SUBSTRATES}

Laboratory studies have shown that a wide variety of organic substrates will stimulate reductive dechlorination including acetate, propionate, butyrate, benzoate, glucose, lactate, methanol, and toluene (Vogel and McCarty, 1985; Scholz-Muramatsu et al., 1995; de Bruin et al., 1992; Freedman and Gossett, 1989; Sewell and Gibson, 1991; DiStefano et al., 1991; Lee et al., 1997). Inexpensive, complex substrates such as molasses, cheese whey, corn steep liquor (Lee et al., 1997), corn oil, hydrogenated cottonseed oil beads, solid food shortening (Dybas et al., 1997), beef tallow, melted corn oil margarine, coconut oil (Lee et al., 1997), 
soybean oil, and hydrogenated soybean oil (Zenker et al., 2000) can support complete reductive dechlorination. Based on thermodynamic considerations, reductive dechlorination will occur only after both oxygen and nitrate have been depleted from the aquifer since oxygen and nitrate are more energetically favorable electron acceptors than chlorinated solvents. Almost any substrate that can be fermented to hydrogen and acetate can be used to enhance reductive dechlorination since these materials are used by dechlorinating microorganisms (Ballapragada et al., 1997; Smatlak et al., 1996; Adamson et al,, 2003; He et al., 2002; Sung et al., 2003).

\subsection{SLOW-RELEASE SUBSTRATES}

A variety of different approaches have been employed in the field for bringing the contaminants to be treated into contact with a biodegradable substrate. One common approach is to dissolve a soluble, readily biodegradable substrate such as lactate or sugar in water and flush this solution through the treatment zone using a system of injection and pumping wells. This approach has been very effective at some sites (Ellis et al., 2000; Martin et al., 2001; Major et al., 2002). However problems with clogging of process piping, injection and pumping wells may increase operation and maintenance costs. An alternative approach employed at some sites has been to distribute a 'slow-release' organic substrate throughout the treatment zone that can support anaerobic biodegradation of the target contaminants for an extended time period. Slow-release substrates used include cellulose, chitin, Hydrogen Release Compound $\left(\mathrm{HRC}^{\circledR}\right)$ and certain edible oils. HRC is a polymerized ester that dissolves over time releasing lactate which can support anaerobic biodegradation of 
chlorinated solvents and other contaminants. Solid phase substrates (chitin and mulch), are typically emplaced in a trench in the field and deployed in a permeable reactive barrier configuration. Chitin is the most plentiful natural polymer next to cellulose (Sorenson et al., 2002), and has been identified as a relatively long-lived source of nitrogen and electron donor in the form of volatile fatty acids for anaerobic bioremediation. Laboratory studies confirmed that chitin produces volatile fatty acids, which are high quality electron donors for anaerobic reductive chlorination and hydrogen generation (Werth, 2002). Mulch is primarily composed of cellulose and green plant material, which provides a source of nitrogen for microbial growth. Substrate degradation by subsurface microbial processes generates a number of breakdown products, including metabolic acids. While the nature of the breakdown products and metabolic acids produced by degradation of mulch are not well known, they likely provide secondary electron donors or fermentable substrates for hydrogen generation. Mulch and chitin have been successfully used to stimulate reductive dechlorination at several field sites (Sorenson et al., 2002; Environ. Security Tech., 2002).

Recently, there has been considerable interest in using soybean oil as a substrate for in-situ bioremediation because of its low cost, food-grade status, and longevity in the subsurface. However, several studies (Zenker et al., 2000; Lee et al., 2001; Casey et al., 2002) suggest that injection of soybean oil into the subsurface as a separate non-aqueous phase liquid (NAPL) may be difficult because of the very limited spread of the oil and large amount of chase water required to displace the oil to residual saturation.

Subsequent studies showed that both liquid soybean oil and semi-solid hydrogenated soybean oil could support complete dehalogenation of TCE to ethene in microcosms 
containing sediment from a chlorinated solvent impacted site. Studies by Hunter (2001; 2002) demonstrated that soybean oil could be used to stimulate anaerobic degradation of other problem contaminants including nitrate and perchlorate.

Ideal substrates for use in BRZs would be (1) non-toxic, food-grade materials; (2) sufficiently resistant to biodegradation to persist for several years in an aquifer; and (3) sufficiently biodegradable to support the anaerobic transformation/degradation of the target contaminants. When the BRZ is intended to treat chlorinated solvents, the substrate must be fermentable to hydrogen and acetate since these materials are the only electron donors known to drive reductive dechlorination (He et al., 2002). However, if the target contaminant is nitrate, perchlorate, or another more oxidized material, substrates that do not readily ferment might be suitable. In addition, techniques must be available to costeffectively distribute and immobilize the substrate throughout the treatment zone. In companion studies, Coulibaly and Borden (2004) and Yong (2002) developed methods for distributing slowly biodegradable, hydrophobic substrates in sandy aquifers as oil-in-water emulsions.

\subsection{SUBSTRATE BIODEGRADATION PATHWAYS}

Anaerobic microorganisms can use carbohydrates, proteins and fats as a source of energy. Under anaerobic conditions, carbohydrates are first hydrolyzed to pyruvic acid, and then fermented to lower molecular weight intermediates prior to release back into solution by 
bacteria. The fermentation products formed depend upon the bacterial species involved, and may include organic acids, alcohols and ketones (Sawyer et al., 1994).

The first step in biological utilization of proteins involves their hydrolysis, yielding alpha-amino acids that can pass through the cell wall. Bacterial deamination under anaerobic conditions may proceed with or without reduction to form the corresponding saturated or unsaturated acids.

Under anaerobic conditions, fats and oils hydrolyze to long chain fatty acids and glycerol. The glycerol then degrades to 1,3-propanediol and subsequently to acetate. The fatty acids undergo further breakdown by oxidation. Oxidation is believed to occur at the beta carbon atom. In the final step, rupture of the molecule occurs, with formation of one molecule of acetic acid, two molecules of hydrogen $\left(\mathrm{H}_{2}\right)$, and the original molecule of acid appears as a new acid derivative with two less carbon atoms. By successive oxidation at the beta carbon atom, long chain fatty acids are whittled into progressively shorter fatty acids and acetic acid. Four hydrogen atoms are released for each acetic acid unit produced (Sawyer et al., 1994).

Ethanol and sodium stearate are easily degradable compounds. The presence of chloro or nitro groups may inhibit anaerobic gas production, while carboxyl and hydroxyl groups facilitate biodegradation (Battersby and Wilson, 1988).

SEFAs are food-grade organic substrates synthesized by esterifying from one to eight fatty acids onto a sucrose core. The most well known SEFA is Olestra, a food-grade fat marketed by Procter \& Gamble Company based on its resistance to biodegradation in the 
human digestive tract. Olestra is a mixture of hexa- to octa-esters of sucrose with long chain fatty acids and is also very resistant to methanogenic biodegradation. Studies on Olestra show that SEFAs can serve as a sole carbon and energy source by various microorganisms (Lee and Ventullo, 1996) and can be mineralized at a low rate compared to sucrose or stearic acid in anaerobic environments (Allgood et al., 1997). The impact of solid and liquid SEFA (determined by the properties of the fatty acids used in preparing Olestra) on anaerobic biodegradation in wastewater treatment plants, has been evaluated. Olestra addition results in a significant decrease in the gas production rate, perhaps explained by the hydrolysis of fats to free fatty acids, which have been shown to inhibit anaerobic digesters. This inhibition is believed to be the result of free fatty acid interactions with bacterial cell walls (McAvoy et al., 1996; Hanaki et al., 1981).

Oleic acid (an 18 carbon acid with one double bond) is primarily found in olive, pecan and teaseed oils, while stearic acid is present in cocoa and tallow. Oleic and stearic acids can both be slowly degraded under anaerobic conditions to shorter chain acids, but may also inhibit anaerobic microbial activity (Hanaki et al., 1981). Lalman and Bagley (2001) showed that stearic acid degradation's rate is much lower compared to oleic acid degradation.

\subsection{MEASUREMENT OF METHANOGENIC BIODEGRADATION RATES}

One of the most common and convenient methods for assessing anaerobic biodegradation potential under methanogenic conditions is to monitor total gas $\left(\mathrm{CH}_{4}\right.$ plus 
$\mathrm{CO}_{2}$ ) production with time (Gledhill, 1979; Shelton and Tiedje, 1984a; ASTM, 1993; Colleran et al., 1992; Shelton and Tiedje, 1984b; Suflita and Concannon, 1995). Owen et al. (1979) provided the first description of this general approach. In the Owen et al. (1979) procedure, excess gas volume (methane and carbon dioxide) production is monitored after addition of a test chemical to an anaerobic seed culture in sealed bottles. Typically, multiple replicates are incubated to reflect the true capabilities of the inoculum, allow statistical interpretation of the data and provide a better prediction of future success. The gas volume is measured by displacement of the piston in a glass syringe whose needle had been inserted into the bottle. Subsequently, Gledhill (1979) improved this method with the goal of defining a simple protocol that could be established by the American Society for Testing Materials (ASTM). Gledhill recommended that the incubations contain $50 \mathrm{mg} / \mathrm{L}$ of carbon substrate with $10 \%$ anaerobic sludge inoculum. Follow up work by Battersby and Wilson $(1988,1989)$ used this procedure to examine the degradation potential of a variety of organic chemicals under methanogenic conditions. The removal of the electron donor or acceptor and the production of end products was monitored as a positive indication of anaerobic metabolism.

The end products of methanogenic metabolism are methane and $\mathrm{CO}_{2}$. Thus, the progress of metabolism can be followed by measuring total gas production. However, monitoring total gas production can result in a significant underestimation of the actual metabolism, since $\mathrm{CO}_{2}$ is slightly soluble in water (Colleran et al., 1992). A more accurate approach is to monitor methane production by gas chromatography (GC) and production of suspected intermediate compounds. 


\section{SUBSTRATE SCREENING INCUBATIONS}

In the first phase of this work, a wide range of food grade oils and surfactants were screened to measure their gas production rates under methanogenic conditions. The objective of this work was to identify organic substrates that would generate slow, steady production of methane and carbon dioxide. In this work, we have assumed that slow, steady methane production is essentially equivalent to slow, steady production of $\mathrm{H}_{2}$ and/or acetate which can both be used by dechlorinating microorganisms to for reductive dechlorination of chlorinated ethene.

The gas production assays were conducted by incubating $50 \mathrm{mg}$ of the target organic substrate, $5 \mathrm{~mL}$ or $1 \mathrm{~mL}$ of inoculum collected from the primary anaerobic sludge digester in Chapel Hill, North Carolina, and $100 \mathrm{~mL}$ of nutrient media $\left[\mathrm{NaHCO}_{3}(3.5 \mathrm{~g} / \mathrm{L}), \mathrm{NH}_{4} \mathrm{Cl}(1.0\right.$ $\mathrm{g} / \mathrm{L}), \mathrm{NaCl}(0.9 \mathrm{~g} / \mathrm{L}), \mathrm{MgCl}_{2}(0.2 \mathrm{~g} / \mathrm{L}), \mathrm{CaCl}_{2}(0.1 \mathrm{~g} / \mathrm{L}), \mathrm{KH}_{2} \mathrm{PO}_{4}(1.61 \mathrm{~g} / \mathrm{L}), \mathrm{Na}_{2} \mathrm{HPO}_{4}(3.19$ $\mathrm{g} / \mathrm{L})$, cysteine hydrochloride $(10 \mathrm{~mL} / \mathrm{L})$, resazurin $(0.002 \%)]$ in 160 serum bottles with thick butyl rubber stoppers. The bottles were incubated at $37^{\circ} \mathrm{C}$. Prior to preparation, the media was boiled under oxygen free nitrogen to remove dissolved oxygen. The bottle headspace was flushed with $80 \% \mathrm{~N}_{2}-20 \% \mathrm{CO}_{2}$. All incubations were conducted in triplicate. Substrate biodegradation rate was assayed by monitoring gas production over time using a wetted glass syringe. Gas production results were compared to parallel incubations that do not contain organic substrate.

Appendix 1 shows the materials screened for their ability to support slow production of methane and carbon dioxide. Mixtures of liquid soybean oil and SEFA were also evaluated 
to determine if mixtures of degradable and nondegradable substrates could be used to control the biodegradation rate in aquifer where methane production was excessive.

\subsection{GAS PRODUCTION RESULTS}

For every group of incubations, soybean oil was included as a positive control along with a no-added carbon blank. The no-added carbon blank accounts for the gas production due to the microbial inoculum. Raw gas production results for a typical set of incubations are shown in Figure 1. To allow direct comparison between different sets of incubations, the mL of gas produced per mg of organic carbon present in the added substrate was computed (Figure 2).

The gas production pattern for soybean oil is typical for substrates where gas production is rapid during the first 100 days, then slows or stops. During the rapid gas production phase, there is often considerable variability between replicates due to slight variations in the lag period between bottles. However for readily biodegradable substrates, the total cumulative gas production is usually very consistent between replicates. Exceptions occur for slowly degradable substrates (e.g. S-970) that are still generating gas after over two years of incubation. In addition, some substrates may initially be inhibitory, and then eventually generate some gas (SEFA soyate).

To allow easier comparison of the gas production results from this large group of substrates, we have grouped the substrate into the following general categories: (a) food grade oils; (b) organic acids and carbohydrates; (c) surfactants; and (d) sucrose esters of fatty 
acids (SEFA). Results from this comparison are presented in Figure 3. Gas production results for all compounds tested are presented in the Appendix 2 in the set of batches as constructed. Results are compared for the first 300 days of incubations.

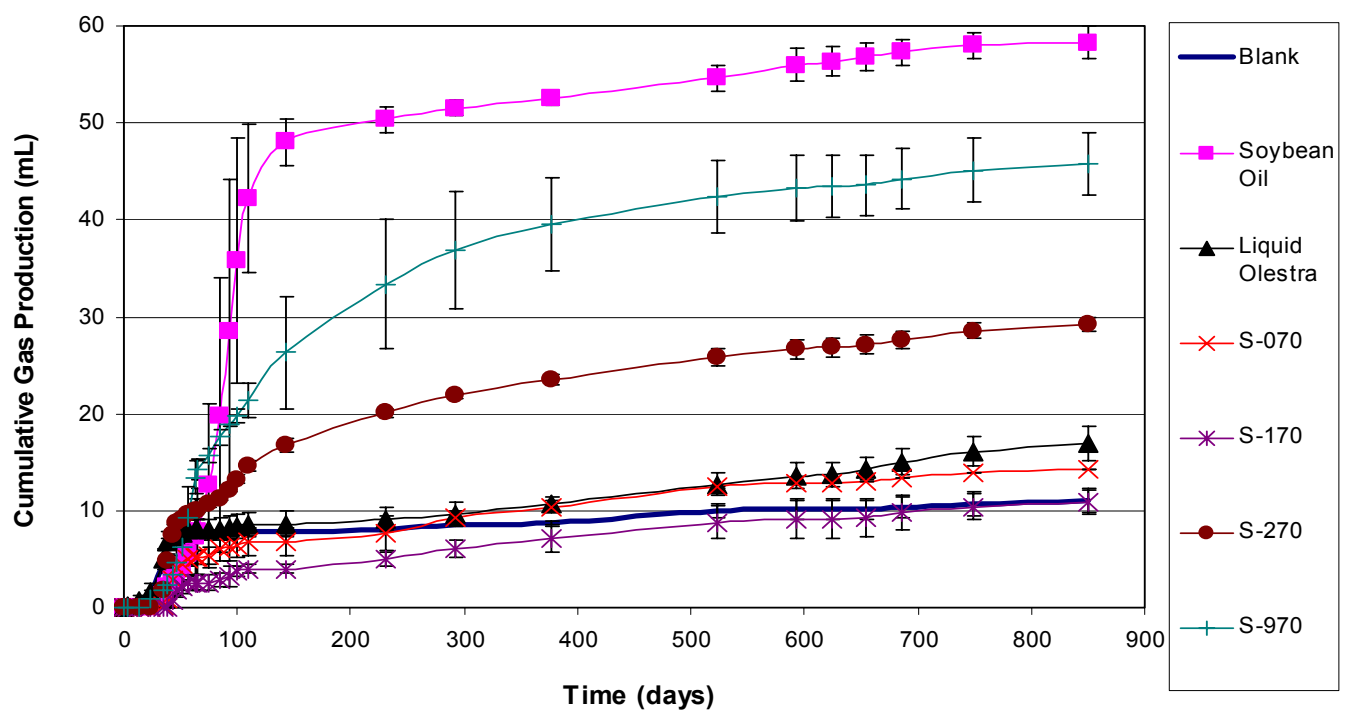

Figure 1. Cumulative gas production under methanogenic conditions from different food grade substrates. Errors bars are \pm 1 standard deviation from triplicate incubations.

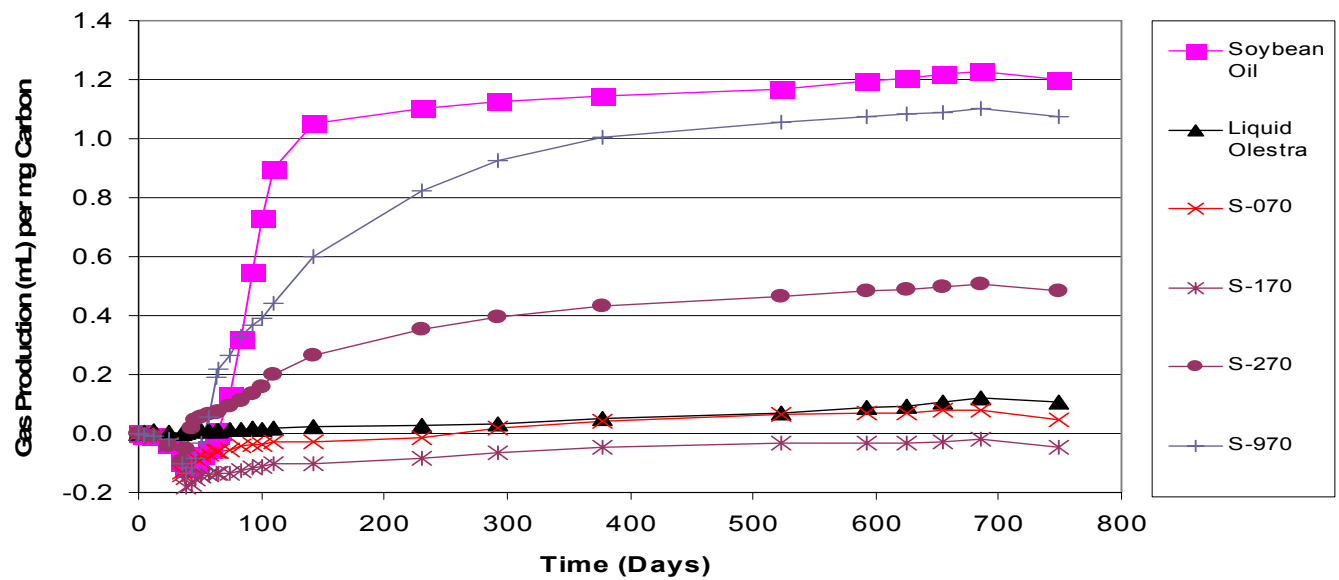

Figure 2. Cumulative gas production per milligram organic carbon corrected for background gas production. 
All of the vegetable oils generated significant gas production while the petroleum based materials (mineral oil, petroleum jelly and paraffin) did not result in significant gas production in any incubation. In the corn oil and soy methyl-ester (biodiesel/soy gold 1000) incubations, gas production was initially lower than in the no-carbon controls indicating that something in these materials inhibited methane production. Gas production was then very rapid from 31 to 120 days, and after that gas production slowed or stopped indicating depletion of the added substrate. In contrast, the soybean oil, expelled soybean oil, hydrogenated soybean oil, and olive oil all showed good steady gas production throughout the monitoring period with significant gas production observed during the last monitoring period (181 to 300 days). Canola oil generated steady gas production throughout the entire incubation period. However total gas production from canola oil was significantly lower than for the other vegetable oils. It may be that the canola oil is not yet completely degraded and gas production will continue for sometime into the future.

In the organic acids and carbohydrates group, acetate, lactate, methyl lactate and molasses all resulted in rapid gas production with no initial inhibition of methanogenesis. In constrast, myristic acid resulted in slower gas production, stearic acid initially inhibited methanogenesis but was eventually degraded, and lauric acid completely inhibited methanogenesis. Gas production in chitin was similar to molasses. Of these materials, only molasses generated significant gas production during the period from 181 to 300 days.

For the surfactants, the modified lecithins (Centromix E, Centrol CA, and Centrophase C) resulted in the most rapid and complete gas production with somewhat slower degradation by the Centrolene A, Actiflow 68-UB and Blendmax K. Gas production 
was somewhat slower for Tween 20,21 and 85. However, there was no evidence of any inhibition of methanogensis. Gas production from Ivory Soap was similar to Blendmax K.

SEFAs with one to three fats are readily biodegradable at low concentrations but can be inhibitory to microbiological processes at higher concentrations. This suggests that SEFAs with an intermediate number of fats may be slowly biodegradable under anaerobic conditions (McAvoy et al., 1996). This hypothesis was borne out in the methanogenic incubation tests. The SEFAs with one or two fats (S-070, S-170) inhibited background gas production and were not fermented to methane. The SEFAs with three or four fats (S-270, S970, S-1670) did not inhibit initial gas production and were metabolized. Finally, the highly saturated SEFAs (SEFA liquid, SEFA solid) did not inhibit gas production, but also did not result in appreciable gas production. These results suggest that SEFAs with intermediate number of fatty acids could be used to provide a slow steady supply of organic carbon to support anaerobic bioremediation processes. Several of the SEFAs continued to support some gas production twelve to eighteen months after being added to the bottles (Figure 4). 

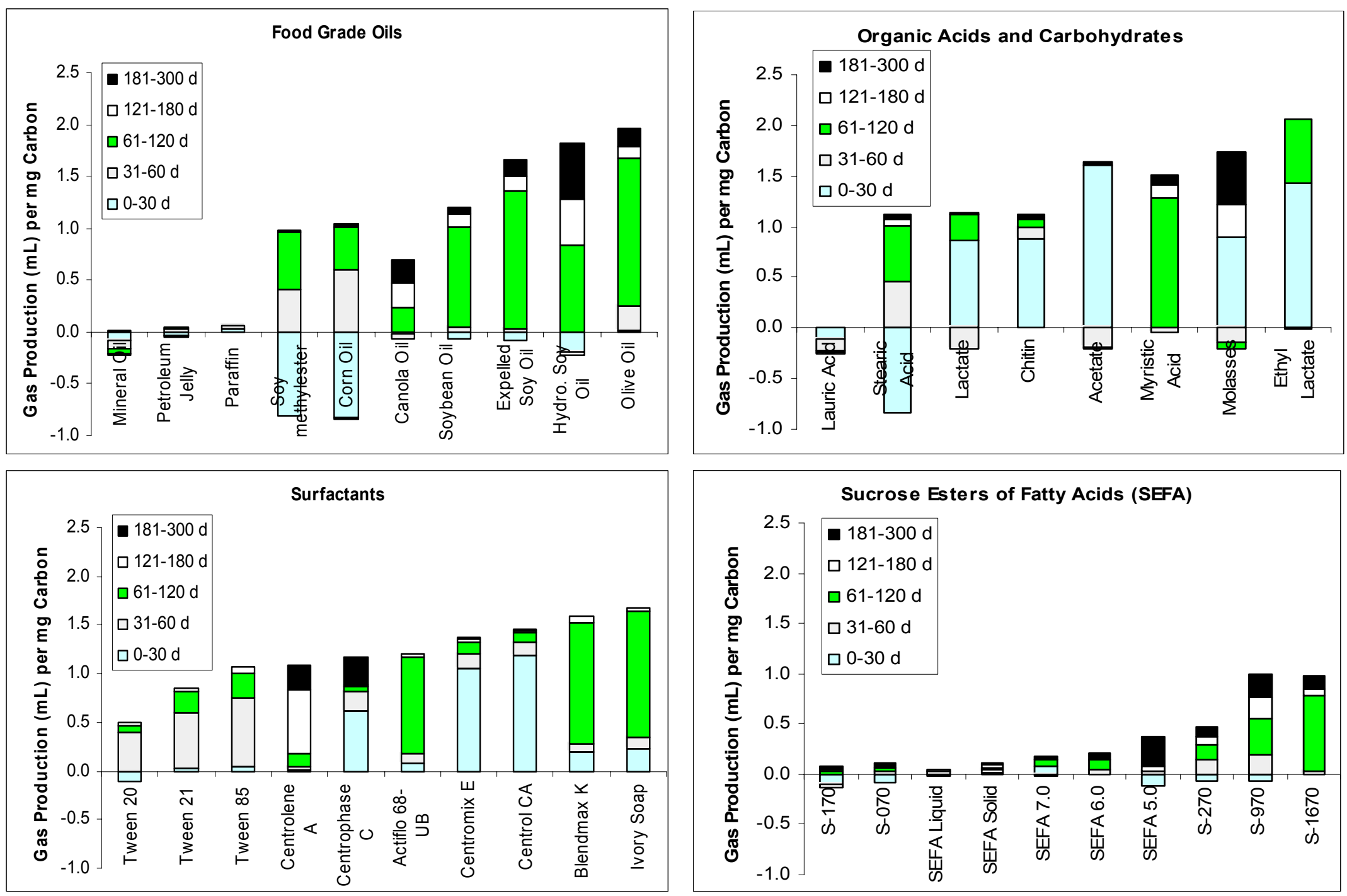

Figure 3. Gas production per milligram organic carbon during different time periods. Production has been corrected for gas production in no-added carbon controls. 


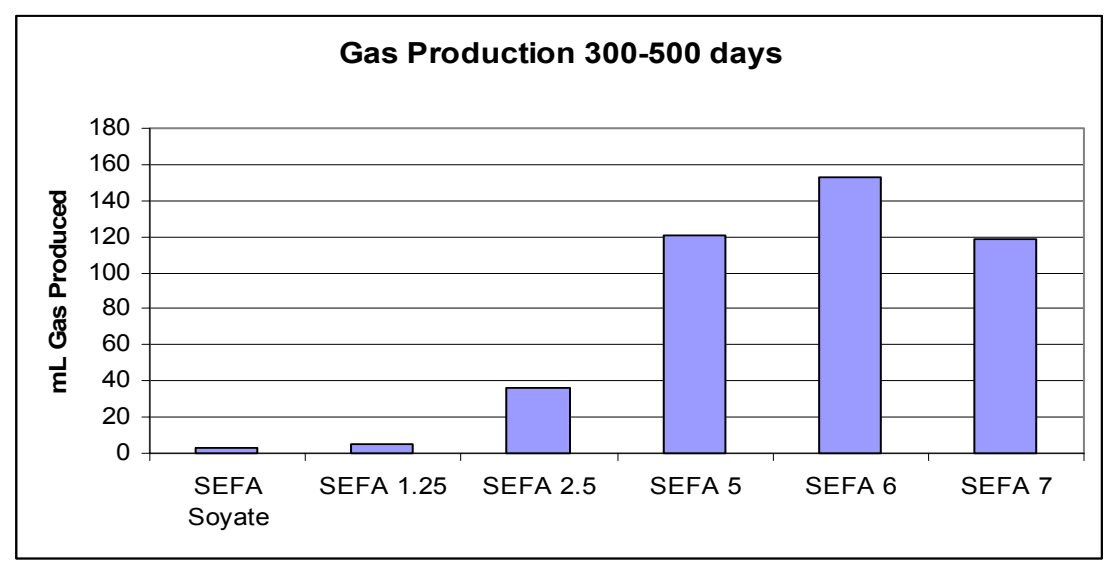

Figure 4. Gas production after 300 days in SEFA incubations.

Blending liquid soybean oil with SEFA at 1:1 volume ratio had no effect on the gas production rate, but mixing soybean oil with SEFA at 1:3 volume ratio substantially reduced the methane production rate (Appendix 2).

The results obtained with the different substrates generally agreed with prior work on biodegradability. 


\section{CHLORINATED COMPOUNDS IN INTERMITTENT FLOW COLUMNS}

The solvents tetrachloroethene (PCE) and trichloroethene (TCE) are among the most pervasive pollutants at groundwater contamination sites. Under aerobic conditions, PCE is considered nonbiodegradable, while TCE can be broken down to mainly nontoxic products by certain nonspecific oxygenases, such as methane monooxygenase or toluene dioxygenase (Major et al., 1991). Under anaerobic conditions, PCE and TCE have been reductively dechlorinated by mixed cultures to less-chlorinated ethenes and, under certain conditions, to the nontoxic products ethene and ethane (Aulenta et al., 2002).

General agreement exists that transformation of PCE under anaerobic condition proceeds by sequential reductive dechlorination to TCE, dichloroethylene (DCE), and vinyl chloride (VC). PCE and TCE are the most susceptible to anaerobic dechlorination because they are the most oxidized and they yield the most energy during the reductive reaction. Conversely, cis-DCE and VC are the least susceptible to reductive dechlorination because they are the least oxidized of the chlorinated ethenes. However, some studies have reported complete dechlorination of PCE to ethene, ethane or $\mathrm{CO}_{2}$ (Major et al., 1991; Major et al., 2002).

\subsection{INTERMITTENT FLOW COLUMN EXPERIMENTS}

Based on the results obtained in the incubation batches, intermittent flow column experiments were conducted to evaluate the ability of emulsified liquid soybean oil and S270 SEFA to support reductive dechlorination without excessive methane production and to 
evaluate the effect of varying sulfate levels on pollutant degradation. The experimental system consisted of eighteen $3.8 \mathrm{~cm}$ diameter by $30 \mathrm{~cm}$ long soil columns. The columns were packed with wet sediment in an anaerobic glove box. During the packing procedure, the sediment was frequently tamped to remove any entrapped gas bubbles. The sediment used to pack the columns was obtained from Dover AFB near the location of a full-scale enhanced bioremediation project. The general setup of the columns is illustrated in Figure 5.

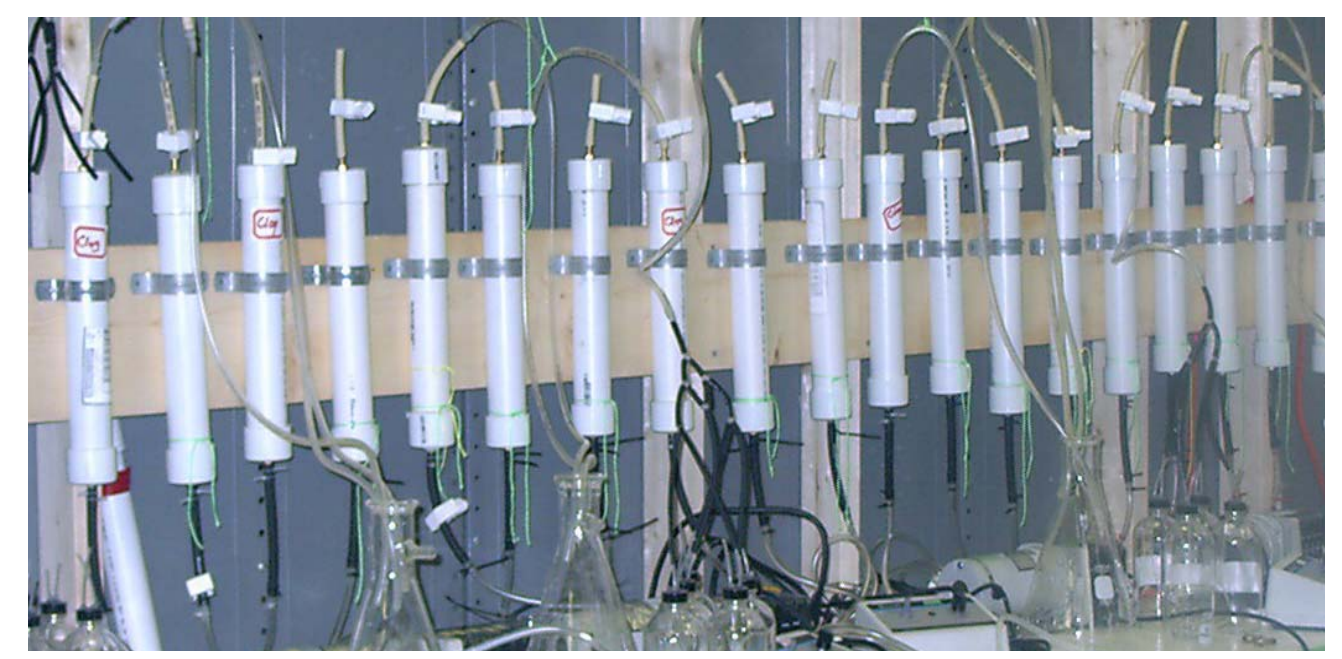

Figure 5. Set up of the intermittent flow columns.

The columns were operated in an intermittent flow mode where $16-25 \mathrm{~mL}$ of influent $(\sim 0.25$ pore volumes) was flushed through the column. Then the column was allowed to rest for 24 hours before the next 0.25 pore volumes were introduced. This resulted in an 'average' groundwater velocity of $7.5 \mathrm{~cm} / \mathrm{d}$ and hydraulic retention time (HRT) of $\sim$ 4days. The influent and effluent from each column were periodically monitored for chlorinated solvents (PCE, TCE, DCE isomers, VC), electron acceptors and donors (oxygen, nitrate, sulfate) phosphate, methane, ethene, ethane, $\mathrm{pH}$, and dissolved organic carbon. 
Experimental treatments are listed in Table 1. Emulsified soybean oil or S-270 $(20 \mathrm{~mL}$ of $10 \%$ by volume) was injected into each column on June 24,2002 using a syringe and separate luer lock fitting and then displaced with $40 \mathrm{~mL}$ deaired salts solution $(100 \mathrm{mg} / \mathrm{L}$ $\mathrm{CaCl}_{2}$ ) to push the emulsion into the column. The column was then allowed to sit for two days, before starting the daily pumping schedule. Effluent samples were collected daily for two weeks and analyzed for volatile solids to determine the amount of emulsion that came out of the columns. The columns were then inoculated with one of the following treatments:

Treatment 1: Inject $25 \mathrm{~mL}$ of bioaugmentation culture, $12 \mathrm{~mL}$ of autoclaved anaerobic digester sludge followed by $25 \mathrm{~mL}$ of BMP media;

Treatment 2: Inject $25 \mathrm{~mL}$ of bioaugmentation culture, $12 \mathrm{~mL}$ of live anaerobic digester sludge followed by $25 \mathrm{~mL}$ of BMP media;

Treatment 3: Inject $21 \mathrm{~mL}$ of autoclaved anaerobic digester sludge followed by $41 \mathrm{~mL}$ of BMP media.

The different volumes of digester sludge and enrichment culture were calculated to add the same amount of volatile solids to each column. 
Table 1. Experimental treatments in intermittent flow column experiments

\begin{tabular}{|c|c|c|c|c|}
\hline COLUMN & BIOAUGMENTATION & HCl & $\mathrm{SO}_{4}(\mathrm{mg} / \mathrm{L})$ & SUBSTRATE \\
\hline 2 & Lumberton & No & 0 & None \\
\hline 9 & Lumberton & No & 0 & Soybean Oil \\
\hline 4 & Lumberton & No & 0 & Soybean Oil \\
\hline 5 & Lumberton & No & 0 & S-270 \\
\hline 6 & Lumberton & No & 0 & S-270 \\
\hline 7 & Lumberton + digester sludge & No & 0 & None \\
\hline 12 & Lumberton + digester sludge & No & 0 & Soybean Oil \\
\hline 15 & Lumberton + digester sludge & No & 0 & Soybean Oil \\
\hline 8 & Lumberton + digester sludge & No & 0 & $\mathrm{~S}-270$ \\
\hline 11 & Lumberton + digester sludge & No & 0 & S-270 \\
\hline 17 & Lumberton & No & 200 & None \\
\hline 1 & Lumberton & No & 200 & Soybean Oil \\
\hline 18 & Lumberton & No & 200 & Soybean Oil \\
\hline 19 & Lumberton & No & 200 & S-270 \\
\hline 16 & Lumberton & No & 200 & S-270 \\
\hline 3 & Autoclaved digester sludge & Yes & 0 & None \\
\hline 10 & Autoclaved digester sludge & Yes & 0 & Soybean Oil \\
\hline 14 & Autoclaved digester sludge & Yes & 0 & S-270 \\
\hline
\end{tabular}

The bioaugmentation culture was enriched from a site in Lumberton, North Carolina, contaminated with PCE. The digester sludge was added to evaluate substrate longevity in an aquifer with a high number of methanogens. One week after bioaugmentation, the influent reservoir for each column was amended with a mixture of pure PCE and hexadecane 
designed to maintain an influent concentration of roughly $10 \mathrm{mg} / \mathrm{L}$ PCE. Some columns received $200 \mathrm{mg} / \mathrm{L} \mathrm{Na}_{2} \mathrm{SO}_{4}$ in the influent to evaluate the effect of high background sulfate levels on substrate longevity and reductive dechlorination. Three columns received dilute $\mathrm{HCl}(0.01 \mathrm{~N})$ in the influent to inhibit biological activity. After 15 months of operation, sediment samples from each column were analyzed to determine the fraction organic carbon remaining. Carbon mass balances were calculated based on the amount of organic and inorganic carbon released from each column. Table 2 shows the results of carbon balances for each treatment. Appendix 3 shows the carbon remaining in the columns at the end of the experiment - results provided by NCSU Soil Science Department analytical service laboratory. 
Table 2a. Carbon balance for chlorinated columns treated with emulsified soybean oil.

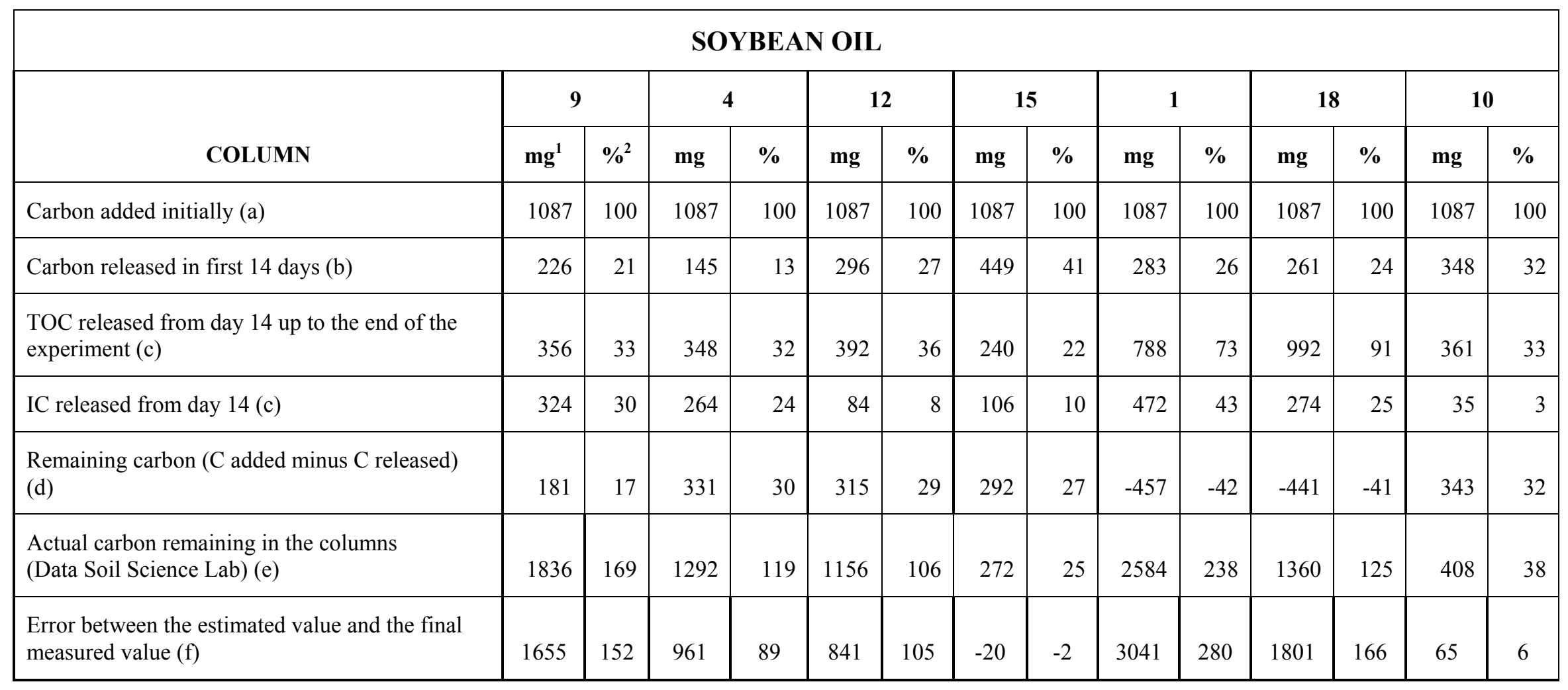

$1-$ Assumes mass of sediment in column $=680 \mathrm{~g}$

2 - \% of organic carbon injected into column as emulsion 
Table 3b . Carbon balance for chlorinated columns treated with S-270.

\begin{tabular}{|c|c|c|c|c|c|c|c|c|c|c|c|c|c|c|}
\hline \multicolumn{15}{|c|}{ S-270 } \\
\hline \multirow[b]{2}{*}{ COLUMN } & \multicolumn{2}{|c|}{5} & \multicolumn{2}{|c|}{6} & \multicolumn{2}{|c|}{8} & \multicolumn{2}{|c|}{11} & \multicolumn{2}{|c|}{19} & \multicolumn{2}{|c|}{16} & \multicolumn{2}{|c|}{14} \\
\hline & $\mathbf{m g}^{1}$ & $\%^{2}$ & mg & $\%$ & mg & $\%$ & mg & $\%$ & mg & $\%$ & mg & $\%$ & mg & $\%$ \\
\hline Carbon added initially (a) & 711 & 100 & 711 & 100 & 711 & 100 & 711 & 100 & 711 & 100 & 711 & 100 & 711 & 100 \\
\hline Carbon released in first 14 days (b) & 249 & 35 & 221 & 31 & 259 & 36 & 263 & 37 & 199 & 28 & 124 & 17 & 125 & 18 \\
\hline $\begin{array}{l}\text { TOC released from day } 14 \text { up to the end of the } \\
\text { experiment (c) }\end{array}$ & 716 & 101 & 532 & 75 & 247 & 35 & 424 & 60 & 437 & 61 & 682 & 96 & 82 & 12 \\
\hline IC released from day $14(\mathrm{c})$ & 151 & 21 & 92 & 13 & 58 & 8 & 142 & 20 & 153 & 22 & 223 & 31 & 41 & 6 \\
\hline Remaining carbon ( $\mathrm{C}$ added minus $\mathrm{C}$ released) (d) & -406 & -57 & -134 & -19 & 147 & 21 & -118 & -17 & -78 & -11 & -318 & -45 & 463 & 65 \\
\hline $\begin{array}{l}\text { Actual carbon remaining in the columns } \\
\text { (Data Soil Science Lab) \% (e) }\end{array}$ & 476 & 67 & 680 & 96 & -68 & -10 & 340 & 48 & -68 & -10 & 0 & 0 & -68 & -10 \\
\hline $\begin{array}{l}\text { Error between the estimated value and the final } \\
\text { measured value (f) }\end{array}$ & 882 & 124 & 814 & 115 & 215 & -31 & 458 & 65 & 215 & -31 & 318 & 45 & 215 & -31 \\
\hline
\end{tabular}

$1-$ Assumes mass of sediment in column $=680 \mathrm{~g}$

2 - \% of organic carbon injected into column as emulsion 
Table 4c. Carbon balance for chlorinated columns treated with no added substrate.

\begin{tabular}{|c|c|c|c|c|c|c|c|c|}
\hline \multicolumn{9}{|c|}{ NO SUBSTRATE } \\
\hline \multirow[b]{2}{*}{ COLUMN } & \multicolumn{2}{|c|}{2} & \multicolumn{2}{|c|}{7} & \multicolumn{2}{|c|}{17} & \multicolumn{2}{|c|}{3} \\
\hline & \multicolumn{2}{|c|}{ mg } & \multicolumn{2}{|c|}{ mg } & \multicolumn{2}{|c|}{ mg } & \multicolumn{2}{|c|}{ mg } \\
\hline Carbon added initially (a) & \multicolumn{2}{|c|}{0} & \multicolumn{2}{|c|}{0} & \multicolumn{2}{|c|}{0} & \multicolumn{2}{|c|}{0} \\
\hline Carbon released in first 14 days (b) & \multicolumn{2}{|c|}{1} & \multicolumn{2}{|c|}{1} & \multicolumn{2}{|c|}{2} & \multicolumn{2}{|c|}{0} \\
\hline TOC released from day 14 up to the end of the experiment (c) & \multicolumn{2}{|c|}{225} & \multicolumn{2}{|c|}{300} & \multicolumn{2}{|c|}{225} & \multicolumn{2}{|c|}{435} \\
\hline IC released from day $14(\mathrm{c})$ & \multicolumn{2}{|c|}{177} & \multicolumn{2}{|c|}{46} & \multicolumn{2}{|c|}{116} & \multicolumn{2}{|c|}{212} \\
\hline Total carbon released & \multicolumn{2}{|c|}{403} & \multicolumn{2}{|c|}{347} & \multicolumn{2}{|c|}{343} & \multicolumn{2}{|c|}{647} \\
\hline Actual carbon remaining in the columns (Data Soil Science Lab) \% (e) & $\begin{array}{c}884 \\
\mathrm{mg}\end{array}$ & $0.13 \%$ & $1768 \mathrm{mg}$ & $0.26 \%$ & $476 \mathrm{mg}$ & $0.07 \%$ & $408 \mathrm{mg}$ & $0.06 \%$ \\
\hline
\end{tabular}

(a) mg of carbon added at the beginning of the treatment. In the first set, soybean oil; in the second set S-270; and in the third set no carbon was added.

(b) $\mathrm{mg}$ of carbon released in the first 14 days of the experiment

(c) $\mathrm{mg}$ of TOC and IC released during day 14 up to the life time of the experiment

(d) carbon remaining in the column, calculated by subtracting the carbon released from the initial carbon added

(e) carbon content in the columns at the end of the experiment - data provide by Soil Science Department Laboratory at NC State University

(f) difference between the measured carbon content at the end of the experiment and the estimation based on the carbon added and released [(e) and (d)] 
As expected, the S-270 was less mobile, and a greater percentage remained within the soil columns after the first 14 days of sampling. For some columns, there was a large mass balance error, presumably due to analytical errors in TOC and IC measurements, and/or analysis of soil samples by the Soil Science analytical services laboratory.

Figure 6 presents a summary of the experimental results from the intermittent flow columns. After 15 months of operation, the carbon content of the soybean oil amended columns and the S-270 amended columns were significantly higher than the unamended control columns indicating a one time addition of a low solubility organic substrate can support anaerobic bioremediation processes for an extended time period. PCE removal was low in all of the columns because of the very short hydraulic retention time ( $\sim 4$ days) and high PCE loading (over $5 \mathrm{mg} / \mathrm{L}$ ). However, cis-DCE production was significant in all soybean oil treated columns. Some cis-DCE was also produced in the S-270 treated columns. However, the cis-DCE production in the S-270 treated columns was consistently lower than in the soybean oil treated columns, presumably due to a much lower amount of biologically available organic carbon. The lower level of bioavailable carbon was also reflected in the smaller amount of methane produced and reduced sulfate removal efficiency. Fewer degradation products, such as cis-DCE, and less methane were produced for the columns treated with sulfate, which is in agreement with several studies regarding the inhibition of dechlorinating activity with excessive sulfate presence. 

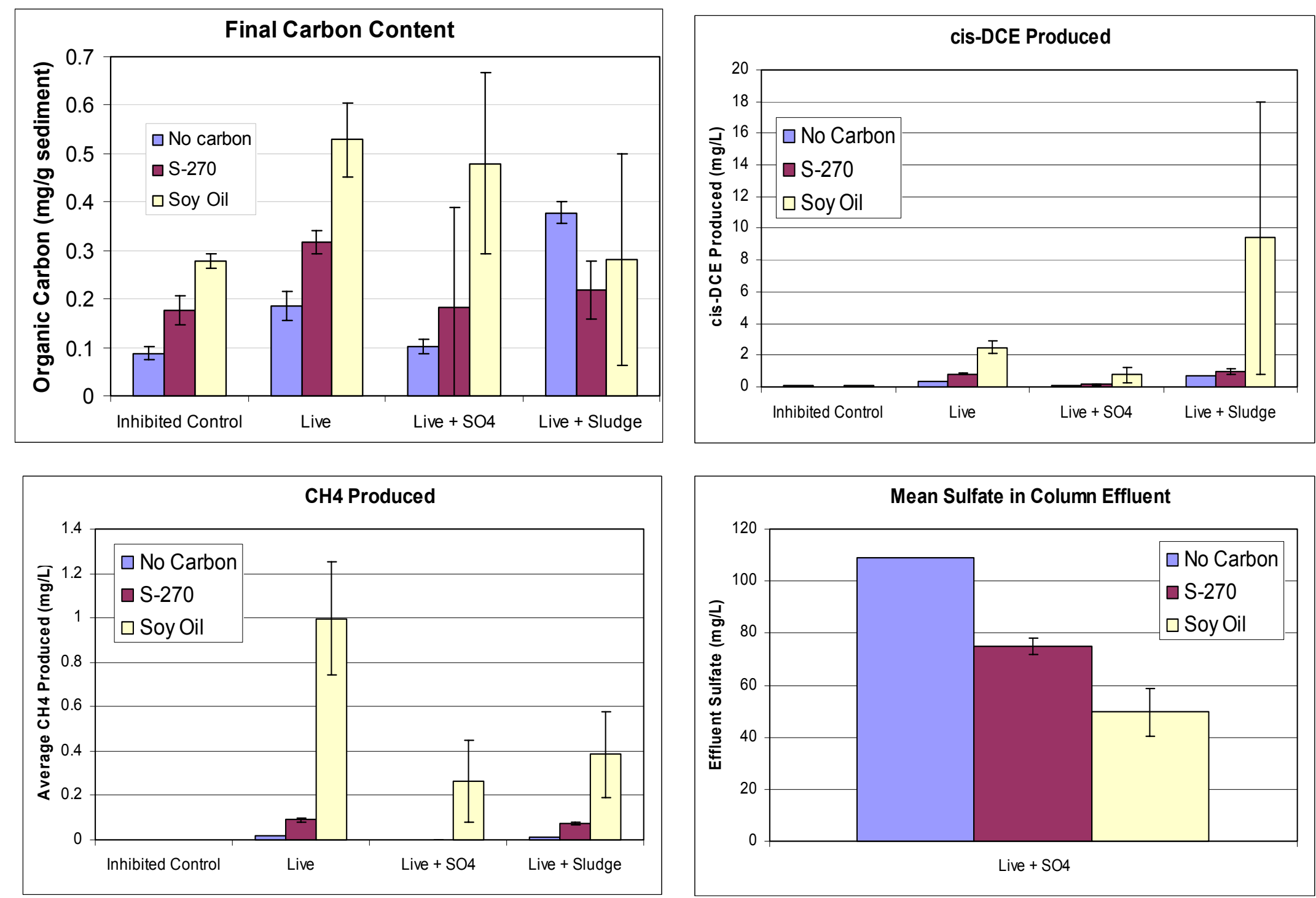

Figure 6. Effect of substrate added and influent solution composition on final carbon content, cis-DCE produced, $\mathrm{CH}_{4}$ produced and effluent $\mathrm{SO}_{4}$. Error bars are experimental range in duplicate columns. 


\section{PERCHLORATE AND TCA}

Perchlorate salts are manufactured in large quantities for use as oxidizers in solid rocket propellants, explosives and automobile air bag inflators (Espenson, 2000; Logan, 2001). Since the development of a new analytical method for perchlorate with a detection limit $(4 \mu \mathrm{g} / \mathrm{L})$, perchlorate has been detected in many drinking water sources. Although it reacts energetically when dry, perchlorate in aqueous solution is extremely stable and highly soluble, and therefore difficult to remove with conventional treatment processes.

Perchlorate ion inhibits the uptake of iodine by the thyroid gland, which identifies it as a suspected endocrine disrupter (King, 1995). Iodine deficiencies are detrimental to fetal development.

Perchlorate reduction occurs through the chemical reaction:

$$
\mathrm{ClO}_{4}^{-}+8 \mathrm{e}^{-}+8 \mathrm{H}^{+} \rightarrow \mathrm{Cl}^{-}+4 \mathrm{H}_{2} \mathrm{O}
$$

In general, perchlorate reduction is very slow even though perchlorate is a strong oxidizing agent. The perchlorate pathway proposed by Rikken (1996) is widely accepted for bacterial respiration, using acetate in each step and forming $\mathrm{CO}_{2}, \mathrm{H}_{2} \mathrm{O}$ and biomass:

$$
\begin{aligned}
& \qquad \mathrm{ClO}_{4} \rightarrow \mathrm{ClO}_{3} \rightarrow \mathrm{ClO}_{2} \rightarrow \mathrm{Cl}+\mathrm{O}_{2} \\
& \text { Perchlorate reductase } \quad \text { Unknown enzyme }
\end{aligned}
$$

Recent epidemiological studies have recommended that the maximum contaminant level (MCL) for perchlorate in drinking water is reduced to $1 \mu \mathrm{g} / \mathrm{L}$. However, this concentration is not measurable by conventional ion chromatography (Handy, 2000). 
Perchlorate is known to occur naturally in only a very few locations (nitrate deposits). However, bacteria capable of degrading perchlorate are surprisingly widespread in nature (Logan, 2001). Despite their abundance, few perchlorate-reducing bacteria (PRB) have been physiologically and phylogenetically characterized, and all perchlorate degrading isolates reported prior to 2001 had been heterotrophic (Achenbach, 2001). The ability to use nitrate and chlorate as the electron acceptors is a common characteristic of many heterotrophic perchlorate reducing organisms. Enzymatic reduction of chlorate to chlorite by nitrate reductase occurs as a competitive reaction between nitrate and chlorate in certain denitrifying bacteria (Stouthamer, 1988). Perchlorate and chlorate respiring bacteria contain chlorite dismutase, an enzyme capable of disproportioning chlorite to chloride and oxygen with high efficiency (Van Ginkel, 1988). This is an interesting biological development because oxygen is a preferred electron acceptor, and under fully aerobic conditions, even bacteria that are capable of carrying out this process do not reduce perchlorate.

1,1,1-Trichloroethane (TCA) is a synthetic organic solvent widely used in industrial processes as a metal degreasing and dry-cleaning solvent and as a feed-stock for production of other organic chemicals. It is a major environmental pollutant commonly found in soil, groundwater, and the atmosphere. Because of TCA's adverse effects on human health, the EPA has set a maximum contaminant level of $200 \mu \mathrm{g} / \mathrm{L}$ in drinking water. TCA is also listed as an ozone-depleting substance by the United Nations Environment Programme. Even when released into soil or leached into groundwater, the primary environmental fate of TCA is volatilization to the atmosphere, where it interacts with ozone and contributes to erosion of the ozone layer. (EPA, 1998). 
TCA is relatively resistant to biodegradation. Transformation of TCA to 1,1dichloroethane (DCA) and chloroethane (CA) occurs through reductive dechlorination. DCA was found as the main product of TCA biotransformation, but conversion to CA and complete dechlorination to $\mathrm{CO}_{2}$, acetic acid and unknown products was also detected (Vogel and McCarty, 1985).

\subsection{EXPERIMENTAL METHODS}

The methods employed in this experiment were designed to mimic groundwater conditions typically seen in contaminated sites. Microcosm and soil column experiments were performed in the NCSU Environmental Engineering Lab with available analytical tools. In all cases, care was taken to ensure the quality of results and the integrity of samples. Duplicate analyses were conducted on approximately $10 \%$ of all samples to evaluate the reproducibility of the analytical measurements. The potential for enhancing biodegradation of perchlorate and TCA using liquid soybean oil and hydrogenated soybean oil were evaluated in batch microcosm and intermittent flow columns.

\subsubsection{Analytical Methods}

Standard method 4110B: 'Ion chromatograph with chemical suppression of eluent conductivity' was used for analysis of sulfate, nitrate and nitrite ions. Typically, samples were collected from sample ports at the top of the columns and diluted 9:1 with a carbonate eluent matrix. Samples were allowed to sit 24 hours permitting the dissolved iron to 
precipitate and settle out of solution, and then filtered using a 0.45 micron syringe filter and frozen until analyzed.

A standard lab analytical $\mathrm{pH}$ probe and meter were used for all $\mathrm{pH}$ measurements. Perchlorate concentration was monitored using a specific ion electrode. The meters were calibrated before and after every $15-20$ samples using $\mathrm{pH} 4.0$ and 7.0 buffers. $5 \mathrm{~mL}$ samples were required for effective measurement and analysis occurred immediately after sampling. Standard storage, handling and calibration procedures supplied by the manufacturer were used. Duplicate samples were sent to a commercial laboratory for perchlorate analysis following USEPA approved protocols for perchlorate.

Total organic carbon (TOC) was analyzed using both the DC-190 TOC analyzer manufactured by Dohrman Scientific Products and the Shimadzu TOC analyzer with autosampler. When using the Dohrman DC-190, total carbon (TC) and inorganic carbon (IC) were determined by manual injection of an undiluted sample. TOC was determined as the difference between TC and IC. When using the Shimadzu TOC analyzer, 1:9 dilutions were used in a DI water matrix for analysis. Samples were stored in $2.5 \mathrm{~mL}$ serum bottles at $4^{\circ} \mathrm{C}$ until analyzed.

Dissolved oxygen was measured using Chemet DO ampoules. The detectable range for the Chemet kits was $0-1.0 \mathrm{mg} / \mathrm{L}$ of dissolved oxygen. Samples were immediately analyzed and the ampoules were broken directly into the sampling syringes to limit exposure to atmospheric conditions. 


\subsubsection{Experimental Materials}

Sediment used for the experiments is from an aquifer in Elkton, MD, sieved before use in microcosms and column experiments using a No. 4 standard size sieve.

The emulsions used for column treatments were prepared according to the procedure outlined by Coulibaly and Borden (2004). They demonstrated that oil-in-water emulsions with small uniform droplets can be prepared by using soybean oil and food grade surfactants that are generally recognized as safe. The emulsions used in this current project were prepared by blending $33 \%$ by volume soybean oil, $62 \%$ water and $5 \%$ premixed surfactant (38\% polysorbate $80,56 \%$ glycerol monooleate GMO from Lambent Technologies, and 6\% water). The outlined proportions were mixed in a Waring Commercial blender at high speed for five minutes to produce an emulsion with droplets ranging from 1 to $3 \mu \mathrm{m}$ in diameter. The wax emulsions were prepared similarly by using a fully hydrogenated soybean wax that was first melted in a hot water bath. Hot water was used in the blending process as well, but insignificant separation occurred after mixing.

\subsubsection{Microcosm Procedure}

Microcosm experiment was conducted to evaluate the potential of liquid soybean oil and hydrogenated soybean oil to enhance biodegradation and/or immobilization of perchlorate, and determine whether bioaugmentation was needed to achieve complete conversion of TCA to non-toxic end products. Each microcosm set was prepared in triplicate $245 \mathrm{~mL}$ serum bottles containing $175 \mathrm{~mL}$ of water from Elkton aquifer, $1.0 \mu \mathrm{L}$ of pure 1,1,1TCA and a bacterial inoculum where necessary. The bioaugmentation culture used in this 
work was enriched from aquifer material in Lumberton, NC and maintained in the NCSU Environmental laboratory by feeding periodically with nutrient media, lactate, yeast extract and PCE and TCA. Bottles were fitted with thick rubber stoppers and aluminum crimp seals to exclude oxygen. In all the substrate amended treatments, $1 \mathrm{~mL}$ of dilute emulsion containing $175 \mathrm{mg}$ oil $/ \mathrm{mL}$ of liquid or hydrogenated emulsion was added to each bottle. In addition, $100 \mathrm{mg} / \mathrm{L}$ of lactate and $50 \mathrm{mg} / \mathrm{L}$ of yeast extract were added to each bottle (assuming $175 \mathrm{~mL}$ liquid volume). Treatment 3-Killed was titrated with 1.0 M sodium hydroxide to increase the $\mathrm{pH}$ to 12 to inhibit biological activity. Experimental conditions for the seven sets of microcosms are shown in Table 3.

A variety of substrates or environmental conditions can be evaluated in this manner to deduce optimal conditions for bacterial growth. Autoclaved, killed controls and live, no added carbon controls were included to observe background reduction. Incubations were monitored over a 7.5 month period for disappearance of the pollutant, $\mathrm{pH}$, dissolved organic carbon and gas production. 
Table 3. Basic setup for the seven treatments of microcosms.

\begin{tabular}{|c|c|c|c|c|}
\hline TREATMENT & $\begin{array}{c}\text { SEDIMENT } \\
\text { VOLUME }\end{array}$ & SUBSTRATE & INOCULATED & ABREVIATION \\
\hline 1 & No & None & No & Water only \\
\hline 2 & $50 \mathrm{~mL}$ & None & No carbon \\
\hline 3 & $50 \mathrm{~mL}$ \\
autoclaved & Liquid soybean oil & No & Killed \\
\hline 4 & $50 \mathrm{~mL}$ & Liquid soybean oil & No & Oil only \\
\hline 5 & $50 \mathrm{~mL}$ & $\begin{array}{c}\text { Hydrogenated } \\
\text { Soybean wax }\end{array}$ & No & Waxly \\
\hline 6 & $50 \mathrm{~mL}$ & $\begin{array}{c}\text { Liquid soybean oil } \\
\text { Hydrogenated } \\
\text { Soybean wax }\end{array}$ & Yes & Wes \\
\hline
\end{tabular}

\subsubsection{Intermittent Flow Column Procedure}

Following the batch microcosms, the emulsified soybean oil and emulsified hydrogenated soybean oil were evaluated in intermittent flow column experiments. The columns were designed to replicate the aquifer environment by using contaminated sediment and slow influent rates. The basic apparatus consisted of 2" PVC pipes $(3.8 \mathrm{~cm}$ interior diameter) cut to $30 \mathrm{~cm}$ lengths packed with aquifer material, capped and fitted with brass fixtures to reduce environmental exposure. Packing the columns began by fixing the bottom end with PVC cement for the end cap and silicon gel around the brass fitting. A circular, fine synthetic mesh screen followed by inserting synthetic cotton fiber packing material into the bottom of the column to prevent sediment washout. Tubing was attached at the bottom and a 
small amount of water was allowed to flow through and quickly clamped to prevent air bubbles. The sediment was packed wet with a rubber tamp for tight settlement of the material and to limit entrapped air. Once the columns were filled, the top and bottom end caps were fitted with synthetic cotton packing and a fine mesh.

Masterflex peristaltic pumps were used to intermittently pump an influent solution at $20 \mathrm{~mL}$ per day through each column, allowing a HRT of $\sim 5$ days. The columns were monitored for 5 months.

Three columns were built. Column 1-Oil was treated with $100 \mathrm{~mL}$ of $8 \%$ soybean oilin-water emulsion, column 2-Wax was treated with $100 \mathrm{~mL}$ of $8 \%$ hydrogenated soybean oil wax emulsion, and column 3-No carbon was left untreated as a control. No inoculum was required due to the natural abundance of perchlorate degrading bacteria.

\subsection{MICROCOSM RESULTS}

The initial concentration of perchlorate for the seven microcosm treatments was 53 $\mathrm{mg} / \mathrm{L}$. After 14 days incubation, perchlorate was depleted to below the analytical detection limit $(8 \mu \mathrm{g} / \mathrm{L})$ in all substrate amended treatments, while $40 \mathrm{mg} / \mathrm{L}$ remained in the three noadded substrate treatments (water only, no carbon and killed). Measured perchlorate and chloride concentrations in each treatment at 2 and 14 days are shown in Figure 7. Perchlorate degraded rapidly in all substrate amended bottles with no detectable difference in degradation time between the liquid and solid hydrogenated soybean oil. In each substrate amended treatment, the perchlorate concentration declined by approximately 0.5 
millimoles/L. At the same time, dissolved chloride increased by approximately 0.5 millimoles per liter, indicating that the perchlorate was completely mineralized. $5 \mathrm{~mL}$ of the bioaugmentation culture for treatments 6 and 7 was added on day 28 with the objective of stimulating TCA degradation. Since the bioaugmentation culture was added after perchlorate was completely degraded, it has no impact on the results presented in Figure 7.

Figure 8 shows the observed variation in dissolved nitrate, sulfate and $\mathrm{pH}$ in the different microcosms. Values shown are the average of triplicate incubations. Nitrate remained constant at around $11 \mathrm{mg} / \mathrm{L}$ in Treatment 1-Water only and Treatment 3-Killed. However in all substrate amended treatments, nitrate was reduced to below detection $(<1$ $\mathrm{mg} / \mathrm{L}$ ) by day 2. There was also substantial nitrate loss in Treatment 2-No carbon, presumably due to organic carbon present in the sediment used to construct the microcosm. Sulfate concentration was constant in the 1-Water only treatment and increased slightly in Treatment 2-No carbon and Treatment 3-Killed. Sulfate was below detection $(<0.05 \mathrm{mg} / \mathrm{L})$ in all substrate amended treatments after 30 days. $\mathrm{pH}$ remained approximately constant in all live treatments ranging from 5.8 to 7.1. In the Killed Control, $\mathrm{pH}$ progressively decreased reaching background levels after 5 months. 

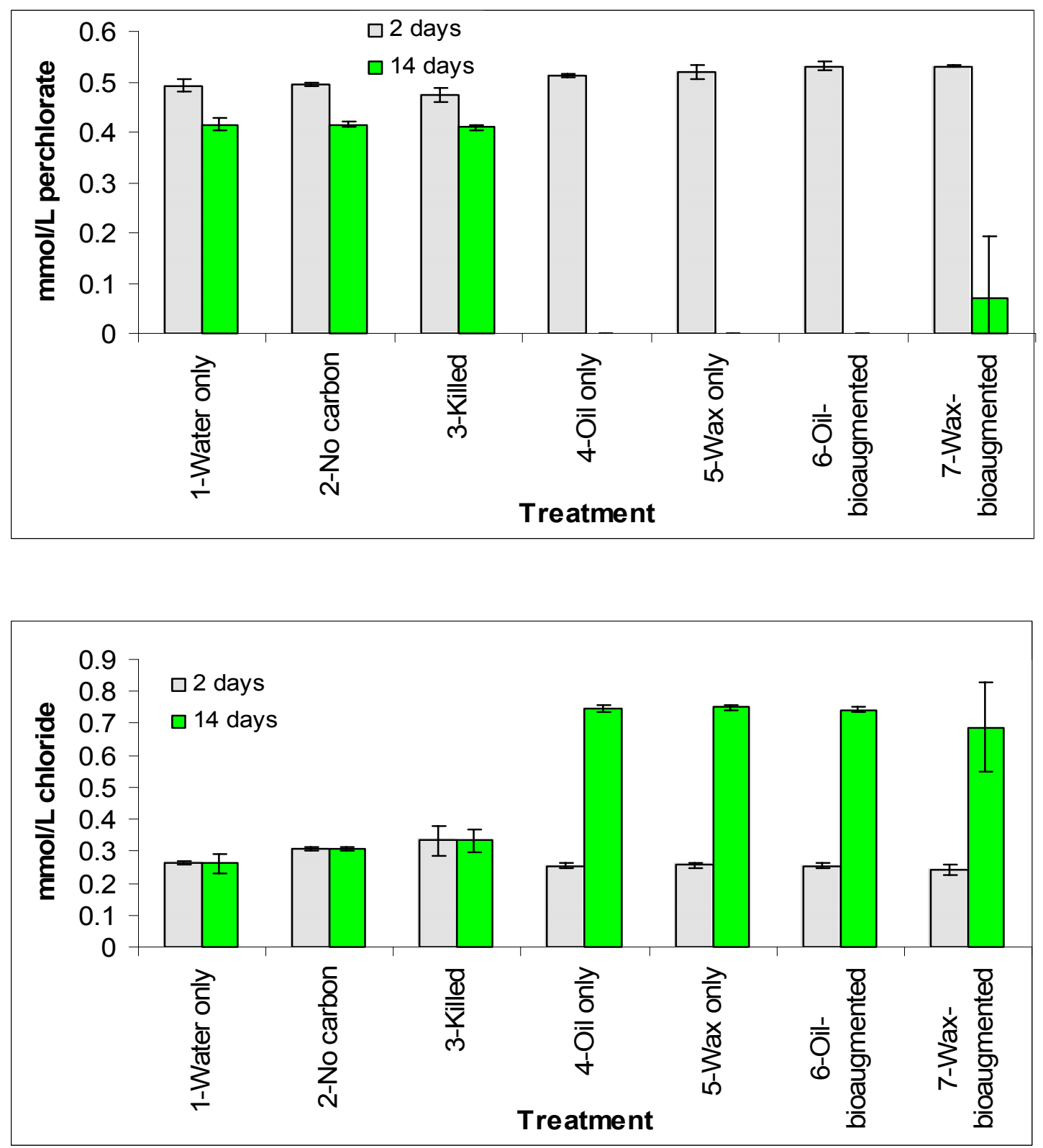

Figure 7. Perchlorate and chloride concentrations in microcosms on days 2 and 14. Errors bars are standard deviation from triplicate incubations.

The microcosm results indicated that both emulsified liquid and solid soybean oil can effectively stimulate perchlorate reduction in aquifer sediment and groundwater from the 
Elkton, MD site. Bioaugmentation is not necessary for rapid and complete perchlorate biodegradation.

Figure 9 shows analytical results versus time for the treatment 1-Water only. Acetate results are presented as $\mathrm{mg} / \mathrm{L}$ of carbon. Similar data is shown for the others treatments in Figures 10-14. 

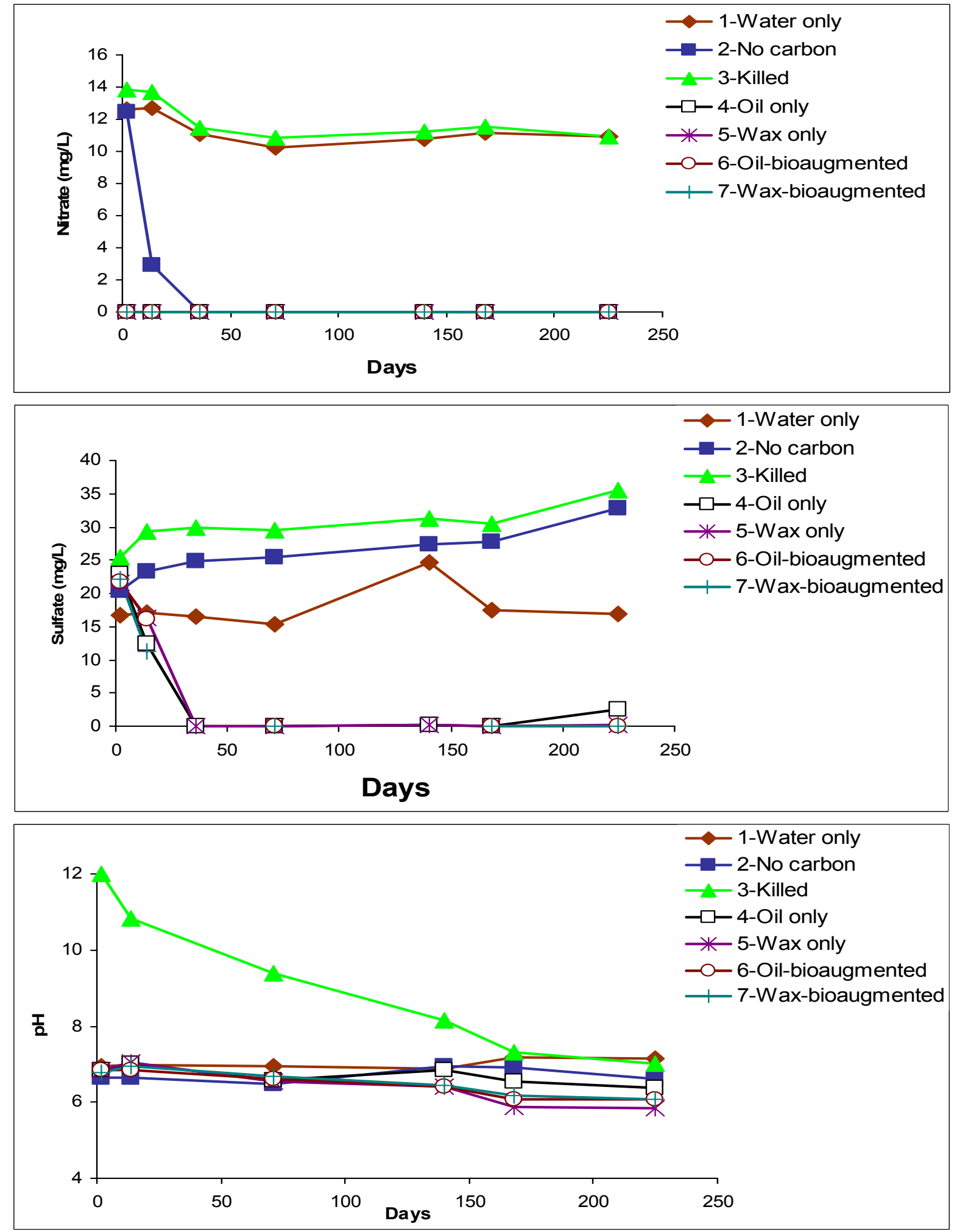

Figure 8. Variation in nitrate, sulfate and $\mathrm{pH}$ in microcosm treatments. 
In Treatment 1-Water only, nitrate and sulfate remained constant throughout the experiment. TOC, acetate and methane concentrations remained low in all incubations. There was a gradual loss of trichloroethane (TCA), presumably due to sorption in the stopper and/or removal of contaminant mass during sampling. Dichloroethane (DCA), 1,1dichloroethene (1,1-DCE), chloroethane (CA), vinyl chloride (VC) and the sum of ethene and ethane (Eth) were not produced in any incubations indicating very limited biological activity.

In Treatment 2-No carbon (Figure 10), nitrate was removed over the first 36 days. Sulfate and chloride steadily increased with time. The increase in sulfate could be due to dissolution/desorption from the aquifer matrix. The increase in chloride may be due to degradation of perchlorate and reductive dechlorination of TCA. Acetate, TOC and methane concentrations remained low throughout the incubation period. However, there appears to have been some reductive dechlorination activity in these incubations. TCA declined more rapidly in these incubations than in Treatment 1 , and significant amounts of DCA were produced.

Treatment 3-Killed was inadvertently amended with very high concentrations of TCA $(\sim 1,000 \mathrm{mg} / \mathrm{L})$. As a consequence, these results were not usable. 

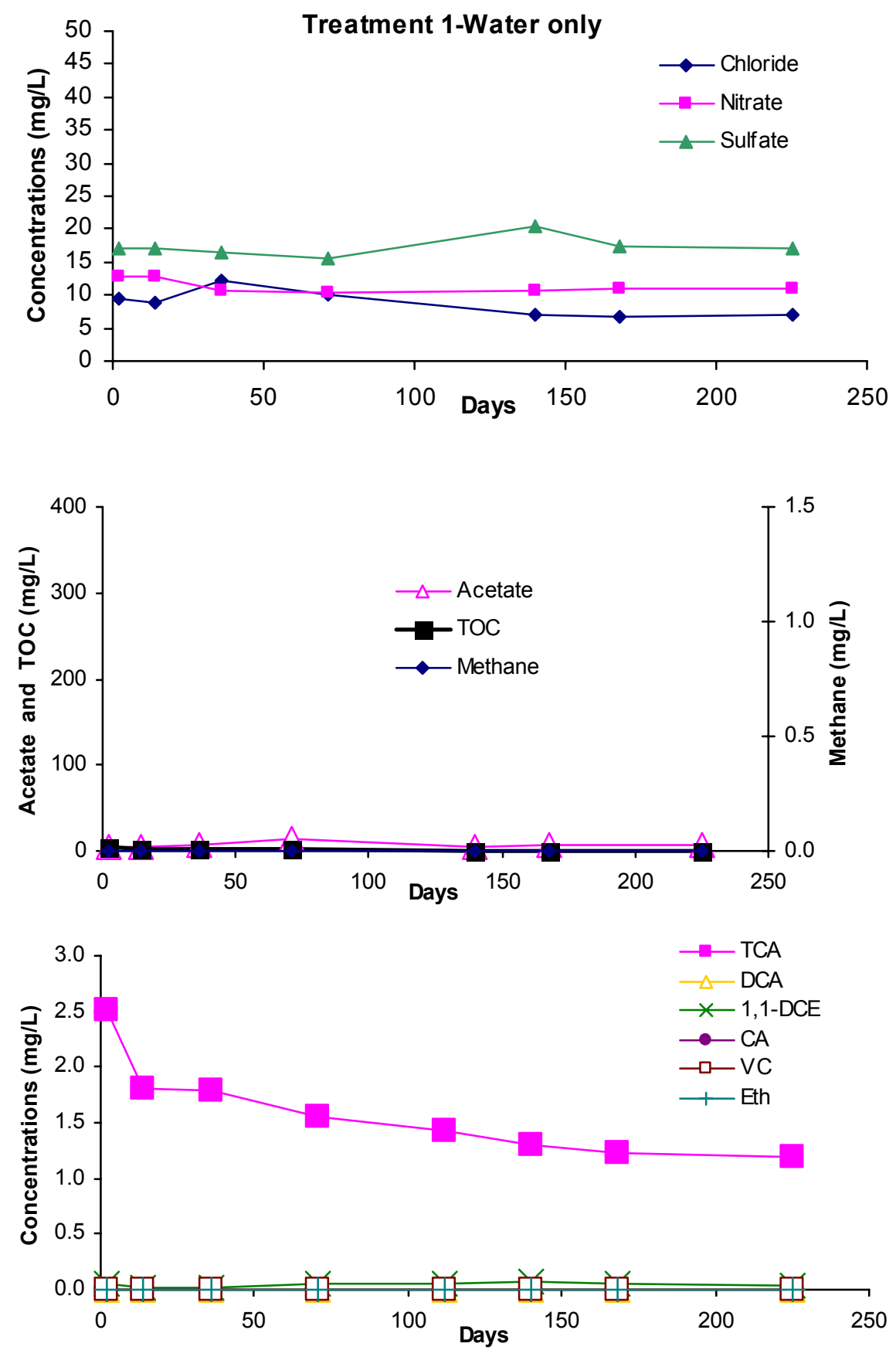

Figure 9. Treatment 1-Water only - analytical results for microcosm concentrations in $\mathrm{mg} / \mathrm{L}$ : chloride, nitrate and sulfate; acetate (mg/L of carbon), TOC and methane; TCA, DCA, 1,1 DCE, CA, $\mathrm{VC}$ and Eth. 

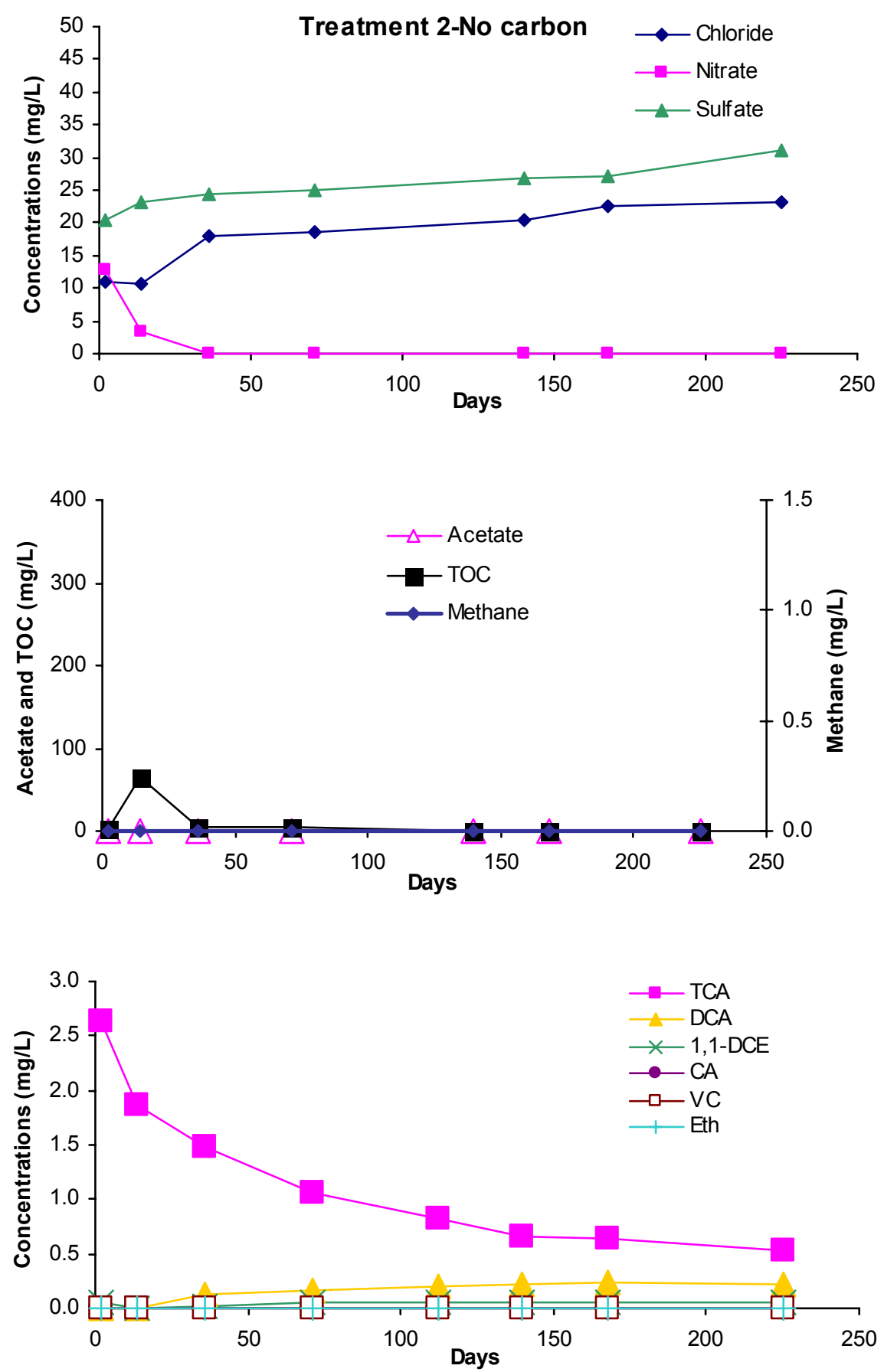

Figure 10. Treatment 2-No carbon - analytical results for microcosm concentrations in mg/L: chloride, nitrate and sulfate; acetate (mg/L of carbon), TOC and methane; TCA, DCA, 1,1 DCE, CA, $\mathrm{VC}$ and Eth. 

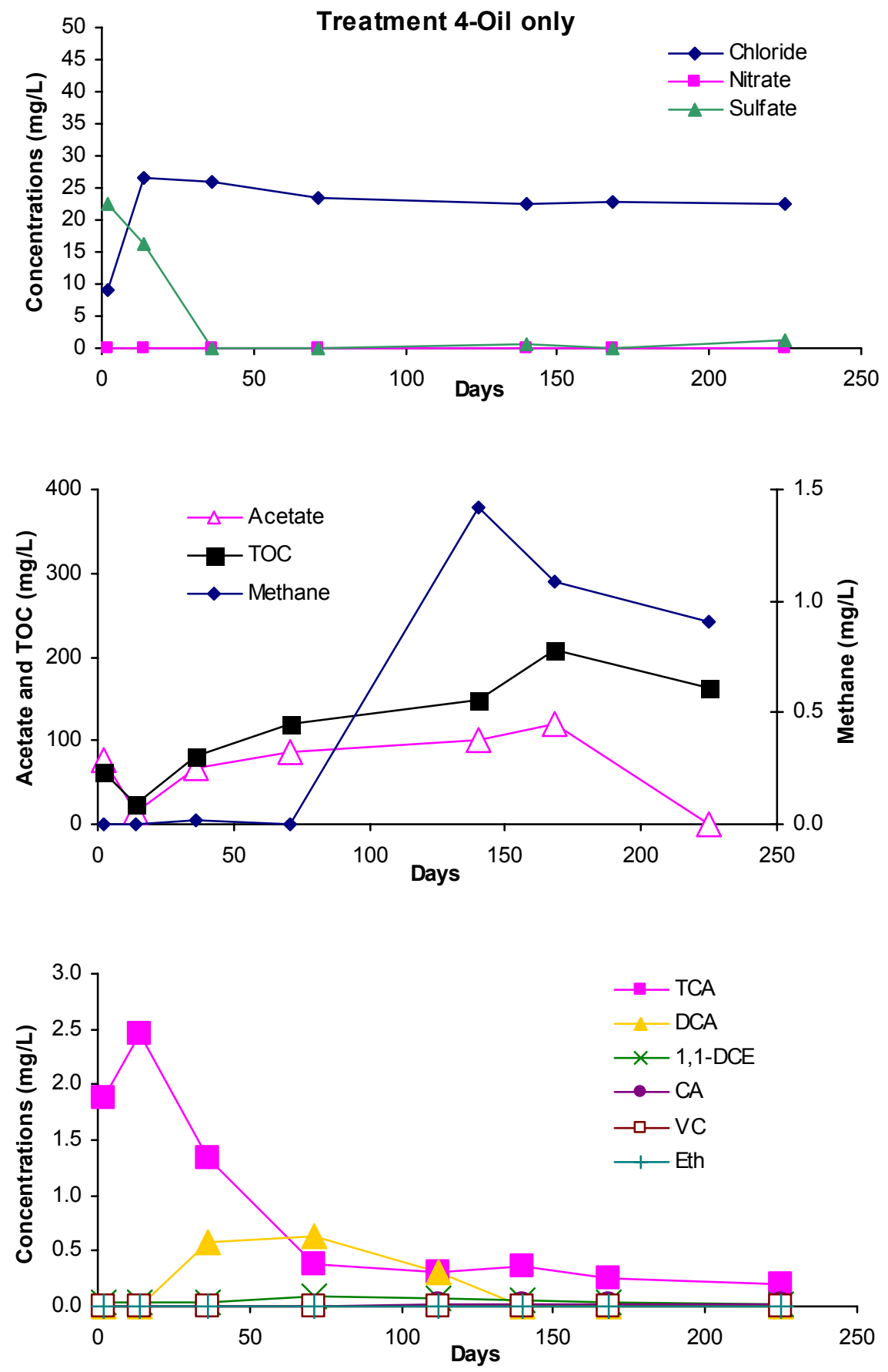

Figure 11. Treatment 4-Oil only - analytical results for microcosm concentrations in $\mathrm{mg} / \mathrm{L}$ : chloride, nitrate and sulfate; acetate (mg/L of carbon), TOC and methane; TCA, DCA, 1,1 DCE, CA, $\mathrm{VC}$ and Eth.

In Treatment 4-Oil only (Figure 11), nitrate was depleted by the first sampling on day 2. Sulfate was removed by day 36. Chloride increased by day 14 and then remained 
constant throughout the remainder of the experiment. Substantial levels of acetate and TOC were present throughout the incubation period with methane produced after day 71 . TCA degraded in all three bottles with concurrent production of DCA. However, TCA degradation rates varied with significantly slower degradation in one of the three replicates. DCA produced through TCA degradation was then reduced to CA. Measured CA concentrations were much lower than the amounts expected based on reaction stoichiometry. This is likely due to release of gaseous CA to the bottle headspace. Significant levels of ethene and ethene were not detected in any of the bottles.

In Treatment 5-Wax only (Figure 12), nitrate was rapidly depleted with somewhat slower removal of sulfate. Acetate and TOC increased gradually over the course of the incubation with methane production after 71 days following the same general pattern observed in the soybean oil incubations. However, maximum methane concentrations in this treatment were about half of those observed in the Treatment 4-Oil only. Reductive dechlorination activity was also variable in this treatment. While TCA degraded to low levels in all three replicates, further degradation of DCA to CA was more variable with accumulation of high levels of DCA in one of three bottles. As in Treatment 4, CA levels remained low (possibly due to volatilization to the headspace) with negligible production of ethene and ethane.

Results from Treatment 6-Oil bioaugmented and Treatment 7-Wax bioaugmented are presented in Figures 13 and 14. In general, experimental results were similar to the previous incubations without bioaugmentation. Nitrate was rapidly depleted followed by sulfate with a concurrent increase in dissolved chloride. TOC and acetate also increased throughout the 
incubation following the same pattern observed in prior incubations. However, methane production appeared to be somewhat slower than in the prior incubations without bioaugmentation. TCA degraded rapidly in both the oil-bioaugmented and waxbioaugmented bottles. However, DCA accumulated in all bioaugmented bottles with little or no production of $\mathrm{CA}$, ethene or ethane.

In summary, nitrate was degraded in all treatments, with the exception of the 1-Water only treatment. Low bacterial activity can be deduced for the behavior of treatments 1-Water only and 2-No carbon. Substantial levels of TOC, acetate and methane were produced in all oil and wax amended bottles. TCA also degraded in all oil and wax amended bottles. However, further conversion of DCA to CA was more variable. Without bioaugmentation, DCA was depleted to below detection in 3 out of 3 oil amended bottles and 1 out of 3 wax amended bottles. In contrast, DCA was not depleted to below detection in any of the bioaugmented bottles (oil or wax). 

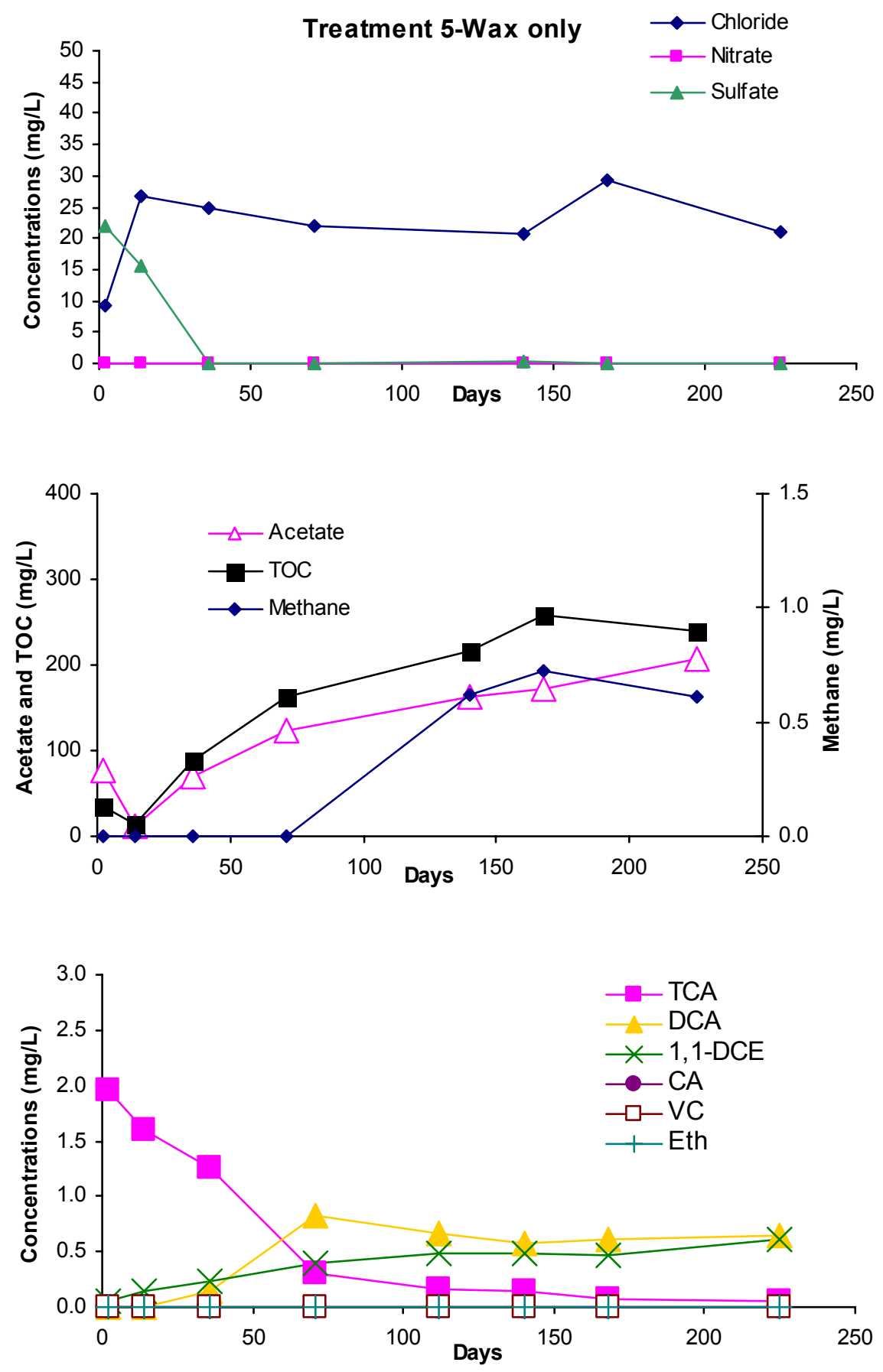

Figure 12. Treatment 5-Wax only - analytical results for microcosm concentrations in $\mathrm{mg} / \mathrm{L}$ : chloride, nitrate and sulfate; acetate (mg/l of carbon), TOC and methane; TCA, DCA, 1,1 DCE, CA, $\mathrm{VC}$ and Eth. 

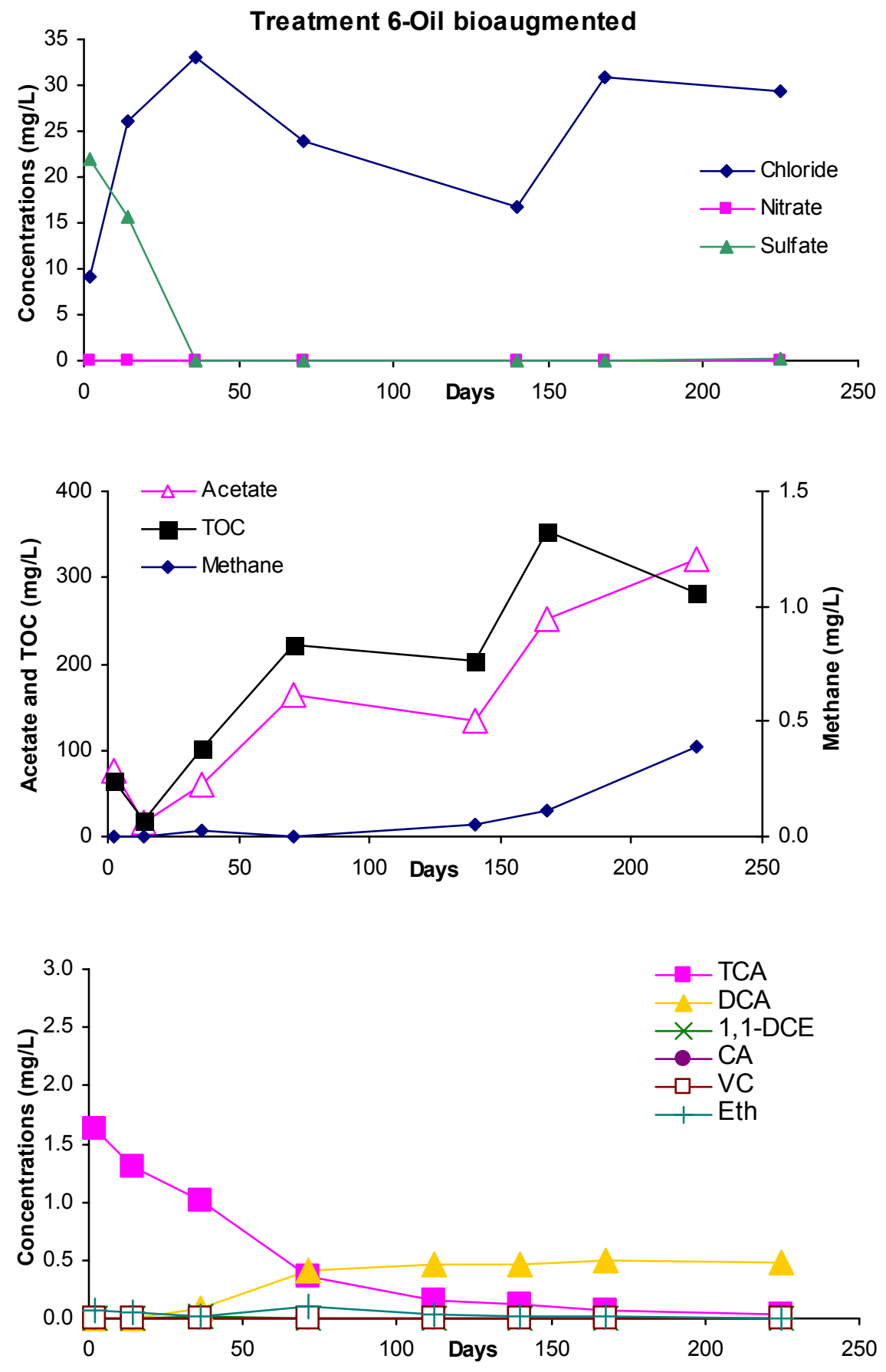

Figure 13. Treatment 6- Oil bioaugmented - analytical results for microcosm concentrations in $\mathrm{mg} / \mathrm{L}$ : chloride, nitrate and sulfate; acetate (mg/L of carbon), TOC and methane; TCA, DCA, 1,1 DCE, CA, VC and Eth. 

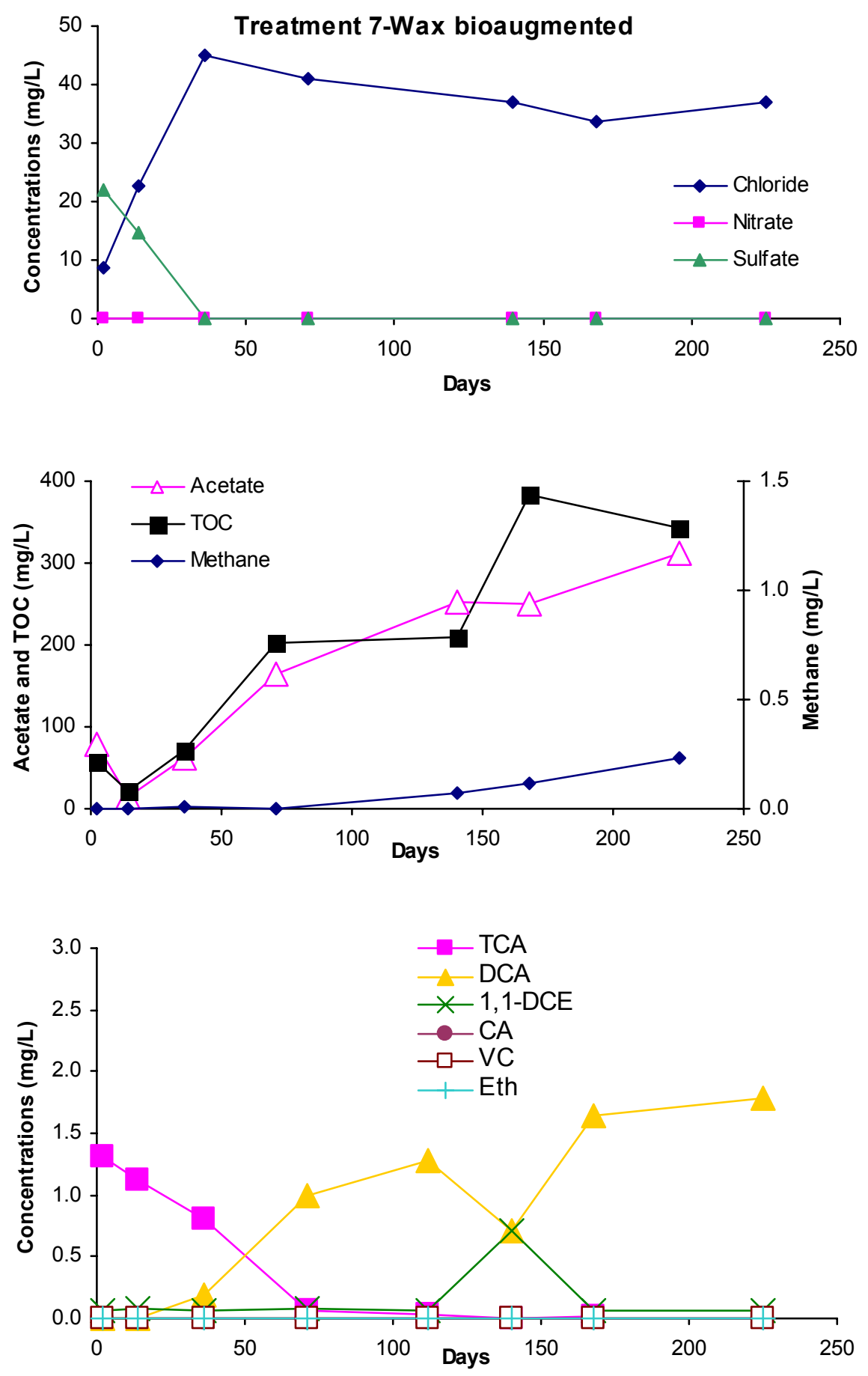

Figure 14. Treatment 7-Wax bioaugmented - analytical results for microcosm concentrations in $\mathrm{mg} / \mathrm{L}$ : chloride, nitrate and sulfate; acetate (mg/L of carbon), TOC and methane; TCA, DCA, 1,1 DCE, CA, VC and Eth. 


\subsection{COLUMN RESULTS}

Experimental columns were operated over a 5 month period to evaluate the biodegradation of perchlorate and TCA in aquifer sediments amended with emulsified soybean oil (Column 1), emulsified hydrogenated soybean oil (Column 2) and an untreated control (Column 3). The TCA and perchlorate concentration in each column influent are shown in Figure 15. Each influent solution contained $0.001 \mathrm{M} \mathrm{NaHCO}_{3}$ and $100 \mathrm{mg} / \mathrm{L} \mathrm{ClO}_{4}$ in aerated DI water. TCA was blended with hexadecane to form a NAPL phase that would slowly release dissolved TCA. The influent $\mathrm{pH}$ was between 6.5 and 7.5.

Perchlorate concentration in effluent from each one of the three columns measured using a specific ion electrode are shown in Figure 16, along with one set of perchlorate measurements by an outside commercial laboratory using USEPA approved methods. On day 21 , the oil or wax emulsions were injected into columns 1 and 2, respectively. In all samples collected after emulsion injection, perchlorate was below the analytical detection limit for the specific ion electrode (less than $10 \mathrm{mg} / \mathrm{L}$ ). For the one set of samples analyzed by the commercial laboratory (day 70), the values obtained using the specific ion electrode were consistent with the commercial lab results. Perchlorate depletion was observed in the substrate columns, confirming the results obtained in the microcosm experiment.

Figures 17-19 show the analytical results for the TCA, DCA, DCE, CA and Eth (sum of ethene and ethane), and the acetate and total organic carbon (TOC) concentration in effluent of each column. 

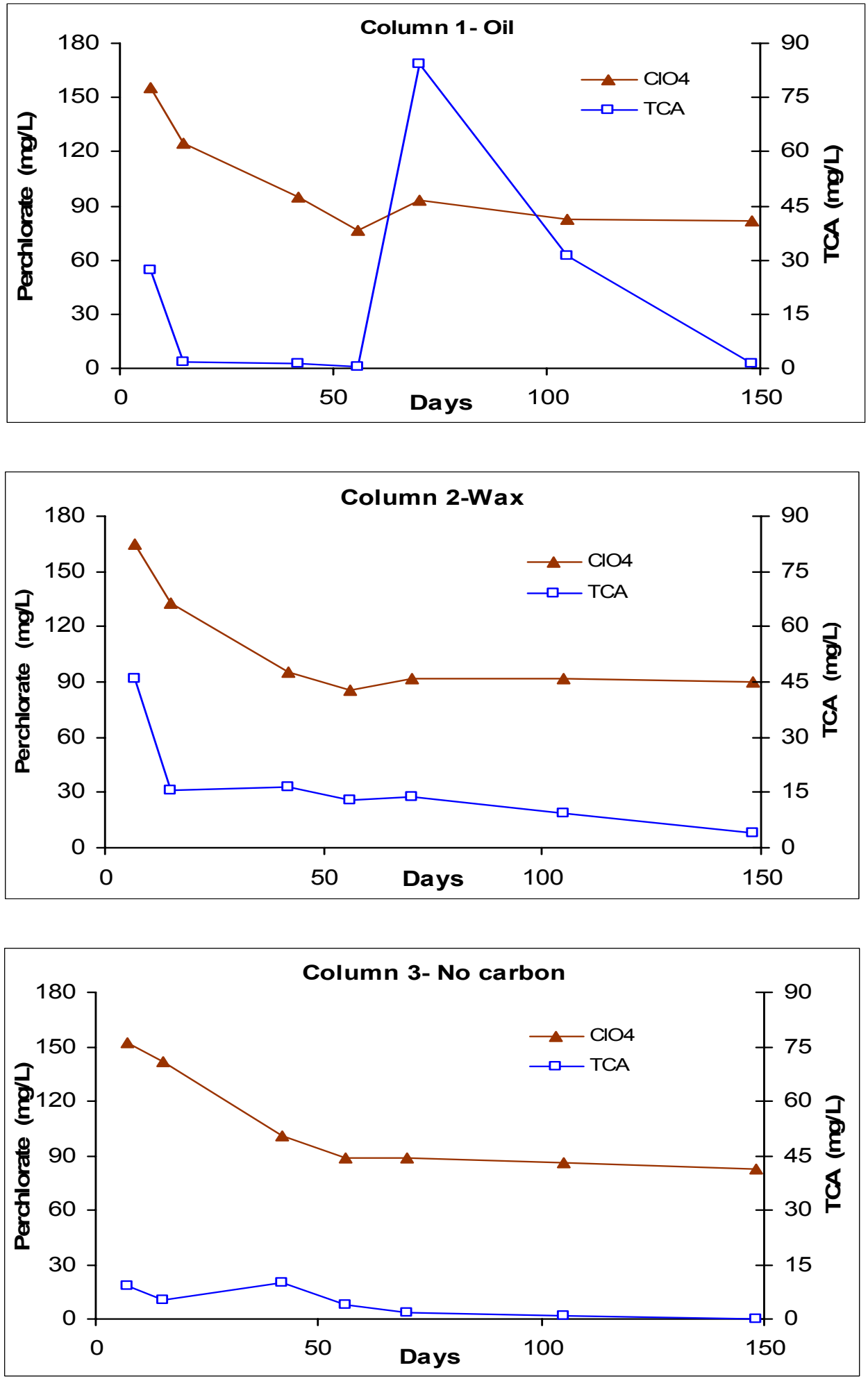

Figure 15. TCA and $\mathrm{ClO}_{4}$ concentrations in the influent. Column 1- Oil, column 2-Wax, and column 3-No carbon (control) 


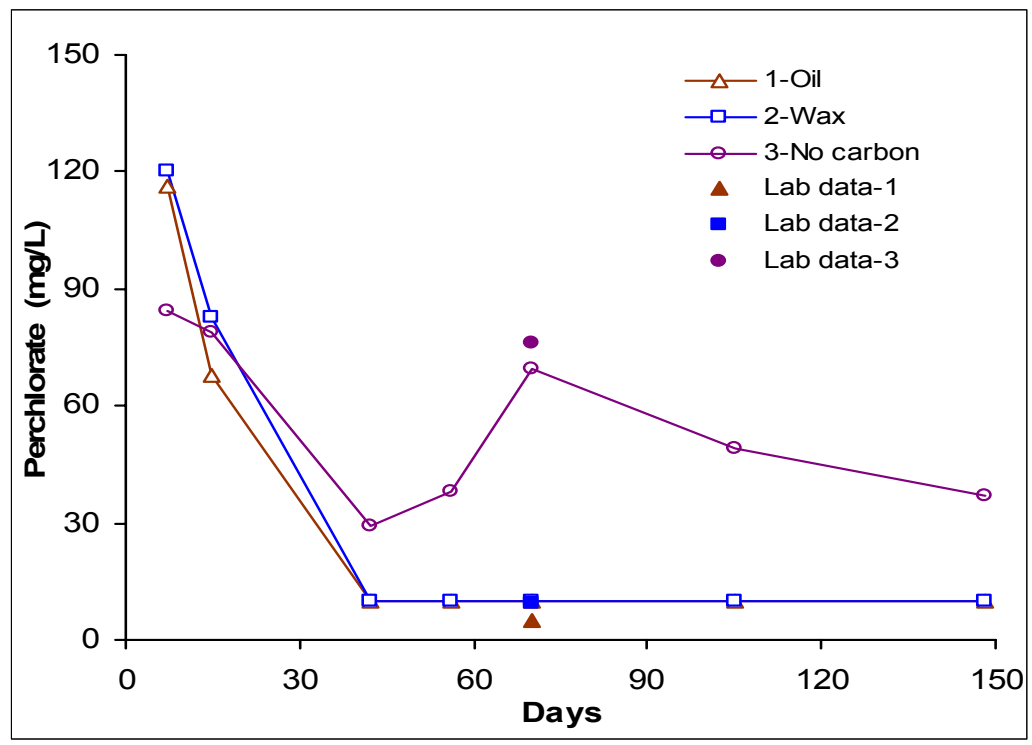

Figure 16. Perchlorate concentration in columns effluent. Data from external commercial lab for each one of the columns is included.

In Column 1-Oil, TCA, DCA and 1,1-DCE gradually increased with time as more of the chlorinated solvents broke through into the column effluent. Low but detectable levels of CA and Eth were observed in the column 1-Oil effluent. TOC and acetate concentrations increased immediately following emulsion injection. However, methane levels remained below $0.001 \mathrm{mg} / \mathrm{L}$ throughout the entire experiment.

In column 2-Wax, DCA was produced indicating some reductive dechlorination of TCA, with more limited 1,1-DCE production. This column also produced measurable amounts of CA and Eth. As with the oil treated column, moderate levels of acetate and TOC were released from the wax treated column but very low levels of methane $(<0.001 \mathrm{mg} / \mathrm{L})$.

In the column 3-No carbon (control), lower but detectable levels of DCA were observed in the column effluent. Similar to the two previous columns, low but detectable 
levels of CA, ethene and ethane were observed in the column 3 effluent, with negligible levels of methane. Low TOC concentrations (5-10 mg/L) were released from column 3 with no detectable acetate. The large spike in TOC observed on day 105 may have been due to an analytical error since this accompanied by a very large spike in inorganic carbon on the same day.

In summary, TCA biodegradation was very limited in the columns, presumably because of the short 5-day contact time of fluid inside the column. However, each of the columns did produce appreciable levels of DCA. 

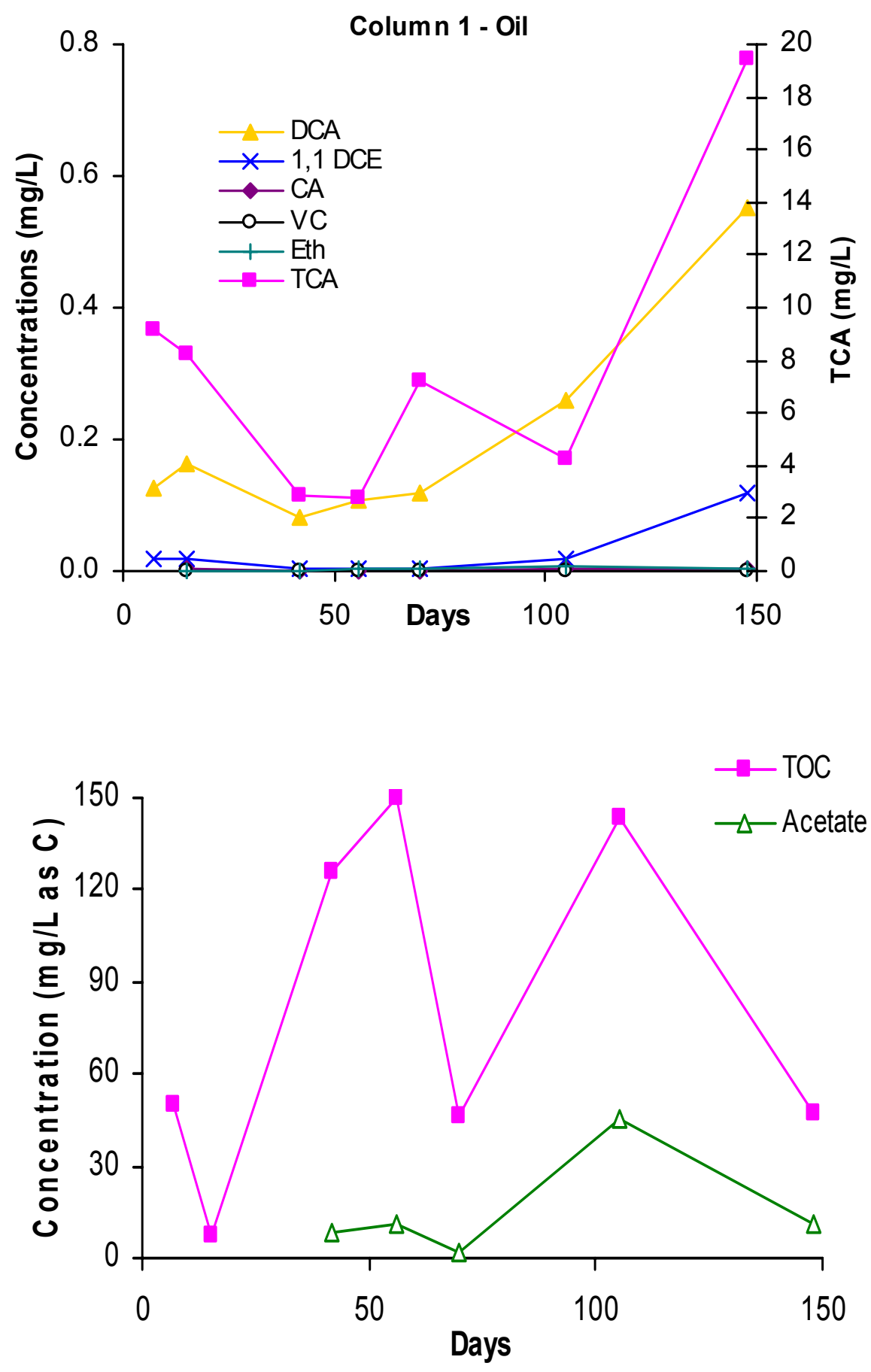

Figure 17. Analytical results for column 1-Oil effluent concentrations in mg/L. Top: TCA, DCA, 1,1, DCE, CA, VC and Eth; bottom: TOC and acetate (mg/L TOC) 

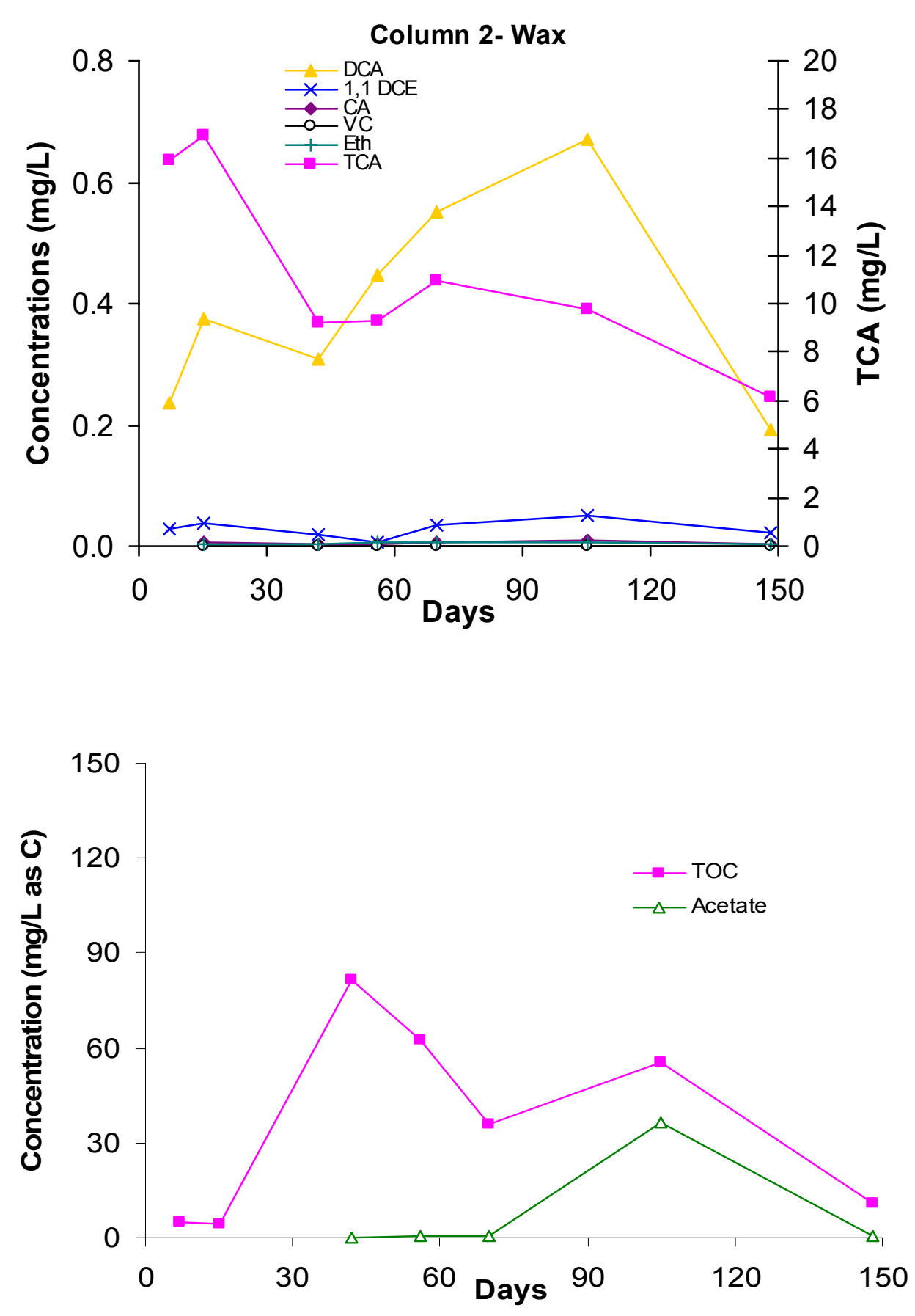

Figure 18. Analytical results for column 2-Wax effluent concentrations in mg/L. Top: TCA, DCA, 1,1, DCE, CA, VC and Eth; bottom: TOC and acetate (mg/L TOC) 

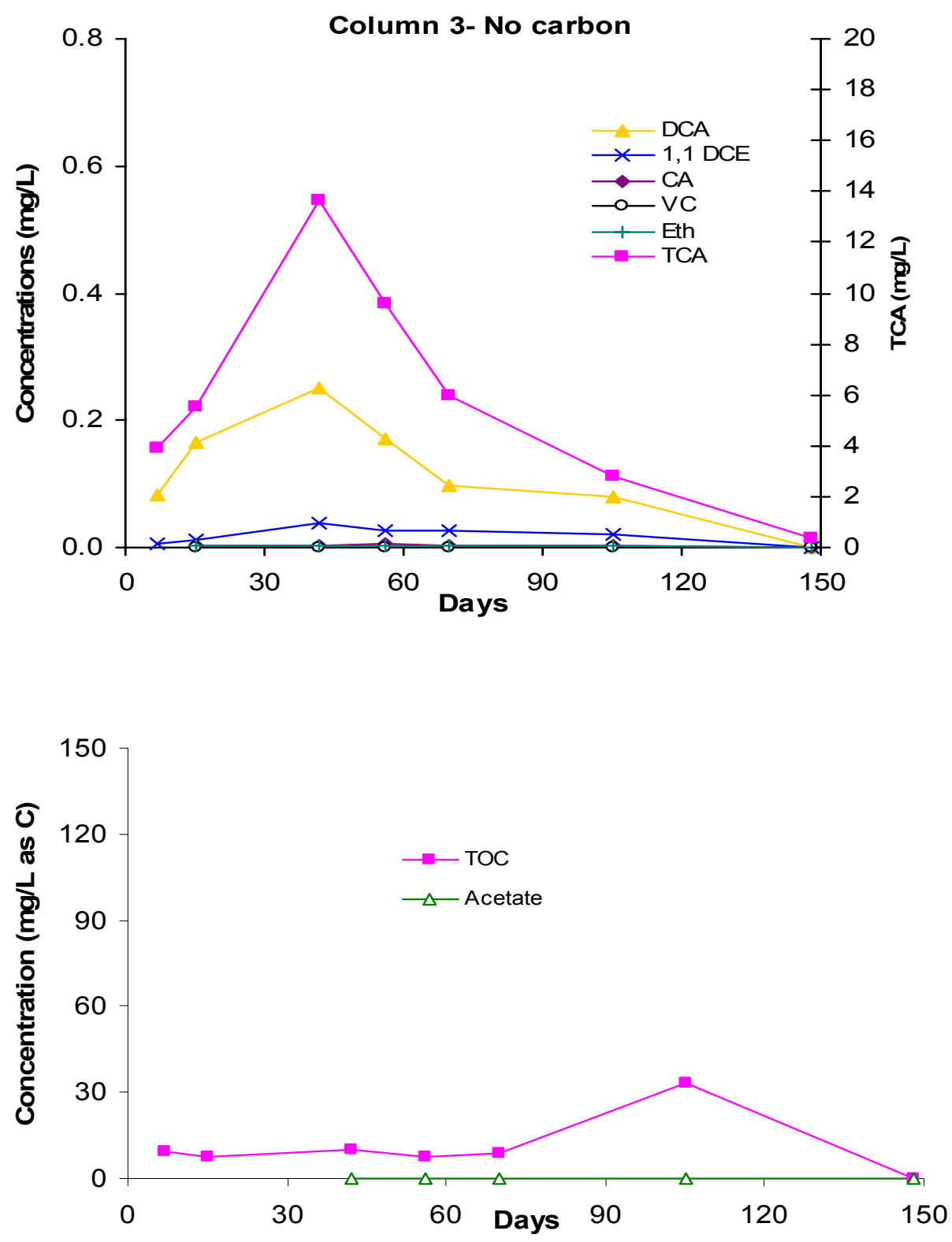

Figure 19. Analytical results for column 3- No carbon (control) effluent concentrations in $\mathrm{mg} / \mathrm{L}$. Top: TCA, DCA, 1,1, DCE, CA, VC and Eth; bottom: TOC and acetate (mg/L TOC) 
Table 4 shows the carbon balance for each of the columns. The carbon injected as soybean oil or hydrogenated oil wax emulsion was assumed to be equal to $100 \%$ of the available carbon. The volatile solids released from the column immediately after emulsion injection was converted to an equivalent organic carbon fraction based on the fraction of organic carbon in the original material. Cumulative IC and TOC released were calculated from the measured IC and TC concentrations and the measured flow rate since the previous sampling. The calculated residual carbon is the difference between the injected carbon and carbon released in the column effluent. Carbon remaining in the sediment at the completion of the experiment was determined by analysis of triplicate samples for total carbon by the NCSU Soil Science Department analytical services laboratory (Appendix 3). Error is the difference between the calculated and measured value of residual carbon at the completion of the experiment. 
Table 4. Carbon balance for perchlorate columns. Column 1-Oil, column 2-Wax, column 3-No carbon (control)

\begin{tabular}{|l|r|r|r|r|r|}
\cline { 2 - 6 } \multicolumn{1}{c|}{} & \multicolumn{2}{c|}{ 1-Oil } & \multicolumn{2}{c|}{ 2-Wax } & 3-No carbon \\
\cline { 2 - 6 } \multicolumn{1}{c|}{} & $\mathbf{m g}^{\mathbf{1}}$ & $\mathbf{\%}^{\mathbf{2}}$ & $\mathbf{m g}$ & $\mathbf{\%}$ & $\mathbf{~ m g}$ \\
\hline $\begin{array}{l}\text { Injected organic carbon } \\
\text { Carbon released in first two } \\
\text { weeks after injection }\end{array}$ & 5033 & 100 & 5868 & 100 & 0 \\
\hline Measured IC released & 147 & 3 & 1509 & 26 & 36 \\
\hline Measured TOC released & 339 & 7 & 324 & 6 & 126 \\
\hline Calculated residual carbon & 4456 & 88 & 3967 & 67 & -259 \\
\hline $\begin{array}{l}\text { Carbon remaining in } \\
\text { sediment at completion of } \\
\text { experiment }\end{array}$ & 2654 & 53 & 2450 & 42 & 408 \\
\hline Error & -1802 & -36 & -1517 & -26 & 667 \\
\hline
\end{tabular}

$1-$ assumes mass of sediment in column $=680.5 \mathrm{~g}$

2 -- \% of organic carbon injected into column as emulsion

Columns 1-Oil and 2-Wax were treated with essentially equal amounts of carbon. Contrary to the expectations, a little more of the treatment remained in the 1-Oil soil column. The difference between the estimation based on measurements throughout the experiment and the results obtained from the Soil Science Laboratory is due presumably to analytical errors in TOC and IC measurements, and/or analysis of soil samples by the Soil Science analytical services laboratory.

An important concern about the soybean oil emulsion treatment is the potential loss of permeability due to treatment. The concept of a permeable reactive barrier system (PRB) 
relies on groundwater to flow through the barrier and not around it. Excessive loss in hydraulic conductivity could lead to problems in design; thus the permeability of the soil columns was measured before treatment and at the end of the experiment. The average permeability of each column before emulsion injection $\left(\mathrm{K}_{\text {initial }}\right)$ and after approximately 5 months of operation $\left(\mathrm{K}_{\text {final }}\right)$ are presented in Table 5. Permeability loss was greatest in column 2-Wax, treated with emulsified hydrogenated soybean oil, with somewhat lower permeability loss in the oil emulsion treated column. This could significantly hinder the ability of affected groundwater to flow through the system and be treated. As the soybean wax cools, it will harden and remain in the sediment where it could block flow paths for water. Biological growth could also be a factor in permeability loss. Although the extent and longevity of permeability loss is not certain, the effect of soybean treatment on the permeability must be taken into account for the design of a PRB.

Table 5. Initial and final permeability in perchlorate columns. Column 1-Oil, column 2-Wax, column 3-No carbon

\begin{tabular}{|c|c|c|c|}
\hline COLUMN & $\mathbf{K}_{\text {initial }}$ & $\mathbf{K}_{\text {final }}$ & $\mathbf{K}_{\text {final }} / \mathbf{K}_{\text {initial }}$ \\
$\mathbf{( \mathbf { c m } / \mathbf { s } )}$ & 0.019 & 0.0044 & 0.23 \\
\hline 1-Oil & 0.011 & 0.0015 & 0.14 \\
\hline 2-Wax & 0.014 & 0.0096 & 0.69 \\
\hline
\end{tabular}




\subsection{DISCUSSION AND CONCLUSIONS}

The microcosm results clearly demonstrated that addition of emulsified soybean oil or hydrogenated soybean oil can be used to stimulate perchlorate and TCA degradation. Perchlorate biodegradation with concurrent chloride production was rapid and complete in every carbon amended bottle. TCA also degraded to DCA in every substrate amended bottle. However, DCA degradation rates were variable between treatments and within each treatment. This illustrates the importance of using triplicates for each experimental treatment, to increase the confidence in the results obtained. Each replicate in the same treatment may present a different behavior due to different initial population of microorganisms, or higher concentration of contaminants in the sediment. Therefore, it is necessary to consider the variability between the samples.

For both the microcosm and columns experiments, denitrification and TCA degradation was most rapid in treatments with added substrate. However, some natural attenuation of nitrate and TCA was seen in the treatments with no carbon, presumably due to organic carbon naturally present in the sediment used to construct the microcosms and columns.

Dechlorination was seen, although the observed values for ethene and ethane were low. This may be due to volatilization of these compounds into the bottle headspace, and the liquid samples collected may not accurately represent ethene and ethane production. Higher aqueous concentrations of CA and VC were found, possibly due to the higher solubility of these compounds. Increased contact time during flow through the columns may have resulted in more complete dechlorination of TCA. 
Differences were found between the carbon balance values measured in the lab and the final carbon remained in the columns, due to many factors, including but not limited to the precision in the analytical equipment, inaccuracy in dilutions, differences in flow rate throughout the experiment.

This work successfully demonstrated the potential application of emulsified soybean oil into groundwater systems contaminated with perchlorate. By incorporating liquid soybean oil and solid soybean wax emulsions, the longevity and reducing capabilities of a treatment area can be controlled. The overall benefits include the in-situ approach, low environmental impact, and effective removal of perchlorate. 


\section{SUMMARY AND CONCLUSIONS}

1. The microcosm and column experiments demonstrated that a low solubility, slow biodegradability organic substrate could be used to support anaerobic bioremediation processes for an extended time period.

2. SEFAs with intermediate number of fatty acids can be used to provide a slow steady supply of organic carbon to support anaerobic bioremediation processes.

3. In the chlorinated columns, S-270 was less mobile than the soybean oil, with a greater percentage of substrate retained within the soil columns after the first 14 days of sampling. However, cis-DCE and methane production and sulfate removal was lower than in the soybean oil treated columns. The lower dechlorination efficiency is presumably due to the more limited bioavailability of this organic substrate.

4. cis-DCE and methane production was lower in the chlorinated columns receiving sulfate, which is in agreement with prior studies regarding the inhibition of dechlorinating activity by sulfate.

5. Both emulsified liquid and solid soybean oil can effectively stimulate perchlorate reduction in aquifer sediment and groundwater from the Elkton, MD site. At this site, bioaugmentation was not necessary for rapid and complete perchlorate biodegradation. 
6. Substantial levels of TOC, acetate and methane were produced in all oil and wax amended microcosms. TCA also degraded in all oil and wax amended bottles.

7. TCA biodegradation was very limited in the perchlorate and TCA columns, presumably because of the short 5-day contact time of fluid inside the column. However, each of the columns did produce appreciable levels of DCA.

8. Permeability loss was greatest in the column treated with emulsified hydrogenated soybean oil, with somewhat lower permeability loss in the oil emulsion treated column. Although the extent and longevity of permeability loss is not certain, the effect of soybean treatment on the permeability must be taken into account for the design of full-scale permeable reactive barriers.

9. Emulsified soybean oil or hydrogenated soybean oil can be used to stimulate perchlorate and TCA biodegradation.

10. For both the microcosm and columns experiments, denitrification and TCA degradation was most rapid in treatments with added substrate. However, some natural attenuation of nitrate and TCA was seen in the treatments with no carbon, presumably due to organic carbon naturally present in the sediment used to construct the microcosm column. 
11. This work successfully demonstrated the potential application of emulsified soybean oil for enhancing the anaerobic biodegradation of perchlorate laboratory systems containing aquifer sediment and groundwater. The overall benefits include the in-situ approach, low environmental impact, and effective removal of perchlorate. 


\section{REFERENCES}

Achenbach, L. Dechloromonas agitate gen. and Dechlorosomona suillum gen. (per)chlorate reducing bacteria. INT J SYST EVOL MICROBIOL. Vol. 51, pp. 527-533. 2001

Adamson, D.T., McDade, J.M., Hughes, J.B. Inoculation of DNAPL source zone to initiate reductive dechlorination of PCE. Env. Sci. Tech., Vol. 37, No. 11, pp. 2525-2533. 2003.

Allgood, G.S., Mc Avoy, D.C., Woltering, D.M. Environmental Assessment of a new food ingredient, the fat replacer olestra. Env. Toxicology and Chemistry, Vol 16, No. 3, pp. 586-600. 1997.

American Society for Testing Materials. Standards on Materials and Environmental Microbiology, $2^{\text {nd }}$ edition. ASTM, Philadelphia. 1993

ARCADIS Geraghty \& Miller, Inc. (ARCADIS). Technical protocol for using soluble carbohydrates to enhance reductive dechlorination of chlorinated aliphatic hydrocarbons. Prepared for the Air Force Center for Environmental Excellence, San Antonio, Texas and the Environmental Security Technology Certification Program, Arlington, Virginia. 2002.

Aulenta, F., Majone, M., Verbo, P., Tandoi, V. Complete dechlorination of tetrachloroethene to ethene in presence of methanogenesis and acetogenesis by an anaerobic sediment microcosm. Biodegradation, Vol. 13, pp. 411-424. 2002.

Ballapragada, B.S., Stensel, H.D., Puhakka, J.A., Ferguson, J.F. Effect of hydrogen on reductive dechlorination of chlorinated ethenes. Environ. Sci. Technol. Vol. 31, No. 6, pp 1728-34. 1997.

Battersby, N., Wilson, V. Evaluation of a serum bottle technique for assessing the anaerobic biodegradability of organic chemicals under methanogenic conditions. Chemosphere Vol 17, pp. 2441-2460. 1988.

Battersby, N., Wilson, V. Survey of the Anaerobic Biodegradation Potential of Organic Chemicals in Digesting Sludge. Appl Env. Microb. Vol 55, No. 2, pp. 433-439. 1989.

Bengtsson, G., Annadotter, H. Nitrate Reduction in a Groundwater Microcosm Determined by ${ }^{15} \mathrm{~N}$ Gas Chromatography-Mass Spectrometry. Appl Environ Microbiol. Vol. 55, No. 11, pp. 2861-2870. 1989.

Casey, C.C., Reed, J., Britto, R., Stedman, J., Henry, B. and Wiedemeier, T. Field-Scale Evaluation of Soybean Oil and Dissolved Substrates for In-Situ Bioremediation, In Third International Conference on Remediation of Chlorinated and Recalcitrant Compounds, Monterey, CA, 2002. 
Colleran, E., Concannon, F., Golden, T., Geoghengan, F., Crumlish, B., Killilea, E., Henry, M., Coates, J. Use of methanogenic activity tests to characterize anaerobic sludges, screen for anaerobic biodegradability, and determine toxicity thresholds against individual trophic groups and species. Water Sci. Technol. Vol. 25, pp. 31-40. 1992.

Cooper, D.C., Picardal, F., Rivera, J., Talbot, C. Zinc immobilization and magnetite formation via ferric oxide reduction by Shewanella putrefaciens 200. Environ. Sci. Tech. Vol. 34, pp. 100-106. 2000.

Coulibaly, K.M., Borden, R.C. Distribution of edible oil emulsions and permeability loss in sandy sediments, In Situ and On-Situ Bioremediation: The Seventh Internat. Sym., Orlando, FL (accepted for publication). 2004.

De Bruin, W.P., Kotterman, M.J., Posthumus, M.A., Schraa, G., Zehnder, A.J. Complete biological reductive transformation of tetrachloroethene to ethane. Appl. Environ. Microbiol. Vol. 58, No. 6, pp. 1996-00. 1992.

Department of Defense. Perchlorate Treatment Technology. www.serdp.gov. 2001.

DiStefano, T.D., Gossett, J.M., Zinder, S.H. Reductive dehalogenation of high concentrations of tetrachloroethene to ethane by an anaerobic enrichment culture in the absence of methanogenesis. Appl. Environ. Microbiol. Vol 57, No.8, pp.2787-92. 1991.

Dybas, M.J., Tatara, G.M., Witt, M.E., Criddle, C.S. Slow-release substrates for transformation of carbon tetrachloride by Pseudomonas strain KC. In In Situ and On Site Bioremediation: Vol. 3. Papers from the 4th Int. In Situ and On Site Bioremediation Sym. New Orleans, LA. pp. 59. Columbus: Battelle Press. 1997.

Earth Tech. In situ reductive treatment of groundwater contaminated with explosives and nitrate using HRC ${ }^{\circledR}$. Technical Bulletin. 2001.

Ellis, D.E., Lutz, E.J., Odom, J.M., Buchanan, R.J., Bartlett, C.L., Lee, M.D., Harkness, M.R., Deweerd, K.A. Bioaugmentation for accelerated in situ anaerobic bioremediation. Env. Sci. Tech. Vol. 34, pp. 2254-2260. 2000.

Environmental Security Technology-Certification Program. Evaluation of performance and costs associated with anaerobic dechlorination techniques. Environmental Security Technology-Phase I, Arlington, Virginia. 2002.

EPA. National Primary Drinking Water Regulations: Disinfectants and Disinfection Byproducts. 1998.

Espenson, J. The problem and perversity of perchlorate. Perchlorate in the Environment. Urbansky, E.T. New York. 2000. 
Freedman, D.L., Gossett, J.M. Biological reductive dechlorination of tetrachloroethylene and trichloroethylene to ethylene under methanogenic conditions. Appl. Environ. Microbiol. Vol 55, No. 9, pp. 2144-2151. 1989.

Gledhill, W. Proposed standard practice for the determination of the anaerobic biodegradability of organic chemicals. Working document, draft 2, No. 35.24. American society for testing materials. Philadelphia. 1979.

Hanaki, Matsuo, K.T., Nagase, M. Mechanism of inhibition caused by long-chain fatty acids in anaerobic digester process. Biotech. Bioeng. Vol 23, pp. 1591. 1981.

Handy, R. Determination of nanomolar levels of perchlorate in water by ESI-FAIM-MS. J. ANAL SPECTROM 15: 907-911. 2000

He, J.Z., Sung, Y., Dollhopf, M.E., Fathepure, B.Z., Tiedje, J.M., Loffler, F.E. Acetate versus hydrogen as direct electron donors to stimulate the microbial reductive dechlorination process at chloroethene-contaminated sites. Env. Sci. Tech., Vol. 36, No. 18, pp. 3945-3952. 2002.

Hunter, W.J. Use of vegetable oil in a pilot-scale denitrifying barrier. J. Cont. Hydro. Vol. 53, pp. 119-131. 2001.

Hunter, W.J. Bioremediation of chlorate or perchlorate contaminated water using permeable barriers containing vegetable oil. Current Microbiol. Vol. 45, p.p. 287-292. 2002.

King, J. Effects of ammonium perchlorate on the thyroid hormone levels. Air Force Institute of Technology, OH. 1995.

Lalman, J.A., and Bagley, D.M. Anaerobic degradation and methanogenic inhibitory effects of oleic and stearic acids. Water Resources, Vol. 35, No. 12, pp. 2975-2983. 2001.

Lee, M.D., Quinton, G.E., Beeman, R.E., Biehle, A.A., Liddle, R.L. Scale-up issues for in situ anaerobic tetrachloroethene bioremediation. J. Ind. Microbiol. Biotechnol. Vol. 18, pp. 106-15. 1997.

Lee, D. M., Lieberman, T.M., Borden, R.C., Beckwith, W., Crotwell T. and Haas, P.E. Effective distribution of edible oils - results from five field applications, In G. B. Wickramanayake, A. R. Gavaskar, B. C. Alleman and V. S. Magar (Eds.), Proc. In Situ and On-Site Bioremediation: The Sixth Internal. Sym., San Diego, CA, 2001.

Lee, D.M. and Ventullo, R.M. Degradation of olestra, a non caloric fat replacer, by microorganisms isolated from activated sludge and other environments. Biodegradation. Vol. 7, pp. 257-265. 1996

Logan, B. Assessing the outlook for perchlorate remediation. Environ Sci. Tech. Vol. 35, pp. 418-487. 2001 
McAvoy, D.C., Shimp, R.J., Namkung, E., Hand, V.C. Fate and effects of olestra during conventional wastewater treatment. Water Env.Research. Vol.68, No.2, pp.169-77. 1996

Major, D.W., Hodgins, E.W., Butler, B.J. Field and laboratory evidence of in situ biotransformation of tetrachloroethene to ethene and ethane at a chemical transfer facility in North Toronto. In R. E. Hinchee and R. F. Olfenbuttel, eds., On-Site Bioreclamation Processes for Xenobiotic and Hydrocarbon Treatment. pp. 147-171. Stoneham, MA: Butterworth-Heinemannn. 1991.

Major, D.W., McMaster, M.L., Cox, E.E., Edwards, E.A., Dworatzek, S.M., Hendrickson, E.R., Starr, M.G., Payne, J.A., Buonamici, L.W. Field demonstration of successful bioaugmentation to achieve dechlorination of tetrachloroethene to ethene. Environ. Sci. Technol. Vol. 36, pp. 5106-5116. 2002.

Martin, J.P., Sorenson, K.S., Peterson, L.N. Favoring efficient in situ dechlorination through amendment injection strategy. In: G. B. Wickramanayake, G.B., Gavaskar, A.R., Alleman, B.C., Magar, V.S. (Eds.): Proc. In Situ and On-Site Bioremediation: The Sixth Internal. Sym., San Diego, CA, pp. 265-272. 2001.

Morse, J.J., Alleman, B.C., Gossett, J.M., Zinder, S.H., Fennell, D.E., Sewell, G.W., Vogel, C.M. Draft technical protocol: A treatability test for evaluating the potential applicability of the reductive anaerobic biological in situ treatment technology (RABITT) to remediate chloroethenes. ESTCP. 1998.

Owen, W., Stuckley, D., Healey, J., Young, L., McCarty, P. Bioassay for monitoring methane potential and anaerobic toxicity. Water Res. Vol. 13, pp. 485-492. 1979.

Regenesis. Chromium remediation in groundwater. HRC Technical Bulletin. 2.7.5. 2003.

Rikken, G. Transformation of perchlorate into chloride by a newly isolated bacterium. Appl. Microbiology Biotech. Vol. 45, pp. 420-426. 1996

Rodin, E. Influence of Microbial Iron and Nitrate Reduction on Subsurface Iron Biogeochemistry and Contaminant Metal Mobilization. University of Alabama. 2001.

Sawyer, C.N., McCarty, P.L., Parkin, G.F. Chemistry for Environmental Engineering. McGraw-Hill Inc. 1994.

Scholz-Muramatsu, H., Neumann, A., Mebmer, M., Moore, E., Diekert, G.. Isolation and characterization of Dehalospirillum multivorans gen. nov., sp. nov., a tetrachloroetheneutilizing, strictly anaerobic bacterium. Arch. Microbiol. Vol. 163, pp. 48-56. 1998.

Sewell, G.W., Gibson, S.A. Stimulation of the reductive dechlorination of tetrachloroethene in anaerobic aquifer microcosms by the addition of toluene. Environ. Sci. Technol. Vol. 25, pp. 982-984. 1991. 
Shelton, D.R., Tiedje, J.M. General method for determining anaerobic biodegradation potential. Appl. Environ. Microbiol. Vol. 47, No. 4, pp. 850-857. 1984a.

Shelton, D.R. and Tiedje, J.M. Isolation and partial characterization of bacteria in an anaerobic consortium than mineralizes 3-chlorobenzoic acid. Appl. Environ. Microbiol. Vol. 45, pp. 840-848. 1984b.

Smatlak, C., Gossett, J.M., Zinder, S.H. Comparative kinetics of hydrogen utilization for reductive dechlorination of tetrachloroethene and methanogenesis in an anaerobic enrichment culture. Environ. Sci. Technol. Vol. 30, No. 9, pp. 2850-58. 1996.

Sorenson, K.S., Martin, J.P., Brennan, R.A., Werth, C.J., Sanford, R.A., and Bures, G.H. Phase I SBIR Final Report: Development of a Chitin-Fracing Technology for Remediation of Chlorinated Solvent Source Areas in Low Permeability Media. North Wind Environmental, NWE-ID-2002-024. 2002.

Stouthamer, A. Bioenergetics and yields with electron acceptors other than oxygen. Handbook on anaerobic fermentations. N.Y. 1988.

Straub, K.L., Benz, M., Schink, B., Widdel, F. Anaerobic, nitrate-dependent microbial oxidation of ferrous iron. Appl. Environ. Microbiol. Vol. 62, pp. 1458-1460. 1996.

Suflita, J., Concannon, F. Screening tests for assessing the anaerobic biodegradation of pollutant chemicals in subsurface environments. J. Microbiol. Methods Vol 21, pp. 267281. 1995.

Sung, Y., Ritalahti, K.M., Sanford, R.A., Urbance, J.W., Flynn, S.J., Tiedje, J.M., Loffler, F.E. Characterization of two tetrachloroethene-reducing, acetate-oxidizing anaerobic bacteria and their description as Desulfuromonas michiganensis sp nov. App. Env. Microb. Vol. 69, No. 5, pp. 2964-2974. 2003.

Van Ginkel, C. Process for degradation of chloride. United States Patent 5, 891. 1988

Vogel, T.M., McCarty, P.L. Biotransformation of tetrachloroethylene to trichloroethylene, dichloroethylene, vinyl chloride, and carbon dioxide under methanogenic conditions. Appl. Environ. Microbiol. Vol. 49, No. 5, pp. 1080-83. 1985.

Weber, K.A., Picardal, F., Roden, E. Microbially-catalyzed nitrate-dependent oxidation of biogenic solid-phase Fe(II) compounds. Environ. Sci. Technol. Vol. 35, pp. 1644-1650. 2001.

Werth, C., Sanford, R. A passive in-situ bioremediation technology for Chlorinated Solvents. Illinois Groundwater Association. Spring meeting 2002. 2002.

Yong, J. Transport of Emulsified Edible Oil in a 3-Dimensional Sandbox: Experimental and Modeling Results. NCSU. 2002. 
Zenker, M.J., Borden, R.C., Barlaz, M.A., Lieberman, M.T., Lee, M.D. Insoluble electron donors for reductive dehalogenation in permeable reactive barriers, Proc. $2^{\text {nd }}$ Internat. Conf. Remediation of Chlorinated and Recalcitrant Compounds, Battelle Press, Columbus, Ohio. 2000. 
APPENDIX 1.

SUBSTRATES 
Substrates used to screen their ability to support slow production of methane.

\begin{tabular}{|c|c|c|c|c|c|c|}
\hline \multirow[b]{2}{*}{ GROUP } & \multirow[b]{2}{*}{ MATERIAL } & \multirow[b]{2}{*}{ HLB } & \multirow[b]{2}{*}{ SOURCE* } & \multicolumn{2}{|c|}{$\begin{array}{c}\text { MASS } \\
\text { ADDED }\end{array}$} & \multirow{2}{*}{\begin{tabular}{|c|} 
CARBON \\
CONTENT \\
$(\%)$
\end{tabular}} \\
\hline & & & & Ave (mg) & ST.DEV. & \\
\hline \multirow{8}{*}{ Fatty Acid } & Blackstrap Molasses & & $\mathrm{g}$ & 50.17 & 0.12 & 32.46 \\
\hline & Chitin & & $\mathrm{c}$ & 50.37 & 0.75 & 44.55 \\
\hline & Ethyl Lactate & & o & 50.53 & 0.91 & 50.35 \\
\hline & Lactate & & $\mathrm{f}$ & 50.73 & 0.23 & 19.50 \\
\hline & Lauric Acid & & $\mathrm{a}$ & 50.67 & 1.10 & 72.26 \\
\hline & Myristic Acid & & $\mathrm{a}$ & 51.63 & 0.57 & 73.88 \\
\hline & Sodium Acetate & & $\mathrm{m}$ & 49.37 & 0.06 & 29.27 \\
\hline & Stearic Acid & & $\mathrm{a}$ & 50.27 & 0.55 & 76.28 \\
\hline \multirow{2}{*}{ Mixture } & Soybean Oil-SEFA (1:1) & & $\mathrm{j}$ & 50.40 & 0.46 & 77.04 \\
\hline & Soybean Oil-SEFA (1:3) & & j & 50.70 & 0.26 & 77.06 \\
\hline \multirow{10}{*}{ Oil } & Canola Oil & & $\mathrm{h}$ & 51.23 & 0.35 & 77.82 \\
\hline & Corn Oil & & $\mathrm{h}$ & 50.60 & 1.30 & 77.78 \\
\hline & Expelled Soybean Oil & & $\mathrm{d}$ & 50.57 & 0.85 & 77.66 \\
\hline & Hydrogenated Soybean Oil & & $\mathrm{d}$ & 50.40 & 0.79 & 77.31 \\
\hline & Mineral Oil & & $\mathrm{i}$ & 50.33 & 0.65 & 86.71 \\
\hline & Olive Oil & & $\mathrm{a}$ & 50.20 & 0.72 & 77.40 \\
\hline & Paraffin & & $\mathrm{k}$ & 49.87 & 0.70 & 85.31 \\
\hline & Petroleum Jelly & & $\mathrm{e}$ & 50.77 & 0.15 & 86.33 \\
\hline & Soybean Oil (100) & & $\mathrm{d}$ & 49.70 & 0.10 & 76.99 \\
\hline & Soy Gold 1000 & & $\mathrm{~b}$ & 49.53 & 0.40 & 76.95 \\
\hline \multirow{12}{*}{ SEFA } & S-1670 & 16 & 1 & 49.90 & 0.56 & 59.31 \\
\hline & S-970 & 9 & 1 & 49.27 & 0.23 & 62.29 \\
\hline & S-270 & 2 & 1 & 49.33 & 0.49 & 68.88 \\
\hline & S-170 & 1 & 1 & 50.00 & 0.17 & 72.72 \\
\hline & S-070 & 0 & 1 & 50.27 & 0.32 & 74.09 \\
\hline & SEFA Soyate $\mathrm{I}=1.25$ & & j & 49.93 & 0.68 & 56.22 \\
\hline & SEFA Soyate $\mathrm{I}=2.5$ & & j & 50.77 & 0.25 & 66.47 \\
\hline & SEFA Soyate I $=5$ & & $\mathrm{j}$ & 49.53 & 0.51 & 73.14 \\
\hline & SEFA Soyate I $=6$ & & $\mathrm{j}$ & 50.07 & 0.61 & 74.04 \\
\hline & SEFA Soyate I $=7$ & & $\mathrm{j}$ & 50.33 & 0.29 & 75.07 \\
\hline & SEFA Behenate I=8 & & $\mathrm{j}$ & 50.33 & 0.21 & 77.08 \\
\hline & SEFA Soyate $\mathrm{I}=8$ & & $j$ & 50.20 & 0.44 & 76.10 \\
\hline \multirow{5}{*}{ Surfactant } & Ivory Soap & & j & 50.53 & 0.55 & 66.85 \\
\hline & Actiflo 68-UB & 2 & $\mathrm{~d}$ & 49.97 & 0.55 & 65.53 \\
\hline & Blendmax K & 8 & $\mathrm{~d}$ & 49.97 & 0.35 & 66.24 \\
\hline & Centrol CA & 6 & $\mathrm{~d}$ & 50.50 & 0.20 & 66.80 \\
\hline & Centrolene A & 10 & $\mathrm{~d}$ & 50.20 & 0.35 & 63.94 \\
\hline
\end{tabular}




\begin{tabular}{|c|c|c|c|c|c|c|}
\hline \multirow{10}{*}{ GROUP } & \multirow[b]{2}{*}{ MATERIAL } & \multirow[b]{2}{*}{ HLB } & \multirow[b]{2}{*}{ SOURCE* } & \multicolumn{2}{|c|}{$\begin{array}{c}\text { MASS } \\
\text { ADDED }\end{array}$} & \multirow{2}{*}{\begin{tabular}{|c|} 
CARBON \\
CONTENT \\
$(\%)$
\end{tabular}} \\
\hline & & & & Ave (mg) & ST.DEV. & \\
\hline & Centromix E & 12 & $\mathrm{~d}$ & 50.03 & 0.38 & 63.55 \\
\hline & Centrophase C & 4 & $\mathrm{~d}$ & 50.07 & 0.12 & 68.76 \\
\hline & Tween 20 & & $\mathrm{n}$ & 49.43 & 0.32 & 56.11 \\
\hline & Tween 21 & & $\mathrm{n}$ & 50.33 & 0.46 & 60.24 \\
\hline & Tween 60 & & $\mathrm{n}$ & 50.50 & 0.46 & 59.77 \\
\hline & Tween 65 & & $\mathrm{n}$ & 50.37 & 0.81 & 63.45 \\
\hline & Tween 80 & & $\mathrm{n}$ & 50.83 & 0.31 & 58.84 \\
\hline & Tween 85 & & $\mathrm{n}$ & 50.00 & 0.50 & 63.02 \\
\hline
\end{tabular}

*Sources:

(a) Acros Organics, NJ

(b) AG Environmental Products L.L.C.

(c) Aldrich Chemical Company Inc. Milwaukee, WI

(d) Central Soya Chemargy Division. Fort Wayne, IN.

(e) Chesebrough - Ponds USA Co. Greenwich, CO

(f) Fisher Chemicals - Fisher Scientific. Fair Lawn, NJ

(g) Golding Farms Foods Inc. Winston-Salem, NC

(h) Harris Teeter ${ }^{\circ}$. Matthews, NC

(i) K-mart Corporation. Troy, MI

(j) Procter \& Gamble Chemicals. New Milford, CT

(k) Royal Oak Sales Inc. Roswell, GA

(1) Ryoto ${ }^{\circledR}$ sugar ester - Mitsubishi-Kagaku Foods Corporation. Tokyo, Japan

(m) Sigma Chemical Co. St. Louis, MO

(n) Uniquema - Imperial Chemical Industries PLC. Wilmington, DE

(o) Vertec Biosolvents Inc. Dowmers Grove, IL 
APPENDIX 2.

\section{GAS PRODUCTION FROM SUBSTRATES}


Set \# 1. Gas production per substrate for 300 days. Standard deviations from triplicates incubations are shown.

\begin{tabular}{|c|c|c|c|c|c|c|c|c|c|c|c|c|}
\hline \multirow[b]{3}{*}{ MATERIAL } & \multicolumn{12}{|c|}{ GAS PRODUCTION } \\
\hline & \multicolumn{2}{|c|}{$0-30$ days } & \multicolumn{2}{|c|}{$31-60$ days } & \multicolumn{2}{|c|}{$61-120$ days } & \multicolumn{2}{|c|}{$121-180$ days } & \multicolumn{2}{|c|}{ 181-300 days } & \multicolumn{2}{|c|}{$0-300$ days } \\
\hline & $\mathbf{m L}$ & SD & $\mathrm{mL}$ & SD & $\mathbf{m L}$ & SD & $\mathrm{mL}$ & SD & $\mathrm{mL}$ & SD & $\mathrm{mL}$ & SD \\
\hline Blank & 6.23 & 0.90 & 1.60 & 0.21 & 1.72 & 0.61 & 0.52 & 0.21 & 1.05 & 0.25 & 11.12 & 1.05 \\
\hline SEFA Liquid & 5.49 & 0.86 & 2.71 & 0.69 & 1.97 & 0.42 & 1.20 & 0.25 & 1.10 & 0.43 & 12.47 & 2.21 \\
\hline Paraffin* & 7.67 & 0.16 & 2.84 & 0.47 & 1.74 & 0.30 & 0.55 & 0.10 & 0.96 & 0.72 & 13.76 & 1.05 \\
\hline SEFA Solid* & 7.07 & 0.31 & 2.59 & 0.20 & 2.39 & 0.15 & 1.58 & 0.14 & 1.65 & 0.12 & 15.28 & 0.22 \\
\hline Tween $20^{*}$ & 3.37 & 0.76 & 12.37 & 0.15 & 3.95 & 1.01 & 1.49 & 0.22 & 0.82 & 0.61 & 22.00 & 1.05 \\
\hline Chitin* & 25.83 & 0.23 & 4.13 & 1.68 & 3.62 & 1.65 & 0.99 & 0.45 & 1.67 & 0.46 & 36.24 & 0.78 \\
\hline Tween 21* & 6.90 & 0.17 & 18.97 & 0.48 & 8.44 & 0.94 & 1.48 & 0.51 & 0.64 & 0.30 & 36.43 & 0.84 \\
\hline Tween 85* & 7.77 & 1.36 & 23.82 & 5.73 & 9.50 & 1.54 & 2.73 & 1.53 & 0.88 & 0.14 & 44.70 & 4.45 \\
\hline Centrolene $A^{*}$ & 6.72 & 0.77 & 2.38 & 0.63 & 5.95 & 0.74 & 21.96 & 3.94 & 8.86 & 3.26 & 45.87 & 1.46 \\
\hline Actiflo 68-UB* & 8.90 & 0.23 & 4.97 & 0.92 & 33.76 & 1.80 & 1.68 & 0.54 & 0.69 & 0.29 & 50.00 & 1.05 \\
\hline $\begin{array}{l}\text { Centrophase } \\
\text { C* }^{*}\end{array}$ & 27.47 & 3.54 & 8.77 & 3.09 & 3.09 & 0.51 & 1.41 & 0.02 & 10.46 & 0.15 & 51.20 & 0.99 \\
\hline Centromix E* & 39.47 & 1.80 & 6.91 & 3.14 & 5.14 & 1.66 & 1.53 & 0.26 & 1.59 & 0.14 & 54.64 & 0.96 \\
\hline Centrol CA* & 46.50 & 1.21 & 5.78 & 0.80 & 5.15 & 0.30 & 1.38 & 0.52 & 1.60 & 0.48 & 60.41 & 1.64 \\
\hline Blendmax $\mathrm{K}^{*}$ & 12.66 & 1.29 & 4.48 & 3.73 & 43.03 & 9.97 & 2.31 & 0.41 & 1.50 & 0.13 & 63.98 & 8.95 \\
\hline Ivory Soap* & 14.18 & 1.51 & 5.59 & 2.41 & 45.34 & 1.57 & 1.73 & 0.33 & 0.81 & 0.41 & 67.65 & 0.55 \\
\hline Hydro. Soy Oil & 18.07 & 15.79 & 42.11 & 11.82 & 9.41 & 6.73 & 1.87 & 0.16 & 1.24 & 0.12 & 72.70 & 1.84 \\
\hline Soybean Oil * & 20.80 & 15.76 & 40.41 & 7.93 & 8.64 & 4.87 & 2.78 & 1.37 & 2.01 & 0.52 & 74.64 & 3.87 \\
\hline
\end{tabular}

* Indicates the differences in means compared with blank bottles is statistically significant, at 95\% confidence level for 300 days. 


\section{GAS PRODUCTION}

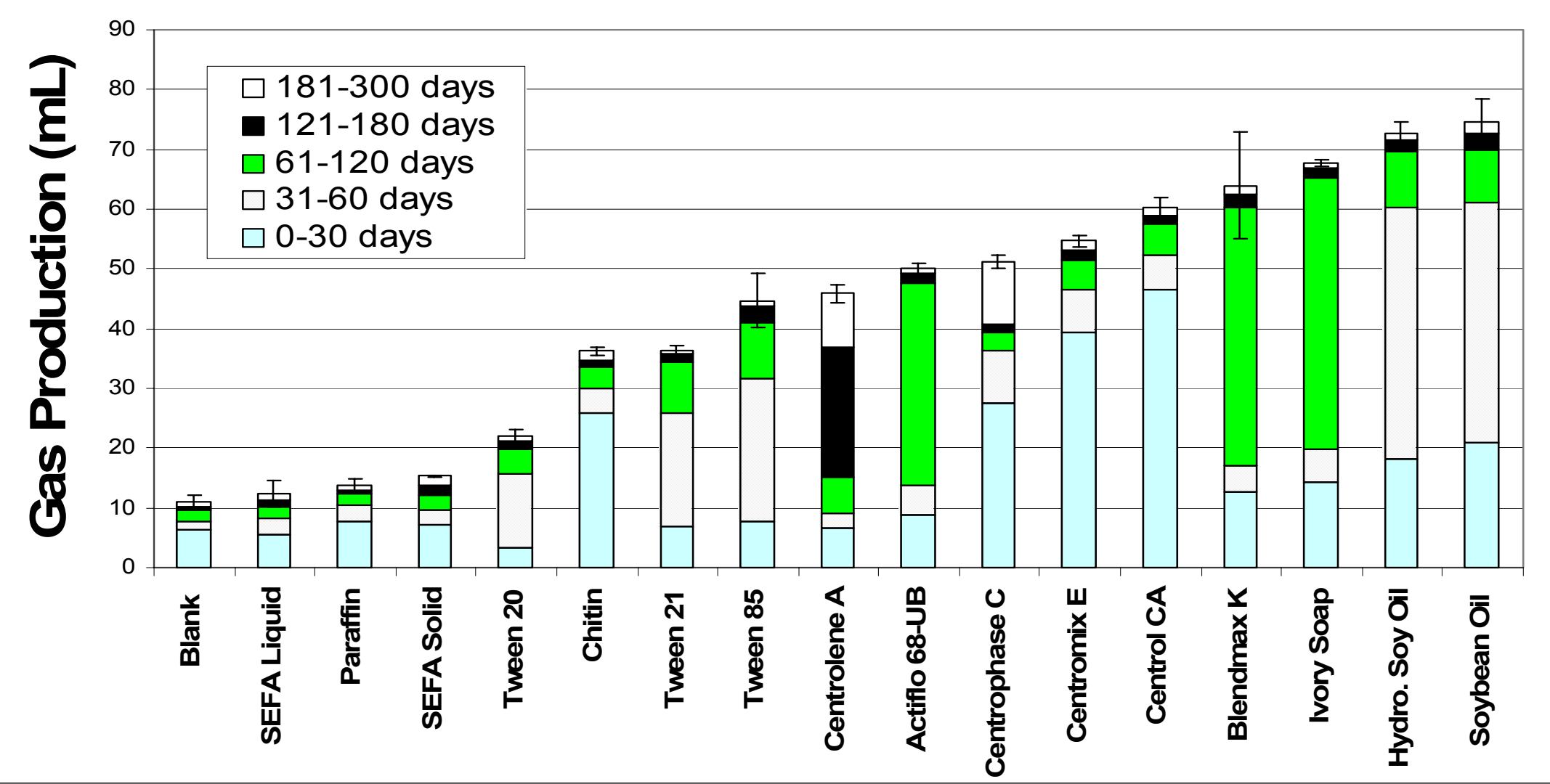


Set \# 2. Gas production per substrate for 300 days. Standard deviations from triplicates incubations are shown.

\begin{tabular}{|c|c|c|c|c|c|c|c|c|c|c|c|c|}
\hline \multirow[b]{3}{*}{ MATERIAL } & \multicolumn{12}{|c|}{ GAS PRODUCTION } \\
\hline & \multicolumn{2}{|c|}{$0-30$ days } & \multicolumn{2}{|c|}{$31-60$ days } & \multicolumn{2}{|c|}{$61-120$ days } & \multicolumn{2}{|c|}{$121-180$ days } & \multicolumn{2}{|c|}{ 181-300 days } & \multicolumn{2}{|c|}{$0-300$ days } \\
\hline & $\mathrm{mL}$ & SD & $\mathrm{mL}$ & SD & $\mathrm{mL}$ & SD & $\mathrm{mL}$ & SD & $\mathrm{mL}$ & SD & $\mathrm{mL}$ & SD \\
\hline Blank & 0.00 & 0.00 & 0.00 & 0.00 & 0.00 & 0.00 & 0.00 & 0.00 & 0.00 & 0.00 & 0.00 & 0.00 \\
\hline Soybean Oil* & 11.33 & 1.17 & 12.32 & 1.26 & 7.76 & 5.01 & 4.67 & 4.53 & 0.53 & 0.29 & 36.61 & 8.62 \\
\hline SEFA I=1.25 & 28.67 & 3.11 & 6.83 & 0.64 & 25.58 & 34.17 & 10.34 & 12.00 & 3.79 & 0.46 & 75.21 & 43.43 \\
\hline Tween 80 & 18.43 & 1.88 & 23.17 & 2.76 & 23.73 & 19.08 & 28.31 & 46.92 & 11.62 & 13.38 & 105.26 & 61.14 \\
\hline SEFA I=7.0* & 3.57 & 0.85 & 11.31 & 0.54 & 12.71 & 8.64 & 39.10 & 9.75 & 54.10 & 7.65 & 120.79 & 23.18 \\
\hline Tween 60* & 3.37 & 1.61 & 35.15 & 4.68 & 114.24 & 2.23 & 9.44 & 0.83 & 4.03 & 0.61 & 166.23 & 4.06 \\
\hline SEFA I=6.0* & 0.00 & 0.00 & 2.85 & 1.57 & 34.59 & 7.91 & 75.30 & 9.69 & 86.34 & 5.97 & 199.07 & 18.03 \\
\hline Tween $65^{*}$ & 15.27 & 2.78 & 55.57 & 15.99 & 77.43 & 30.93 & 52.63 & 10.65 & 30.41 & 6.46 & 231.30 & 11.23 \\
\hline SEFA I=5.0* & 5.87 & 1.36 & 26.41 & 9.85 & 54.40 & 7.51 & 87.16 & 13.91 & 89.55 & 6.55 & 263.39 & 28.45 \\
\hline SEFA I=2.5* & 18.13 & 1.42 & 60.49 & 0.73 & 108.48 & 18.07 & 171.90 & 13.22 & 91.75 & 5.92 & 450.75 & 15.05 \\
\hline
\end{tabular}

* Indicates the difference in means compared with blank bottles is statistically significant, at 95\% confidence level for 300 days.

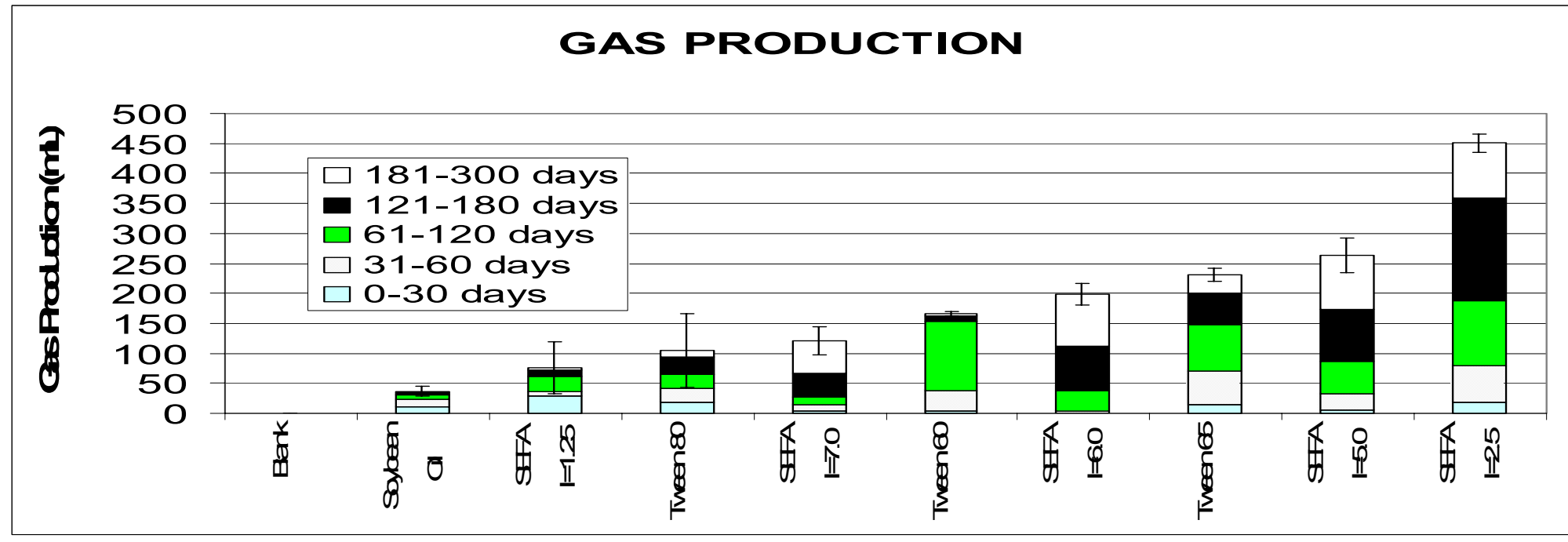


Set \# 3. Gas production per substrate for 300 days. Standard deviations from triplicates incubations are shown.

\begin{tabular}{|c|c|c|c|c|c|c|c|c|c|c|c|c|}
\hline \multirow[b]{3}{*}{ MATERIAL } & \multicolumn{12}{|c|}{ GAS PRODUCTION } \\
\hline & \multicolumn{2}{|c|}{$0-30$ days } & \multicolumn{2}{|c|}{$31-60$ days } & \multicolumn{2}{|c|}{$61-120$ days } & \multicolumn{2}{|c|}{ 121-180 days } & \multicolumn{2}{|c|}{$181-300$ days } & \multicolumn{2}{|c|}{$0-300$ days } \\
\hline & $\mathrm{mL}$ & SD & $\mathrm{mL}$ & SD & $\mathrm{mL}$ & SD & $\mathrm{mL}$ & SD & $\mathrm{mL}$ & SD & $\mathrm{mL}$ & SD \\
\hline Blank & 4.93 & 1.49 & 2.33 & 1.29 & 1.60 & 0.51 & 0.97 & 0.42 & 0.43 & 0.15 & 10.26 & 0.71 \\
\hline Soy-SEFA 1:3* & 6.08 & 2.59 & 17.43 & 2.38 & 7.39 & 2.14 & 3.07 & 0.33 & 2.15 & 0.21 & 36.12 & 1.91 \\
\hline Soy-SEFA 1:1* & 8.25 & 1.38 & 31.25 & 2.90 & 15.73 & 0.38 & 3.94 & 1.00 & 3.03 & 0.35 & 62.20 & 1.80 \\
\hline Soybean Oil* & 7.77 & 1.56 & 30.43 & 17.35 & 31.23 & 16.63 & 3.34 & 0.31 & 1.85 & 0.29 & 74.62 & 1.02 \\
\hline
\end{tabular}

* Indicates the difference in means compared with blank bottles is statistically significant, at $95 \%$ confidence level for 300 days.

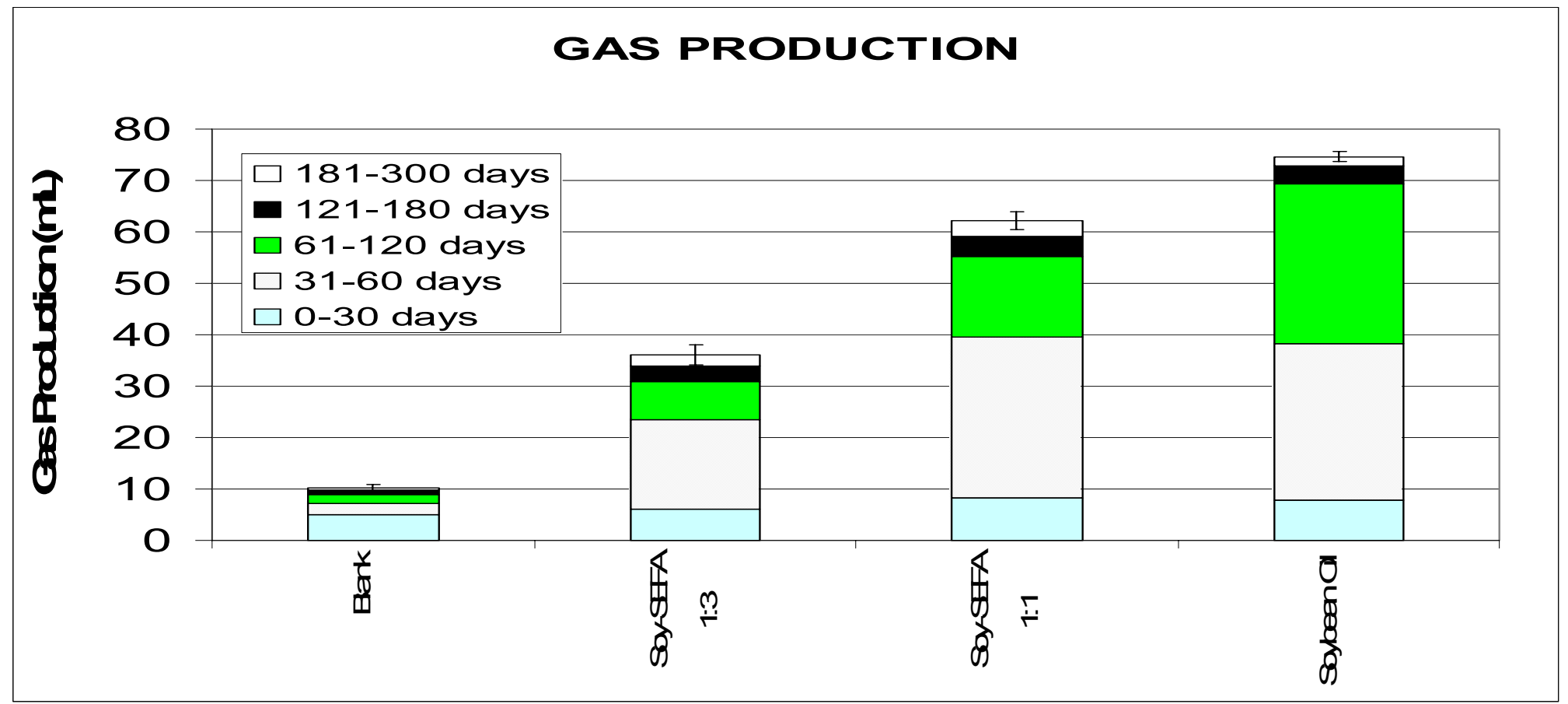


Set \# 4. Gas production per substrate for 300 days. Standard deviations from triplicates incubations are shown.

\begin{tabular}{|c|c|c|c|c|c|c|c|c|c|c|c|c|}
\hline \multirow[b]{3}{*}{ MATERIAL } & \multicolumn{12}{|c|}{ GAS PRODUCTION } \\
\hline & \multicolumn{2}{|c|}{$0-30$ days } & \multicolumn{2}{|c|}{$31-60$ days } & \multicolumn{2}{|c|}{$61-120$ days } & \multicolumn{2}{|c|}{$121-180$ days } & \multicolumn{2}{|c|}{$181-300$ days } & \multicolumn{2}{|c|}{$0-300$ days } \\
\hline & $\mathrm{mL}$ & SD & $\mathrm{mL}$ & SD & $\mathrm{mL}$ & SD & $\mathrm{mL}$ & SD & $\mathrm{mL}$ & SD & $\mathrm{mL}$ & SD \\
\hline S-170* & 0.00 & 0.00 & 2.48 & 0.76 & 1.52 & 0.98 & 0.45 & 0.09 & 1.73 & 0.65 & 6.18 & 0.94 \\
\hline Blank & 3.38 & 0.64 & 4.12 & 0.30 & 0.30 & 0.17 & 0.13 & 0.11 & 0.64 & 0.31 & 8.57 & 0.09 \\
\hline S-070 & 0.05 & 0.09 & 5.03 & 0.62 & 1.65 & 1.11 & 0.40 & 0.17 & 2.23 & 0.93 & 9.36 & 0.66 \\
\hline SEFA Liquid & 3.45 & 1.01 & 4.48 & 0.14 & 0.62 & 0.26 & 0.26 & 0.08 & 1.01 & 0.19 & 9.82 & 1.19 \\
\hline S-270* & 1.02 & 0.41 & 8.78 & 0.59 & 5.51 & 0.79 & 2.89 & 0.06 & 3.83 & 0.67 & 22.03 & 0.23 \\
\hline S-970* & 1.40 & 0.62 & 9.90 & 1.82 & 11.60 & 5.29 & 6.42 & 3.08 & 7.74 & 1.01 & 37.06 & 5.96 \\
\hline S-1670* & 3.47 & 0.35 & 4.95 & 0.66 & 22.47 & 0.93 & 2.21 & 1.46 & 4.44 & 2.86 & 37.54 & 5.58 \\
\hline Soybean Oil* & 0.67 & 0.65 & 5.74 & 2.66 & 37.57 & 3.32 & 5.00 & 4.47 & 2.64 & 1.21 & 51.62 & 0.73 \\
\hline
\end{tabular}

* Indicates the difference in means compared with blank bottles is statistically significant, at $95 \%$ confidence level for 300 days

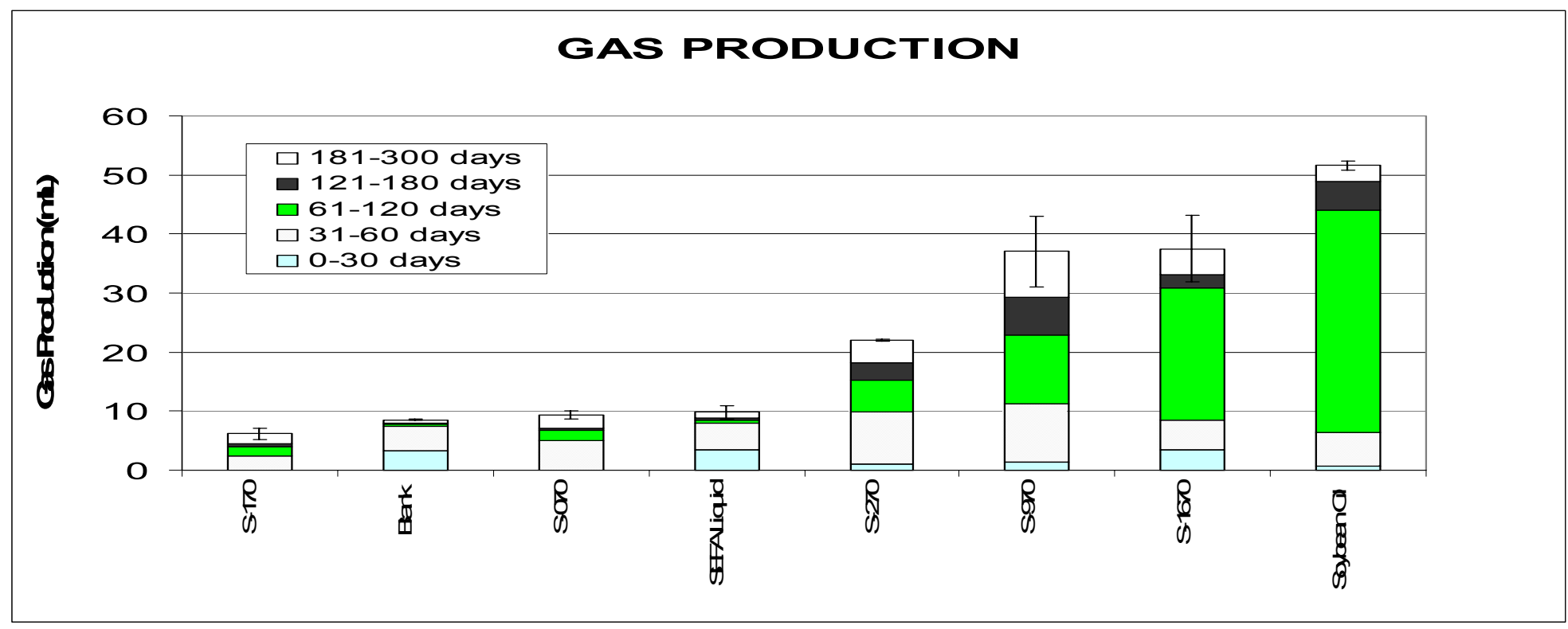


Set \# 5. Gas production per substrate for 300 days. Standard deviations from triplicates incubations are shown.

\begin{tabular}{|c|c|c|c|c|c|c|c|c|c|c|c|c|}
\hline \multirow[b]{3}{*}{ MATERIAL } & \multicolumn{12}{|c|}{ GAS PRODUCTION } \\
\hline & \multicolumn{2}{|c|}{$0-30$ days } & \multicolumn{2}{|c|}{$31-60$ days } & \multicolumn{2}{|c|}{$61-120$ days } & \multicolumn{2}{|c|}{ 121-180 days } & \multicolumn{2}{|c|}{ 181-300 days } & \multicolumn{2}{|c|}{$0-300$ days } \\
\hline & $\mathrm{mL}$ & SD & $\mathrm{mL}$ & SD & $\mathrm{mL}$ & SD & $\mathrm{mL}$ & SD & $\mathrm{mL}$ & SD & $\mathrm{mL}$ & SD \\
\hline Soymilk* & 1.00 & 0.20 & 1.41 & 0.20 & 2.36 & 0.85 & 0.03 & 0.06 & 0.10 & 0.10 & 4.90 & 0.95 \\
\hline Lauric Acid* & 33.73 & 0.61 & 1.07 & 0.31 & 2.00 & 2.46 & 0.00 & 0.00 & 0.00 & 0.00 & 36.80 & 2.82 \\
\hline Mineral Oil ${ }^{*}$ & 33.63 & 2.89 & 1.97 & 1.33 & 0.77 & 0.33 & 0.10 & 0.08 & 0.43 & 0.67 & 36.90 & 1.57 \\
\hline SEFA Liquid* & 32.87 & 0.90 & 4.94 & 1.02 & 1.40 & 0.13 & 0.26 & 0.03 & 2.13 & 0.47 & 41.60 & 0.46 \\
\hline Paraffin & 38.77 & 1.07 & 3.23 & 0.93 & 2.07 & 0.64 & 0.00 & 0.00 & 0.20 & 0.20 & 44.27 & 1.51 \\
\hline Blank & 37.47 & 2.86 & 5.47 & 2.73 & 2.74 & 0.84 & 0.43 & 0.05 & 0.13 & 0.23 & 46.23 & 0.84 \\
\hline Petroleum Jelly & 35.87 & 3.37 & 6.47 & 1.76 & 4.00 & 5.02 & 0.00 & 0.00 & 0.10 & 0.10 & 46.43 & 8.94 \\
\hline SEFA $7.0^{*}$ & 40.63 & 0.67 & 4.49 & 0.82 & 4.81 & 0.27 & 0.57 & 0.16 & 1.49 & 1.14 & 52.00 & 1.64 \\
\hline Soy Gold 1000 & 6.47 & 0.68 & 21.14 & 18.64 & 23.82 & 15.19 & 0.27 & 0.26 & 0.57 & 0.55 & 52.27 & 3.15 \\
\hline SEFA $6.0^{*}$ & 37.67 & 1.47 & 7.25 & 2.74 & 5.95 & 1.61 & 0.77 & 0.84 & 2.43 & 1.79 & 54.07 & 0.50 \\
\hline Corn Oil & 4.73 & 1.53 & 28.78 & 20.74 & 19.18 & 15.98 & 0.27 & 0.12 & 1.47 & 1.33 & 54.43 & 6.80 \\
\hline Lactate* & 45.93 & 0.42 & 3.48 & 0.98 & 5.34 & 0.84 & 0.32 & 0.07 & 0.30 & 0.10 & 55.37 & 0.46 \\
\hline SEFA 5.0* & 33.23 & 0.91 & 6.74 & 0.62 & 2.53 & 0.90 & 2.31 & 0.88 & 10.56 & 2.31 & 55.37 & 3.39 \\
\hline Stearic Acid & 5.63 & 3.46 & 23.18 & 4.16 & 23.62 & 5.08 & 2.92 & 2.67 & 1.95 & 0.80 & 57.30 & 6.97 \\
\hline Soybean Oil $(100)^{*}$ & 44.37 & 3.23 & 17.34 & 2.28 & 3.03 & 0.15 & 0.00 & 0.00 & 0.40 & 0.53 & 65.13 & 1.81 \\
\hline Acetate* & 60.80 & 2.61 & 2.67 & 0.06 & 2.70 & 0.36 & 0.33 & 0.08 & 0.50 & 0.44 & 67.00 & 2.43 \\
\hline Blackstrap Molasses* & 52.17 & 9.86 & 3.10 & 2.77 & 1.85 & 0.81 & 5.54 & 4.17 & 8.69 & 6.44 & 71.34 & 2.88 \\
\hline Canola Oil* & 36.60 & 1.06 & 3.81 & 3.32 & 11.91 & 18.34 & 10.24 & 10.62 & 8.78 & 7.43 & 71.35 & 36.98 \\
\hline Ethyl Lactate* & 73.77 & 3.78 & 5.68 & 1.73 & 18.76 & 4.83 & 0.19 & 0.00 & 0.13 & 0.23 & 98.53 & 1.47 \\
\hline Myristic Acid & 37.40 & 2.99 & 3.79 & 3.12 & 51.48 & 44.46 & 5.88 & 5.11 & 3.65 & 3.53 & $\begin{array}{r}102.2 \\
0\end{array}$ & 54.08 \\
\hline Exp & 34.07 & 0.95 & 0 & 1.49 & 55.15 & 7.98 & 5.86 & 3.18 & 6.45 & 2.98 & $\begin{array}{r}108.1 \\
0\end{array}$ & 3.68 \\
\hline $\begin{array}{l}\text { Hydrogenated } \\
\text { Soybean Oil* }\end{array}$ & 29.90 & 1.73 & 4.60 & 2.58 & 35.48 & 26.94 & 17.34 & 3.80 & 21.53 & 22.53 & $\begin{array}{r}108.8 \\
5\end{array}$ & 4.81 \\
\hline Olive Oil* & 37.87 & 1.10 & 14.91 & 2.88 & 58.01 & 7.40 & 4.66 & 2.55 & 6.78 & 2.90 & $\begin{array}{r}122.2 \\
3\end{array}$ & 12.44 \\
\hline
\end{tabular}

* Indicates the difference in means compared with blank bottles is statistically significant, at $95 \%$ confidence level for 300 days 


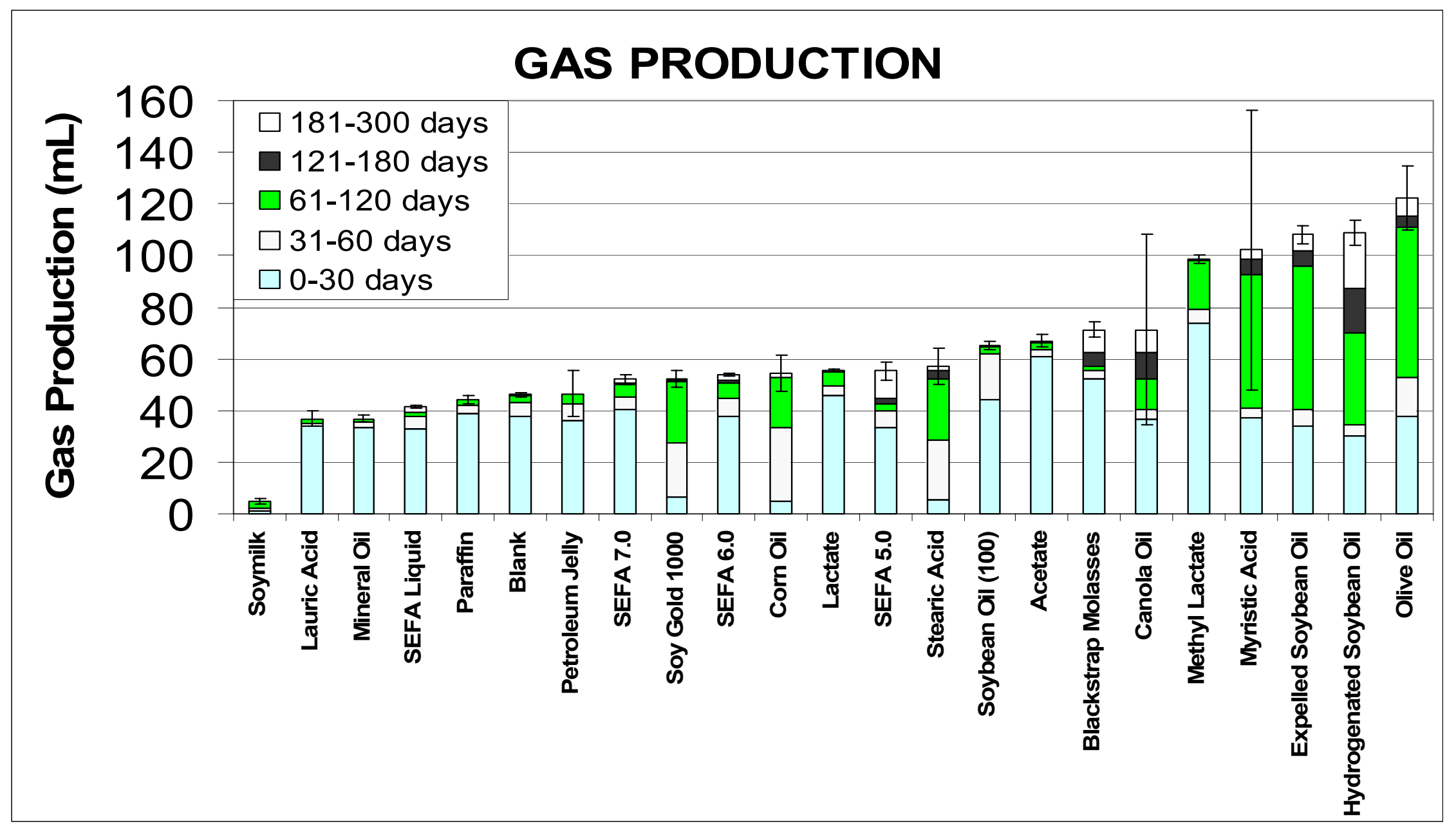




\section{APPENDIX 3.}

RESULTS FOR CARBON REMAINING IN THE COLUMNS

NCSU SOIL SCIENCE DEPARTMENT - ANALYTICAL SERVICE LABORATORY 


\section{CHLORINATED COLUMNS}

\begin{tabular}{|c|c|c|c|c|c|}
\hline \multirow[b]{2}{*}{ COLUMN } & \multicolumn{2}{|c|}{ DESCRIPTION } & \multirow[b]{2}{*}{$\% \mathrm{C}$} & \multirow[b]{2}{*}{ AVERAGE } & \multirow[b]{2}{*}{ SD } \\
\hline & BIOAUGMENTATION & SUBSTRATE & & & \\
\hline \multirow[b]{3}{*}{1} & \multirow[b]{3}{*}{ Lumberton } & \multirow{3}{*}{$\begin{array}{l}\text { SO4 / Soybean } \\
\text { Oil }\end{array}$} & 0.46 & \multirow[b]{3}{*}{0.51} & \multirow[b]{3}{*}{0.11} \\
\hline & & & 0.63 & & \\
\hline & & & 0.43 & & \\
\hline \multirow[b]{3}{*}{2} & \multirow[b]{3}{*}{ Lumberton } & \multirow[b]{3}{*}{ None } & 0.12 & \multirow[b]{3}{*}{0.13} & \multirow[b]{3}{*}{0.02} \\
\hline & & & 0.15 & & \\
\hline & & & 0.11 & & \\
\hline \multirow[b]{3}{*}{3} & \multirow[b]{3}{*}{ Autoclaved digester sludge } & \multirow[b]{3}{*}{ HCL / None } & 0.05 & \multirow[b]{3}{*}{0.06} & \multirow[b]{3}{*}{0.01} \\
\hline & & & 0.07 & & \\
\hline & & & 0.06 & & \\
\hline \multirow[b]{3}{*}{4} & \multirow[b]{3}{*}{ Lumberton } & \multirow[b]{3}{*}{ Soybean Oil } & 0.28 & \multirow[b]{3}{*}{0.32} & \multirow[b]{3}{*}{0.09} \\
\hline & & & 0.43 & & \\
\hline & & & 0.26 & & \\
\hline \multirow[b]{3}{*}{5} & \multirow[b]{3}{*}{ Lumberton } & \multirow[b]{3}{*}{ S-270 } & 0.19 & \multirow[b]{3}{*}{0.20} & \\
\hline & & & 0.21 & & \\
\hline & & & 0.21 & & 0.01 \\
\hline & & & 0.18 & & \\
\hline & & & 0.24 & & \\
\hline 6 & Lumberton & S-270 & 0.26 & 0.23 & 0.04 \\
\hline & & & 0.26 & & \\
\hline & Lumberton and digester & & 0.24 & & \\
\hline 7 & sludge & None & 0.27 & 0.26 & 0.02 \\
\hline & & & 0.1 & & \\
\hline & Lumberton and digester & & 0.11 & & \\
\hline 8 & sludge & S-270 & 0.15 & 0.12 & 0.03 \\
\hline & & & 0.32 & & \\
\hline & & & 0.43 & & \\
\hline 9 & Lumberton & Soybean Oil & 0.44 & 0.40 & 0.07 \\
\hline & & & 0.18 & & \\
\hline & & HCL / Soybean & 0.19 & & \\
\hline 10 & Autoclaved digester sludge & Oil & 0.2 & 0.19 & 0.01 \\
\hline & & & 0.16 & & \\
\hline & Lumberton and digester & & 0.18 & & \\
\hline 11 & sludge & S-270 & 0.19 & 0.18 & 0.02 \\
\hline
\end{tabular}




\begin{tabular}{|c|c|c|c|c|c|}
\hline \multirow[b]{2}{*}{ COLUMN } & \multicolumn{2}{|c|}{ DESCRIPTION } & \multirow[b]{2}{*}{$\% \mathrm{C}$} & \multirow[b]{2}{*}{ AVERAGE } & \multirow[b]{2}{*}{ SD } \\
\hline & BIOAUGMENTATION & SUBSTRATE & & & \\
\hline \multirow[b]{3}{*}{12} & \multirow{3}{*}{$\begin{array}{l}\text { Lumberton and digester } \\
\text { sludge }\end{array}$} & \multirow[b]{3}{*}{ Soybean Oil } & 0.31 & \multirow[b]{3}{*}{0.30} & \multirow[b]{3}{*}{0.01} \\
\hline & & & 0.29 & & \\
\hline & & & 0.29 & & \\
\hline \multirow[b]{3}{*}{14} & \multirow[b]{3}{*}{ Autoclaved digester sludge } & \multirow[b]{3}{*}{ HCL / S-270 } & 0.14 & \multirow[b]{3}{*}{0.12} & \multirow[b]{3}{*}{0.02} \\
\hline & & & 0.1 & & \\
\hline & & & 0.12 & & \\
\hline \multirow[b]{3}{*}{15} & \multirow{3}{*}{$\begin{array}{l}\text { Lumberton and digester } \\
\text { sludge }\end{array}$} & \multirow[b]{3}{*}{ Soybean Oil } & 0.11 & \multirow[b]{3}{*}{0.09} & \multirow[b]{3}{*}{0.03} \\
\hline & & & 0.09 & & \\
\hline & & & 0.06 & & \\
\hline \multirow[b]{3}{*}{16} & \multirow[b]{3}{*}{ Lumberton } & \multirow[b]{3}{*}{ SO4 / S-270 } & 0.09 & \multirow[b]{3}{*}{0.13} & \multirow[b]{3}{*}{0.05} \\
\hline & & & 0.11 & & \\
\hline & & & 0.18 & & \\
\hline \multirow[b]{3}{*}{17} & \multirow[b]{3}{*}{ Lumberton } & \multirow[b]{3}{*}{ SO4 / None } & 0.08 & \multirow[b]{3}{*}{0.07} & \multirow[b]{3}{*}{0.01} \\
\hline & & & 0.06 & & \\
\hline & & & 0.07 & & \\
\hline \multirow[b]{3}{*}{18} & \multirow[b]{3}{*}{ Lumberton } & \multirow{3}{*}{$\begin{array}{l}\text { SO4 / Soybean } \\
\text { Oil }\end{array}$} & 0.26 & & \\
\hline & & & 0.31 & & \\
\hline & & & 0.41 & 0.33 & 0.08 \\
\hline & & & 0.14 & & \\
\hline & & & 0.09 & & \\
\hline 19 & Lumberton & SO4 / S-270 & 0.13 & 0.12 & 0.03 \\
\hline & & & 0.07 & & \\
\hline & & & 0.06 & & \\
\hline 20 & Background carbon & None & 0.05 & 0.06 & 0.01 \\
\hline
\end{tabular}


PERCHLORATE AND TCA COLUMNS

\begin{tabular}{|c|c|c|c|c|}
\hline COLUMN & SUBSTRATE & $\% \mathrm{C}$ & AVERAGE & SD \\
\hline \multirow[b]{3}{*}{1} & \multirow[b]{3}{*}{ Oil } & 0.45 & \multirow[b]{3}{*}{0.39} & \multirow[b]{3}{*}{0.07} \\
\hline & & 0.31 & & \\
\hline & & 0.42 & & \\
\hline \multirow[b]{3}{*}{2} & \multirow[b]{3}{*}{ Wax } & 0.34 & \multirow[b]{3}{*}{0.36} & \multirow[b]{3}{*}{0.03} \\
\hline & & 0.34 & & \\
\hline & & 0.40 & & \\
\hline \multirow[b]{3}{*}{3} & \multirow[b]{3}{*}{ None } & 0.07 & & \multirow[b]{3}{*}{0.01} \\
\hline & & 0.07 & & \\
\hline & & 0.05 & 0.06 & \\
\hline
\end{tabular}

